\title{
STRAIN RATE SENSITIVITY OF ULTRA-HIGH PERFORMACNE FIBER REINFORCED CONCRETE
}

by

ARIA AGHAJANI-NAMIN

B.Eng., M.Sc., EMU, Northern Cyprus, 2012

\author{
A report \\ presented to Ryerson University \\ in partial fulfillment of the \\ requirements for the degree of \\ Master of Engineering \\ in the Program of \\ Civil Engineering
}

Toronto, Ontario, Canada, 2014

CARIA AGHAJANI-NAMIN 2014 


\section{Author's Declaration}

I hereby declare that I am the sole author of this project. This is a true copy of the project, including any required final revisions as accepted by examiner.

I thereby authorize Ryerson University to reproduce or lend this project by photocopying or by other means, in total or in part, at the request of other institutions or individuals for the purpose of scholarly research.

I understand that my project may be made electronically available to the public. 


\begin{abstract}
STRAIN RATE SENSITIVITY OF ULTRA-HIGH PERFORMACNE

FIBER REINFORCED CONCRETE
\end{abstract}

by

\author{
ARIA AGHAJANI-NAMIN \\ Masters of Engineering \\ Civil Engineering \\ Ryerson University, Toronto, Canada 2014
}

Ultra High Performance Fiber Reinforced Concrete (UHP-FRC) is relatively new cementitious material, which has been developed to enhance material performance such as, durability, workability and strength. UHP-FRC has an outstanding dynamic performance with high capacity to absorb damage. Because of its superior performance under dynamic loading, UHP-FRC has been induced in structures where dynamic resistance is required. It is proven that like other concrete materials, UHP-FRC strength increases significantly when subjected to high strain rates. The objective of this study is to develop understanding of strain rate sensitivity of UHPFRC with 2\% steel fiber by volume fraction and plain High Strength Concrete (HSC). Compressive and flexural tensile strength of each concrete composite were investigated to evaluate and compare their strain rate sensitivity through dynamic increase factor (DIF). The specimens were tested under six different strain rates; three in quasi-static and three in dynamic domain. Strain rates in quasi-static domain conducted by MTS test machine and strain rates in dynamic domain conducted using the drop hammer technique. The test results revealed that UHP-FRC exhibits less strain rate sensitivity while HSC show much higher rate sensitivity in comparison to other materials.

Keywords: UHP-FRC, HSC, DIF, Strain Rates, Quasi-static, Dynamic, Rate Sensitivity 


\section{Acknowledgement}

I am heartily thankful to my supervisor, Dr. Hesham Marzouk whose encouragement, guidance and support from the initial to the final level enabled me to develop an understanding of the subject.

Lastly, I would like to add my heartfelt appreciation for all of those who supported me in any respect during the completion of this thesis; especially Mr. Hesham Othman who helped me at every step of this project. I would also like to thank Ryerson Civil Engineering Lab technicians, who provided me technical assistance throughout this project. 
This project is dedicated to my beloved family and lovely wife for their understanding, encouragement and undying support throughout the project. 


\section{Table of Content}

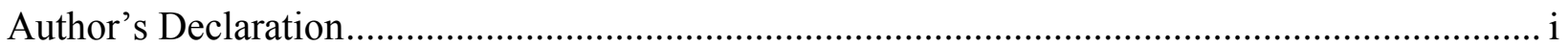

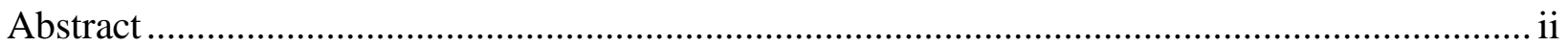

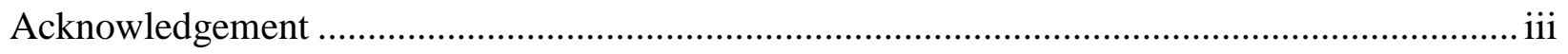

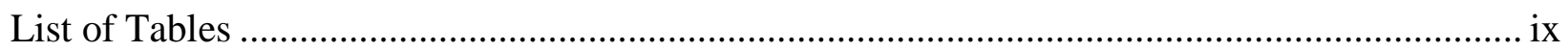

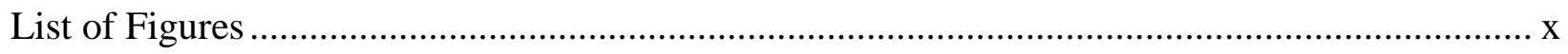

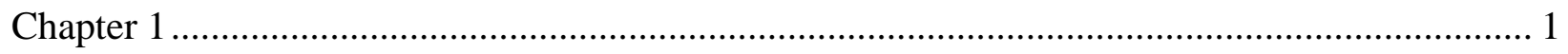

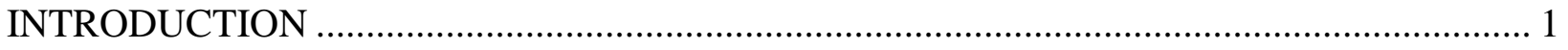

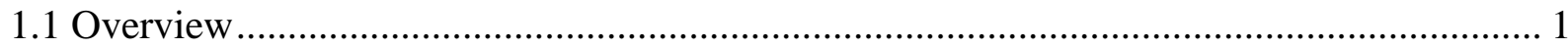

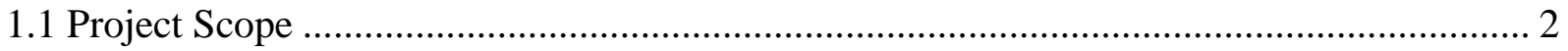

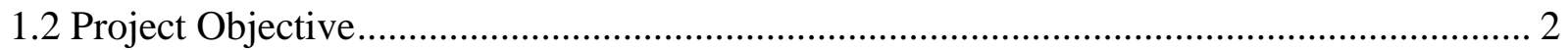

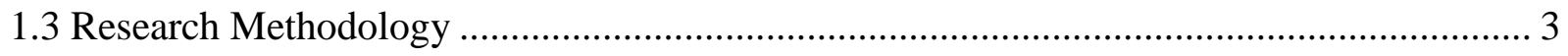

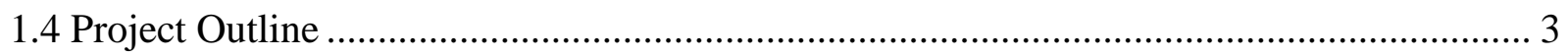

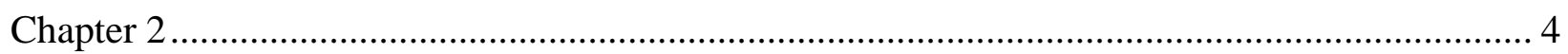

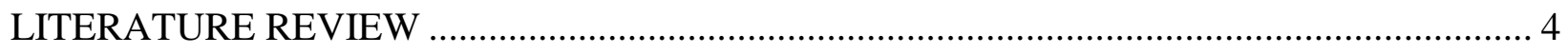

2.1 Ultra High Performance Fiber Reinforced Concrete .............................................. 4

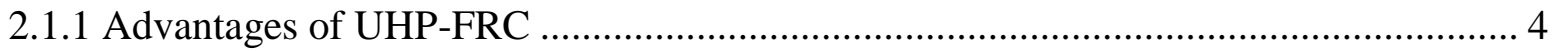

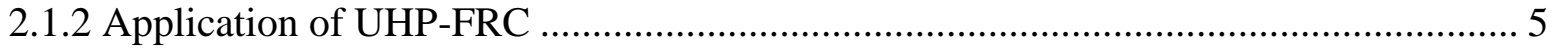

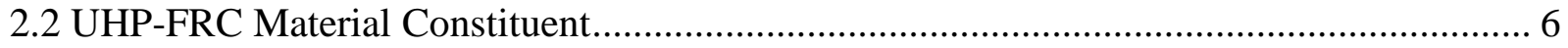

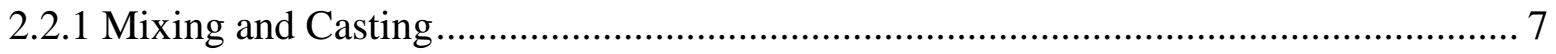

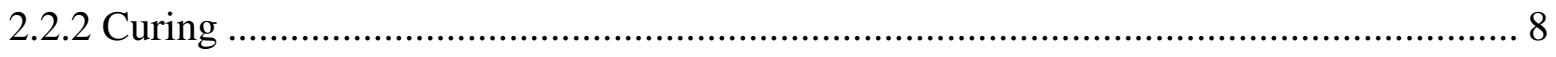

2.3 Influence of Mix Parameters on Compressive Strength $\left(f^{\prime} c\right)$........................................ 8

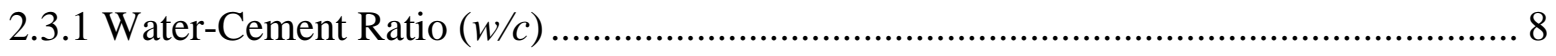

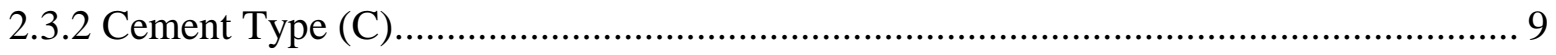




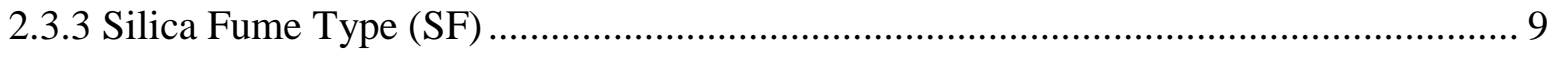

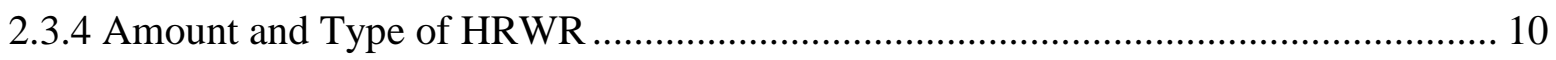

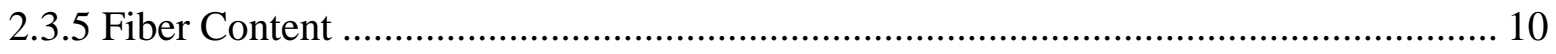

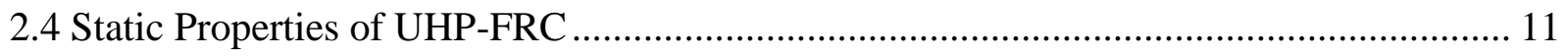

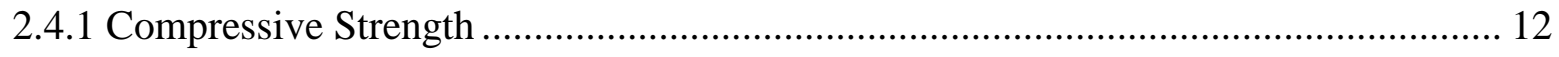

2.4.1.1 Compressive Strength Testing ..................................................................... 13

2.4.2 Tensile Strength (Direct Tension Test) ..................................................................... 14

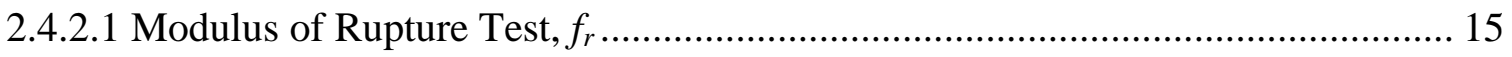

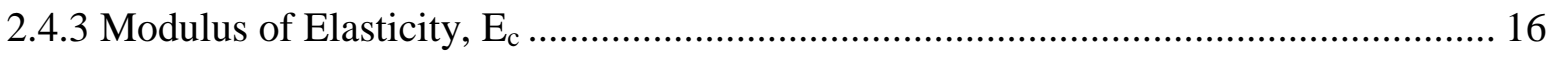

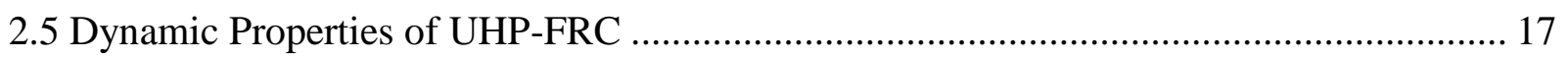

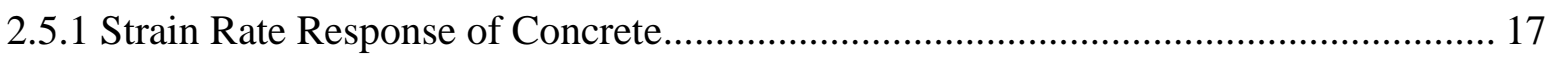

2.5.2 Strain Rate Effect on the Strength of Concrete ......................................................... 18

2.5.2.1 Dynamic Increase Factor, DIF ........................................................................ 18

2.5.2.2 Strain Rate Properties of Concrete in Compression ............................................. 19

2.5.2.3 Strain Rate Properties of Concrete in Tension................................................... 21

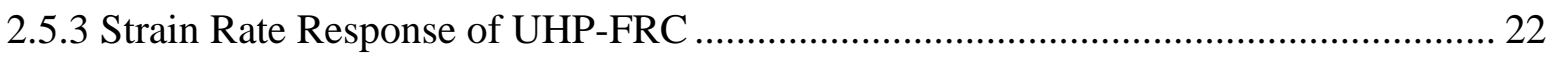

2.6 Testing Methods for Concrete under High Strain Rates ................................................... 24

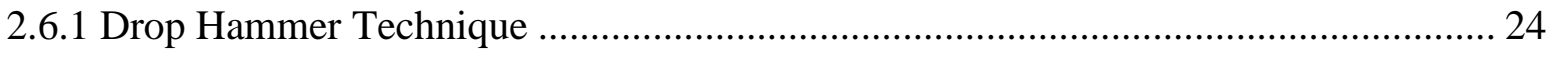

2.6.1.1 University of Toronto Drop Hammer Strain Rate Test ......................................... 24

2.6.1.2 RMIT University Drop Hammer Strain Rate Test............................................... 25

2.6.1.3 University of Liverpool Drop Hammer Strain Rate Test...................................... 26

2.6.1.4 UBC Drop Hammer Strain Rate Test ................................................................... 27

2.6.2 Split Hopkinson Pressure Bar (SHPB) ................................................................. 28 


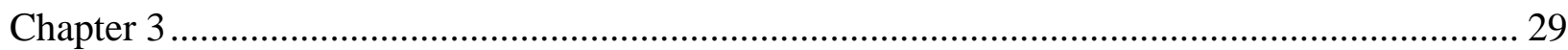

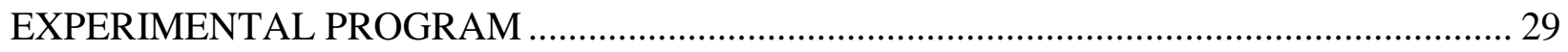

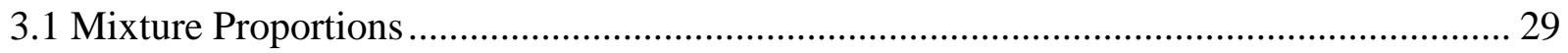

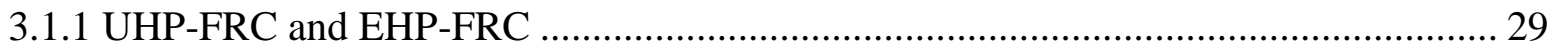

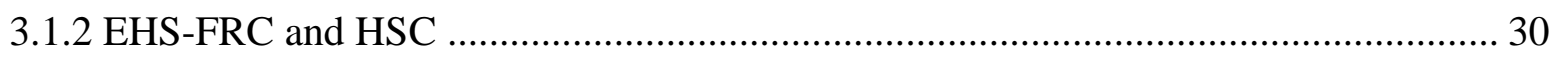

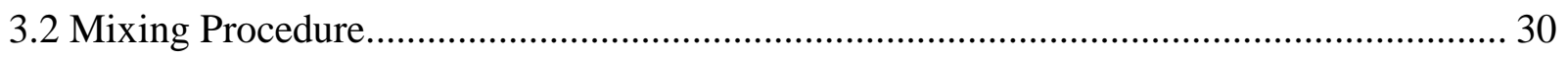

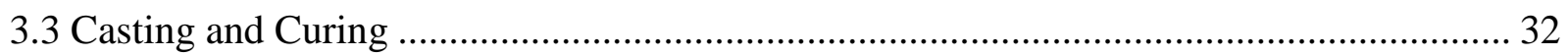

3.4 Compressive Strength Test ……………………………............................................. 34

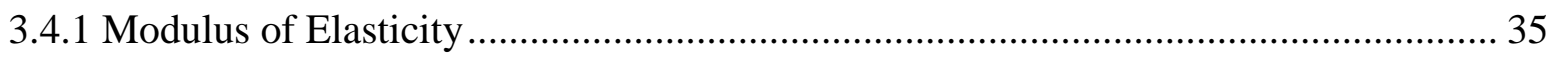

3.4.2 Compressive Strength under Quasi-static and Dynamic Loading .............................. 36

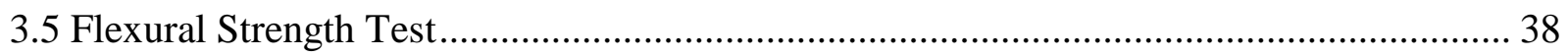

3.5.1 Flexural Strength under Quasi-static Loading ......................................................... 38

3.5.2 Flexural Strength under Dynamic (Impact) Loading ................................................... 40

3.6 Development of Drop Hammer Facility ………………................................................... 42

3.6.1. Drop Hammer Weight and Magnetic Release …………………………………..... 43

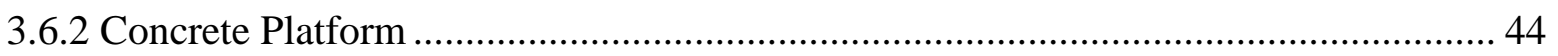

3.6.3 Ryerson University Drop Hammer Test Setup Instrumentation.................................. 45

3.6.3.1 Dynamic Load Cells ...................................................................................... 45

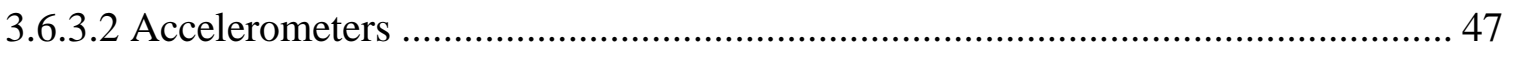

3.6.3.3. Data Acquisition System.................................................................................. 48

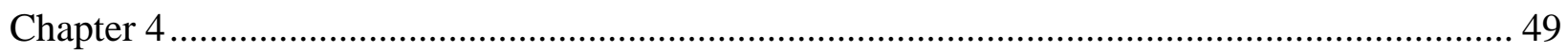

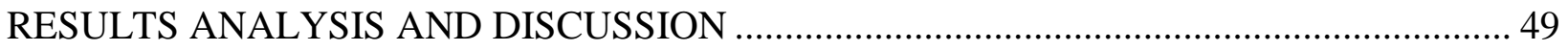

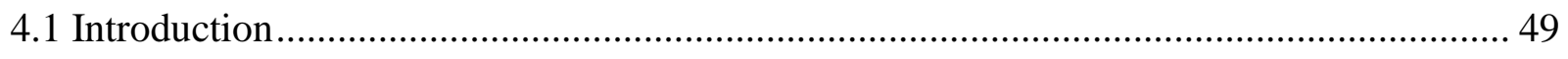

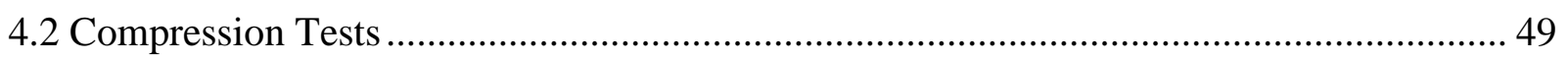

4.2.1 Compressive Strength ............................................................................................... 49 


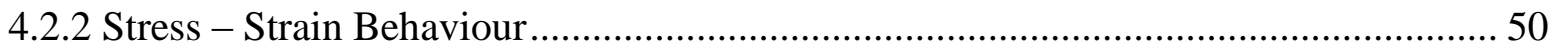

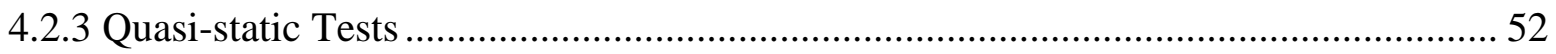

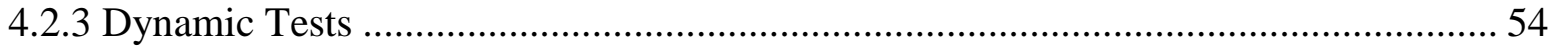

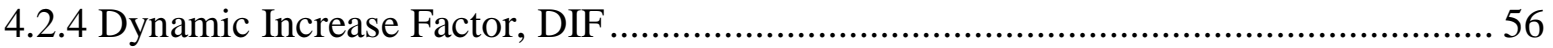

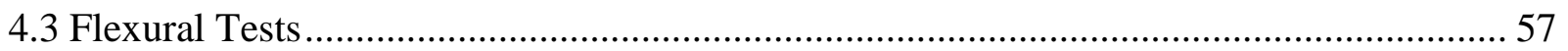

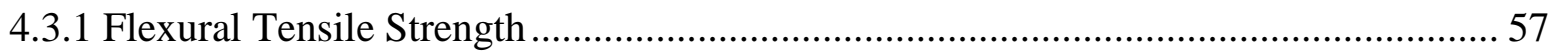

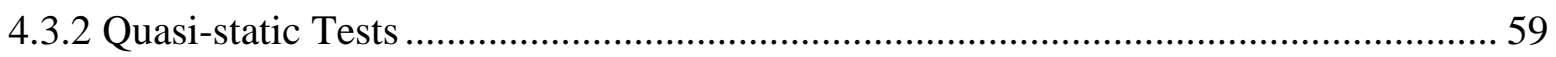

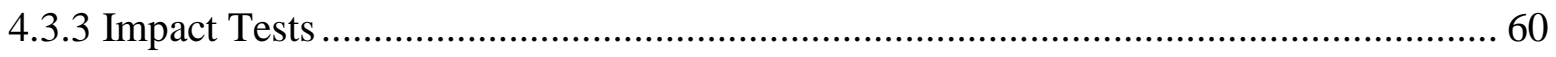

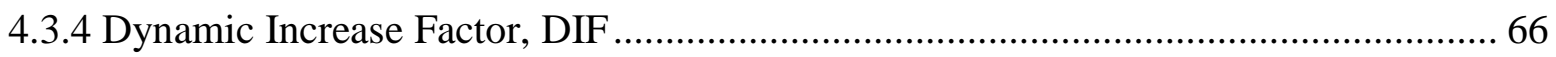

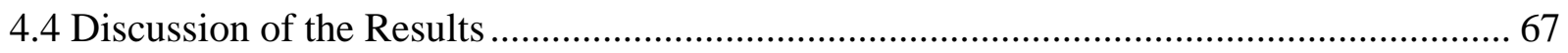

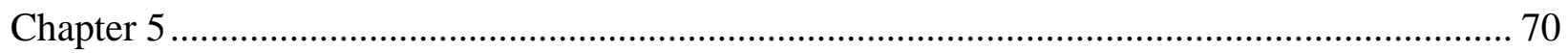

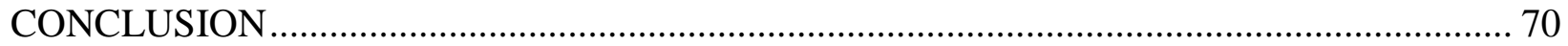

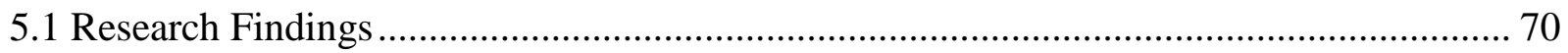

5.2 Recommendation for Future Studies ............................................................................. 71

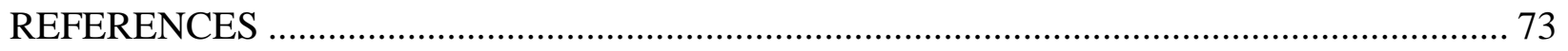

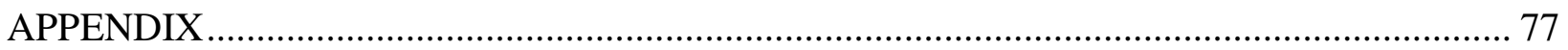




\section{List of Tables}

Table 2.1: UHP-FRC Application in Canada [10] ............................................................... 5

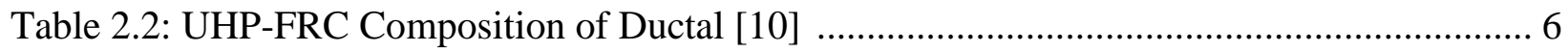

Table 2.3: Mechanical Properties Range of UHP-FRC [10] …........................................... 11

Table 3.1: Mixture proportions for UHP-FRC and EHP-FRC …....................................... 29

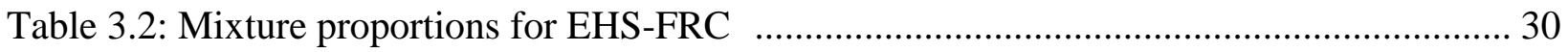

Table 3.3: Compressive Strength of each Composite at Different Age .................................... 35

Table 3.4: Displacement and Strain Rates for Compressive Strength ................................... 37

Table 3.5: Quasi-static Strain Rates for Flexural Strength ............................................... 40

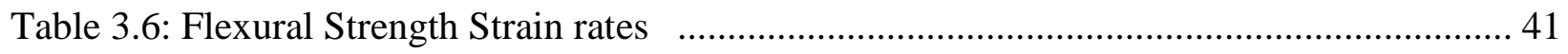

Table 4.1: Compressive Strength of each Composite at Different Age ................................... 49

Table 4.2: Stress-Strain Response of Concrete Composites ................................................ 50

Table 4.3: Quasi-static Compressive Strength Test Results for all Composites ........................ 52

Table 4.4: Dynamic Compressive Strength Test Results for all Composites .......................... 54

Table 4.5: Dynamic Compressive Strength of Concrete .................................................. 56

Table 4.6: Flexural strength of UHP-FRC, EHP-FRC, EHS-FRC and HSC ….....................5 58

Table 4.7: Quasi-static Flexural Strength Test Results for EHP-FRC and EHS-FRC ............... 59

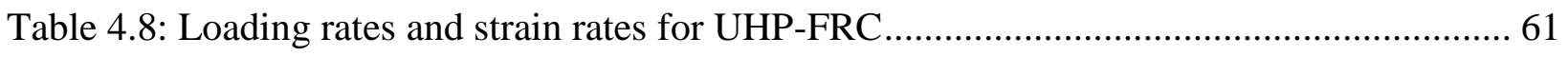

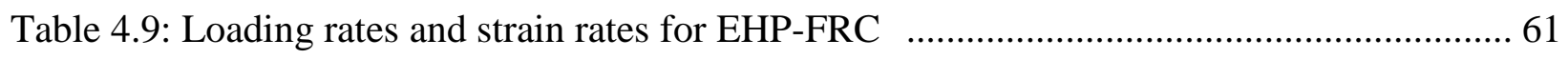

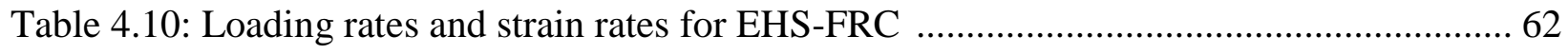

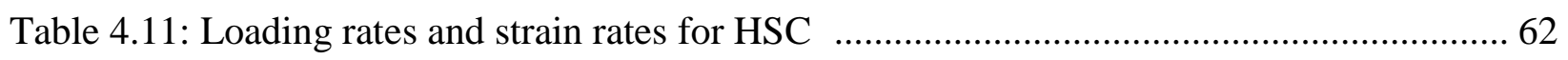

Table 4.12: Dynamic Flexural Strength Test Results for all Composites ................................ 64

Table 4.13: Dynamic Flexural Strength of Concrete Composites ......................................... 66 


\section{List of Figures}

Figure 2.1: Effect of Water-Cement Ratio on Compressive Strength [1]................................ 9

Figure 2.2: Stress-Strain Curve for UHPC without Fibers [16] ........................................ 12

Figure 2.3: Stress-Strain Curve for UHP-FRC (1\% - 2.5\%) [16] ......................................... 13

Figure 2.4: Tensile Stress-Strain of UHP-FRC by Graybeal et al [19] ................................... 14

Figure 2.5: Idealized Uniaxial Tensile Response of UHP-FRC [20].................................... 15

Figure 2.6: Various Load Cases with Corresponding Strain Rates [24] ................................. 17

Figure 2.7: Strain rate effect on compressive strength of different concrete types [24] ............ 20

Figure 2.8: Strain rate effect on tensile strength of different concrete types [24] ................... 21

Figure 2.9: Proposed DIF Model for Peak Stress by Ngo et al [28] ...................................... 23

Figure 2.10: Drop-hammer test setup developed at RMIT [3] ........................................... 25

Figure 2.11: Liverpool University Drop-hammer test facility [3] ....................................... 26

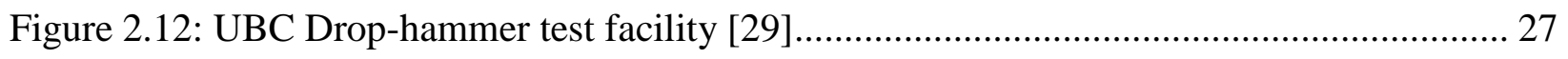

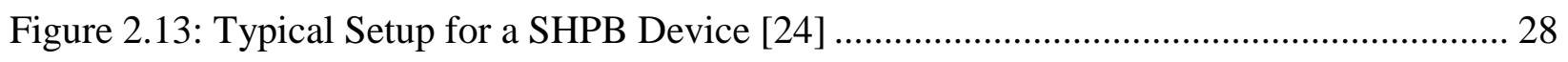

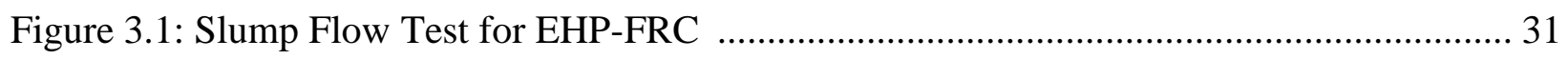

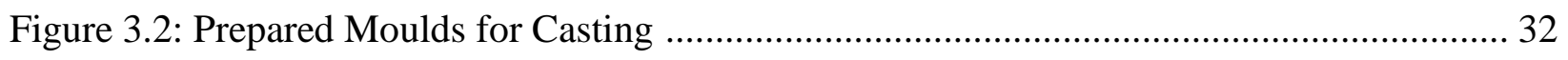

Figure 3.3: Covered Samples with Damp Burlap during First Three Days ............................. 33

Figure 3.4: Specimens in the Curing Room: a) Prisms, b) Cylinders ...................................... 34

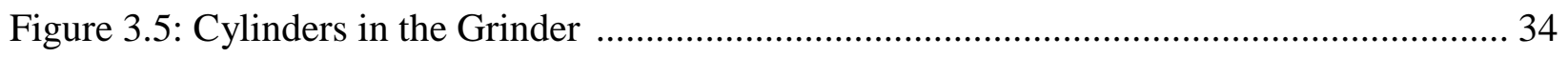

Figure 3.6: Cylinder Specimens before and after Grinding ............................................. 34

Figure 3.7: MTS Test Machine for Compression Tests ...................................................... 36

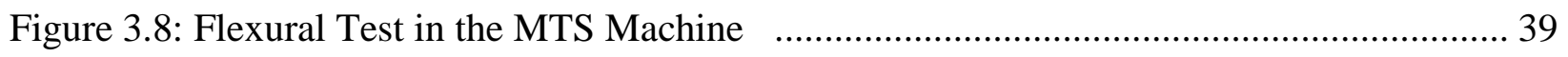

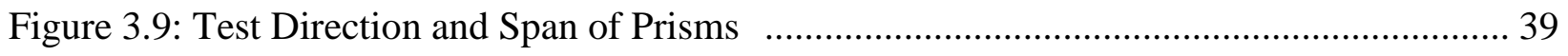


Figure 3.10: Drop Hammer Facility Built at Ryerson University ............................................... 40

Figure 3.11: Drop Hammer Facility and Accessories ........................................................... 42

Figure 3.12: Drop Hammer Weight and Electrical Magnet …................................................ 43

Figure 3.13: Steel Rebars and Hanger for Concrete platform .................................................... 44

Figure 3.14: Placement of Sand and Concrete Platform ………………................................ 44

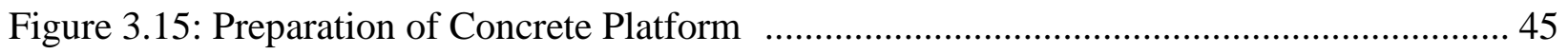

Figure 3.16: Location of the Dynamic Load Cell on Steel Cover ............................................... 46

Figure 3.17: Position of the Dynamic Load Cells, Steel Rollers and Steel Covers ...................... 46

Figure 3.18: Settled Dynamic Load Cell between Steel Covers ............................................. 46

Figure 3.19: Position of the Mounted Accelerometers on Drop Weight ……………………..... 47

Figure 3.20: Applying Rubber on Drop Weight before Mounting Accelerometer ...................... 47

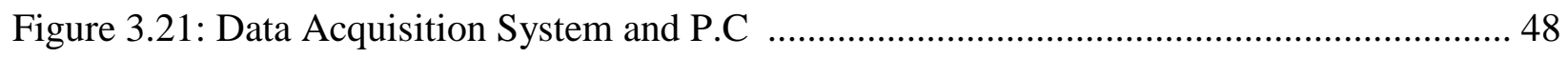

Figure 4.1: Stress - Strain Curve for all Composites ……………............................................. 50

Figure 4.2: EHP-FRC Cylinders after Compressive Test ....................................................... 51

Figure 4.3: EHS-FRC Cylinders after Compressive Test ……………………………….... 51

Figure 4.4: HSC Cylinders after Compressive Test ……………………………………....... 51

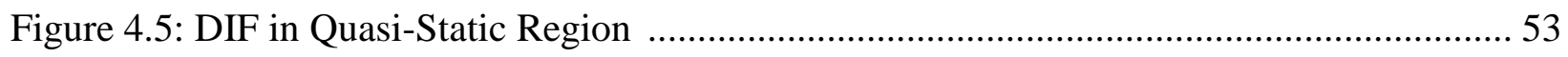

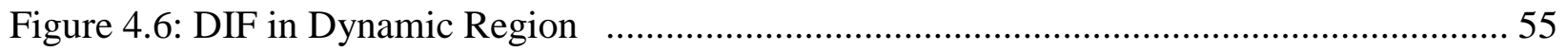

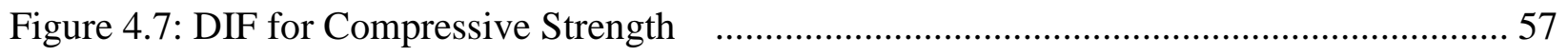

Figure 4.8: Flexural Performance of EHP-FRC, EHS-FRC and HSC ………………............. 58

Figure 4.9: Typical Force - Time curve extracted from Load Cells $\quad$.......................................... 60

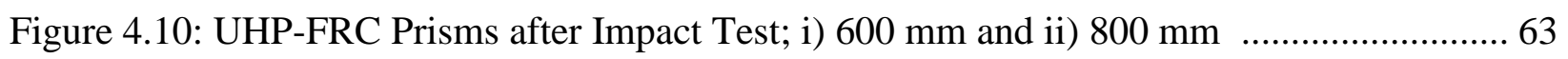

Figure 4.11: EHP-FRC Prisms after Impact Test; i) $400 \mathrm{~mm}$, ii) $600 \mathrm{~mm}$ and iii) $800 \mathrm{~mm}$...... 63 
Figure 4.12: EHS-FRC Prisms after Impact Test; i) $400 \mathrm{~mm}$, ii) $600 \mathrm{~mm}$ and iii) $800 \mathrm{~mm}$....... 63

Figure 4.13: HSC Prisms after Impact Test; i) $200 \mathrm{~mm}$, ii) $400 \mathrm{~mm}$ and iii) $600 \mathrm{~mm}$............. 63

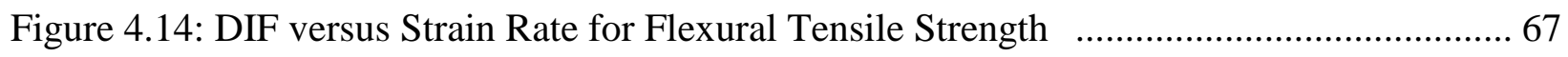




\section{Chapter 1 \\ INTRODUCTION}

\subsection{Overview}

Ultra-High Performance Concrete also known as UHPC was initially known as reactive powder concrete (RPC) with a compressive strength over $150 \mathrm{MPa}$ produced in bulk quantities, which have been in interest around the world since early 1990s [1]. Despite of high compressive strength and durability, UHPC shows poor tensile and flexural strength which make it prone to cracking, and gradual increase of brittleness. Therefore many researches developed to reveal that the mechanical characteristics of UHPC including high tensile strength and large ductility continues to develop even after cracking in cooperation with fibers [2]. From these studies, Ultra High Performance Fibre Reinforced Concrete (UHP-FRC) has merged. The composition of UHP-FRC contains, high cement content, silica sand, silica fume, superplasticiser, metallic or non-metallic fibres and very low water/cement ratio (as low as 0.2 ). The addition of high dosage of steel fibres results in high flexural tensile strength, typically between 25 to $50 \mathrm{MP}$ [3]. UHPFRC has several advantages because of their high compressive strength including, high durability, flexibility, impact resistance, corrosion resistance, improved freezing and thawing resistance, increasing resistance against various chemical and higher penetration resistance [1].

Researches indicate that UHP-FRC has an outstanding dynamic performance and very high toughness, which makes it potentially suitable for structures that require to-resist impact, shock and explosive loading. These structures include bridges, gas tanks, offshore structures, nuclear reactor containment shields, heavy-duty runways, defense shelter, crash barriers, seismic resistance structures, and structures of military and strategic importance designed to withstand explosive blast [4]. However, despite the recent efforts for evaluation of the static behavior of UHP-FRC, much lower investigation carried out for understanding of its behaviour under dynamic loading. 
The need of the civilian and military structures protection from terrorist or enemy attacks has never been greater. To minimize damage and prevent total collapse, such structures must possess greater resistance to impact loading [4]. Researches show that concrete have the ability to response at very high strain rate when subjected to dynamic loading, and its strength increases significantly within these rates [5]. Dynamic Increase Factor (DIF) is the most popular method for taking account of strain rate effects on both deformation and failure.

Therefore, this study will investigate and compare the high strain rate response and provides dynamic increase factor (DIF) in compression and tension for UHP-FRC, and High Strength Concrete (HSC).

\subsection{Project Scope}

The scope of the study is:

- To evaluate the strain rate sensitivity of different UHP-FRC mix designs and compare them with HSC.

\subsection{Project Objective}

The objectives of this study are as follows:

- To develop a fully understanding of UHP-FRC and HSC behaviour at high strain rate response,

- To develop an understanding of the mechanical properties of mentioned concrete composites under impact loading,

- To develop and approach to evaluate mechanical properties of mentioned material under impact loading using drop weight hammer setup,

- To evaluate and compare the dynamic increase factor for each material in compression and tension. 


\subsection{Research Methodology}

In order to fulfill the objectives of this study, the experimental program was designed form to investigate the strain rate effect on the concrete properties. The experimental program aims to develop a fundamental understanding of strain rate dependency of different concrete types. To do so, four different types of concrete mix designs were tested. Compressive and flexural strengths of each concrete type were investigated at different strain range from quasi-static to dynamic. Finally, obtained results were evaluated and discussed, and major findings of the study were presented in point form. In the following sections, concrete types used in this study and tests procedures are described.

\subsection{Project Outline}

This project comprises of five chapters including the introductory chapter. The appendices are also included to provide supporting data for drop weight hammer setup.

Chapter 2 is comprised of literature review on Ultra High Performance Concrete. This section is devoted to review of material composition, mechanical properties, influence of cooperation of steel fibers, strain rate effect and dynamic properties of UHP-FRC.

Chapter 3 identifies the experimental program that was undertaken to achieve the desired objective and experimental basis on which this program is formulated. The details and construction of drop weight hammer setup is discussed as well as the quasi-static and dynamic testing procedure of each set of the specimens.

Chapter 4 discusses the observed result from compressive and flexural strength test procedure, and evaluation of dynamic increase factor. The test results are illustrated in terms of graph and tables for better comparison and understanding of dynamic enhancement of UHP-FRC with $2 \%$ steel fibers.

Chapter 5 includes the summary and the conclusion of the project. In this chapter major findings in project is discussed and finally at the end introduces recommendations for future work and studies. 


\section{Chapter 2 \\ LITERATURE REVIEW}

\subsection{Ultra High Performance Fiber Reinforced Concrete}

In the last two decades a remarkable development had been discovered in concrete technology. One of the most important discoveries in this field was the development of Ultra-High Performance Fiber Concrete (UHP-FRC). UHP-FRC is in the category of High Performance Fiber Reinforced Cement Composites (HPFRCC), which defines as a type of Fiber Reinforced Concretes (FRC) that exhibit strain-hardening under tensional force [6]. Furthermore, UHP-FRC is characterized by a dense matrix and very low permeability in comparison to HPFRCC, High Strength Concrete (HSC) and Normal Strength Concretes (NSC) [4, 6].

In general, UHP-FRC is integration of Ultra High Performance Concrete (UHPC) and Fibre Reinforced Concrete which exhibits a unique combination of significant technical characteristics, such as, ductility, durability, and high strengths (compressive strength over $150 \mathrm{MPa}$ and tensile strength over $10 \mathrm{MPa}$ ) [2, 7]. Regarding the tensile characteristics, Rossi et al. [8] reported that the fiber of UHP-FRC plays and important role in the ductile behaviour of a structure until flexural failure and found the increase in ultimate tensile strain capacity up to $5 \times 10^{-3}$.

\subsubsection{Advantages of UHP-FRC}

The main advantage of UHP-FRC is the low permeability obtained through dense particle packing in combination with strain hardening behaviour which can improve the durability of UHP-FRC structural member in compare to normal concrete member [8, 1]. Furthermore, Katrin \& Paul [9] reported that in comparison to normal strength concrete UHP-FRC materials show improved structural behaviour, high energy absorption, high resistance to spalling and scabbing under impact loading. Therefore, such characteristic make it potentially suitable for structures that require impact, shock and explosive loading [4]. 


\subsubsection{Application of UHP-FRC}

In general, UHP-FRC is suitable for use in the following structures $[4,6]$ :

- Bridge Rehabilitation

- Offshore structures

- Blast or impact proactive structures

- Seismic resistance structures

- Gas tank and crash barriers

- Archi-structural features

- The fabrication of precast element

- Durable components exposed to marine

In recent years many UHP-FRC structures have been constructed in different countries such as, Canada, France, Germany, Japan, South Korea and USA. The first application of UHP-FRC was the UHP-FRC in-filled steel tube composite used in the construction of a footbridge in 1997 at Sherbrook, Canada [6]. Table 2.1 provides a list of the recent UHP-FRC applications in bridge construction in Canada.

Table 2.1: UHP-FRC Applications in Canada [10]

\begin{tabular}{|c|c|c|c|}
\hline Name & Location & Year & Application \\
\hline $\begin{array}{l}\text { Middle Lake Bridge on } \\
\text { Highway 17A, }\end{array}$ & Ontario, Canada & 2012 & $\begin{array}{c}\text { Joint fill between precast } \\
\text { curbs and precast } \\
\text { approach slabs }\end{array}$ \\
\hline $\begin{array}{c}\text { McCauley Creek } \\
\text { Bridge on Highway 11, }\end{array}$ & Ontario, Canada & 2013 & $\begin{array}{l}\text { Joint fill between } \\
\text { adjacent box beams }\end{array}$ \\
\hline $\begin{array}{l}\text { Little Pic River Bridge } \\
\text { on Highway } 17,\end{array}$ & Ontario, Canada & 2013 & $\begin{array}{l}\text { Shear connector pockets } \\
\text { and panel joints }\end{array}$ \\
\hline $\begin{array}{c}\text { Jackfish River Bridge } \\
\text { on Highway } 17,\end{array}$ & Ontario, Canada & 2013 & $\begin{array}{l}\text { Shear connector pockets } \\
\text { and panel joints }\end{array}$ \\
\hline Westminster Drive & Ontario, Canada & 2014 & $\begin{array}{l}\text { Longitudinal joints to connect } \\
\text { superstructure modules. }\end{array}$ \\
\hline
\end{tabular}




\subsection{UHP-FRC Material Constituent}

The development of UHP-FRC mixtures without heat or pressure treatment has been a challenge because of its large array of influencing parameter [1]. These include properties and particle size of the material component, mixture proportions, the mixing procedure and test method. Many researches have done to evaluate the correlation between flow ability and packing density of the paste. The idea is to optimize the mixtures developed to decrease the effort needed to achieve high compressive strength (exceeding $150 \mathrm{MPa}$ ) without need for special heat or pressure treatment $[1,8]$.

Different combinations of UHP-FRC materials may be used, depending on the application and supplier. In general, formulations often consist of a combination of Portland cement, fine sand, silica fume, high-range water-reducing admixture (HRWR) or superplasticizer, fibers (usually steel), and water. Small aggregates are sometimes used, as well as a variety of chemical admixtures. In the following section (2.3) influence of each component on compressive strength of the UHP-FRC is discussed. Note that coarse aggregates are eliminated from UHP-FRC in order to enhance homogeneity [5, 10]. The UHP-FRC used most often in North America for both research and applications is a commercial product produced by Lafarge Co. known as Ductal®. Table 1 shows a typical composition of this material with $2 \%$ steel fiber by volume fraction.

Table 2.2: UHP-FRC Composition of Ductal $[$ [10].

\begin{tabular}{ccc}
\hline Material & Bulk Density $\left(\mathbf{k g} / \mathbf{m}^{\mathbf{3}}\right)$ & Percent by Weight $(\%)$ \\
\hline Portland Cement & 712 & 28.5 \\
Silica Sand & 1020 & 40.8 \\
Silica Fume & 231 & 9.3 \\
Ground Quartz & 211 & 8.4 \\
HRWR & 30.7 & 1.2 \\
Accelerator & 30 & 1.2 \\
Steel Fibers $(2 \%)$ & 156 & 6.2 \\
Water & 109 & 4.4 \\
\hline
\end{tabular}


Wille et al. [11] obtained compressive strength exceeding $200 \mathrm{MPa}$ at 28 days on $50 \mathrm{~mm}$ cubes with no heat or pressure curing by optimizing the cementitious matrix, packing density, and flowability; using very high strength, fine-diameter steel fibers; and tailoring the mechanical bond between the steel fiber and cement matrix. In addition, a tensile strength of $34.6 \mathrm{MPa}$ at a strain of 0.46 percent was achieved.

\subsubsection{Mixing and Casting}

Most of conventional concrete mixers are able to mix UHP-FRC. However, mixing time is increased in compare to normal concrete because UHP-FRC requires more increased energy input. Therefore mixing time should be increased. The use of modified procedure is suggested to ensure that UHP-FRC does not overheat during mixing. In this case, high-energy mixers could be used or by lowering the temperature of constituents or partially replacing the mix water with ice could help the mixing [10].

In mixing UHP-FRC, the number of ingredient is higher and the fineness of particles is more than NSC. Therefore, it is important that all particles are uniformly distributed [1]. The reason is that very fine particle tend to form chunks and minimal shear force for breaking these chunks can be reduced by keeping the particles dry.

Therefore, it is recommended that all dry compositions such as, silica fume, sand and cement should be mixed first for 10 minutes. Afterwards mix of water and HRWR to be added gradually for improvement of flowability [1,9]. After 5 minutes of addition of water and HRWR, UHPFRC becomes fluid. Finally, the last step is to add the fibers and let the batch to mix for additional 5 minutes.

UHP-FRC casting requires special considerations in terms of placement operations. This material tend to exhibit rheological behaviors similar therefore, it requires additional form preparation. Internal vibration of UHP-FRCC is not recommended due to fiber reinforcement, but limited external form vibration can be done to facilitate the release of entrapped air [10]. 


\subsubsection{Curing}

The two critical components of UHP-FRC curing are temperature and moisture. Like any other cementitious material, maintaining an appropriate temperature is vital to achieving the desired rate of the cementitious reactions. Additionally, because of the low water content of UHP-FRC, the loss of internal water must be prevented by maintaining a high humidity environment [10].

The curing of UHP-FRC occurs in two phases. The initial curing phase consists of maintaining an appropriate temperature while preventing moisture loss until setting has occurred and rapid mechanical property growth is occurring. The second curing phase may include elevated temperature conditions and a high moisture environment [10,12].

Graybeal et al. [12] conducted a study to determine material properties of UHP-FRC using four different post-set curing procedures. In this steam curing was involved at $90{ }^{\circ} \mathrm{C}$ and $60{ }^{\circ} \mathrm{C}$ for 48 hours, starting about 24 hours after casting; steam curing at $90{ }^{\circ} \mathrm{C}$, starting after 15 days of standard curing; and curing at standard laboratory temperatures until test age. These three steam curing methods increased the measured compressive strengths and modulus of elastic. The researcher observed that enhancements achieved by the lower steam temperature and delayed steam curing (after 15 days) were slightly less than achieved by steam curing at the higher temperature.

\subsection{Influence of Mix Parameters on Compressive Strength $\left(f^{\prime} c\right)$}

\subsubsection{Water-Cement Ratio $(w / c)$}

In Figure 2.1 (next page) influence of water-cement ratio on the compressive strength of UHPC with $2.5 \%$ fiber by volume fraction is illustrated by Wille et al. [1]. It can be seen that the compressive strength decreases significantly with an increase in $w / c$. This can be confirmed as least-square fitting line is decreasing. The researchers reported a compressive strength as low as $115 \mathrm{MPa}$ for a $w / c$ of 0.265 , and as high as $206 \mathrm{MPa}$ for $w / c$ of 0.22 . On the other hand variation of compressive strength for $w / c$ of $0.22(150 \mathrm{MPa}$ to $206 \mathrm{MPa})$ indicates that $w / c$ is not the only dominant parameter influencing compressive strength. This is due to different Silica-FumeCement ratio (SF/C) ranging between 18 and $25 \%$ used in the mixture for their investigation. 


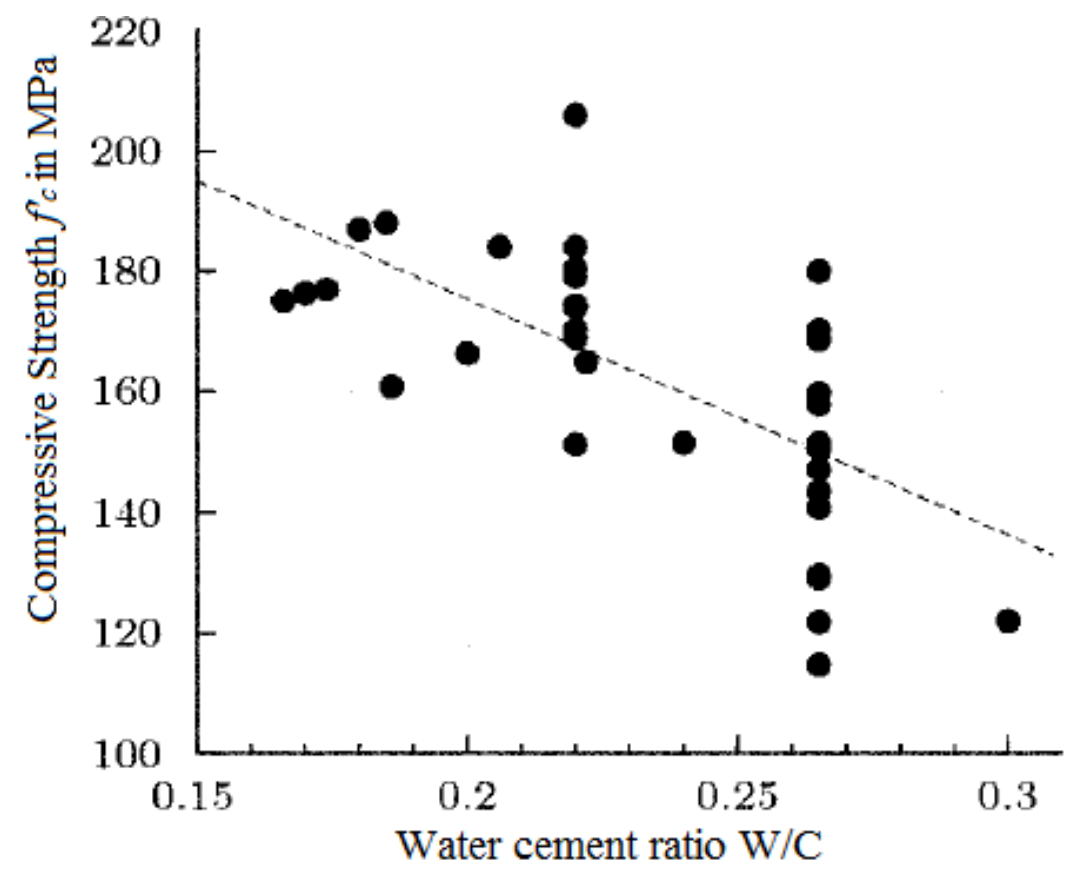

Figure 2.1: Effect of Water-Cement Ratio on Compressive Strength by Wille et al. [1]

\subsubsection{Cement Type (C)}

Type I ASTM Standard or Type 10 CSA standard Portland cement with a low content of $\mathrm{C}_{3} \mathrm{~A}$ and low-to-moderate fineness of approximately $4000 \mathrm{~cm}^{2} / \mathrm{g}$ is suggested by Wille et al. [1] because of fast hydration process of $\mathrm{C}_{3} \mathrm{~A}$. Additionally, the associated increase in the surface area of the particles and the demand for water to surround the particles reported to lead to a higher viscosity during the mixing process. The researcher also reported that between fifteen different mixture with different cement type the best results were achieved with Type I Portland cement which had a high amount of $\mathrm{C}_{3} \mathrm{~S}+\mathrm{C}_{2} \mathrm{~S}$, and amount of $\mathrm{C}_{3} \mathrm{~A}$ of $5 \%$.

\subsubsection{Silica Fume Type (SF)}

Silica Fume (SF) can improve the packing density of the matrix both physically and chemically [1]. With a median particle size of approximately $0.5 \mu \mathrm{m}, \mathrm{SF}$ is approximately 20 times smaller than cement particles. The specific area of SF particles varies between 12 and $25 \mathrm{~m}^{2} / \mathrm{g}$ in comparison to specific area of $0.4 \mathrm{~m}^{2} / \mathrm{g}$ for typical type 10 cement. In this investigation Wille et al. [1] found that effect of the type of SF on compressive strength is negligible. 


\subsubsection{Amount and Type of HRWR}

According to Wille et al. [1] fresh properties of the paste are highly influenced by the type of high-range water-reducing admixture (HRWR) and it's interaction with the cement particles. The most commonly used type of the HRWR for mixing UHP-FRC is based on polycarboxylate ether such as, superplasticizer (SP) with different side chain lengths. In their experimental program Wille et al. [1] carried out three test series with same mixture but different amounts of HRWR with $8 \%, 4 \%$ and $3.4 \%$ respectively. From these tests they observed that reducing the amount of HRWR increases both the flowability and the compressive strength. It has been reported that the optimum range of 1.4 to $2.4 \%$ of cement by weight or a solid content of HRWR between 0.5 and $0.9 \%$ if cement by weight.

\subsubsection{Fiber Content}

To-date many researches have done on the influence of the fiber content on mechanical properties of UHP-FRC such as, compressive strength, flexural tensile strength and tensile fracture properties. In their research study on tensile fracture properties of UHP-FRC with different steel fibers, Su-Tae et al. [2] observed that flexural tensile strength of UHP-FRC linearly increases as the fiber volume ratio increase from 0 to $5 \%$.

A content of $2 \%$ by volume of $13-15 \mathrm{~mm}$ length steel fibres with diameters around $0.2 \mathrm{~mm}$ found to be the best optimum out of thousands of tests with high bending and direct tensile strength [13]. On the other hand, the 5\% fiber content was found as the most effective percentage to resist spalling and defragment [9].

Improvement of the mechanical properties of UHP-FRC observed by addition of straight (13 $\mathrm{mm}$ long, $0.2 \mathrm{~mm}$ diameter), high strength steel fibers of $2.5 \%$ by volume in replacement of the equivalent volume of sand [1]. Maximum direct tensile strength of $14 \mathrm{MPa}$ and an equivalent bending strength of $30 \mathrm{MPa}$ also achieved. More influence of fiber content on UHP-FRC mechanical properties are discussed in section 2.4. 


\subsection{Static Properties of UHP-FRC}

UHP-FRC is known by its outstanding mechanical properties, such as, high compressive strength, strain hardening behaviour under uniaxial tension, stiffness, high modulus of elasticity, and toughness $[14,15]$.

The type of curing has a significant effect on mechanical properties of UHP-FRC. The application of heat and pressure curing will increase the mechanical properties such as, compressive strength, tensile strength and modulus of elasticity [10]. However, due to practical and economic reasons, heat or pressure curing cannot be used in the field applications [15]. It should be mentioned that, the orientations of the fiber reinforcement are critical parameters which could influence the mechanical behavior of UHP-FRC. Mixing and placing methods also could affect its mechanical response; therefore it must be appropriately coordinated to ensure acceptable mechanical performance [10].

In this section (2.4.1 - 2.4.3) mechanical property of UHP-FRC related to this study in quasistatic region is discussed. The typical mechanical properties range for UHP-FRC is listed in Table below (Table 2.3).

Table 2.3: Mechanical Properties Range of UHP-FRC [10]

\begin{tabular}{cc}
\hline Mechanical Property & Range \\
\hline Compressive Strength & $150-200 \mathrm{MPa}$ \\
Direct Tensile Strength & $8-15 \mathrm{MPa}$ \\
Flexural Strength & $30-45 \mathrm{MPa}$ \\
Modulus of Elasticity & $45-55 \mathrm{GPa}$ \\
Poisons Ratio & 0.2 \\
Density & $2400-2550 \mathrm{~kg} / \mathrm{m}^{3}$ \\
\hline
\end{tabular}




\subsubsection{Compressive Strength}

Compressive strength is an important property in the design of any concrete structure. It is also the property that is most frequently measured. As mentioned earlier a typical compressive strength of UHP-FRC is in the range of 150 to $200 \mathrm{MPa}$. Until about 70 to $80 \%$ of the compressive strength, UHPC and UHP-FRC show a linear elastic behaviour (See Figure 2.2 and 2.3). It is proven that the failure of UHPC (without fibres) is brittle which means there is no descending branch in the stress-strain diagram after failure (Figure 2.2). The same fact can be observed for High Strength Concrete (HSC) [10, 16].

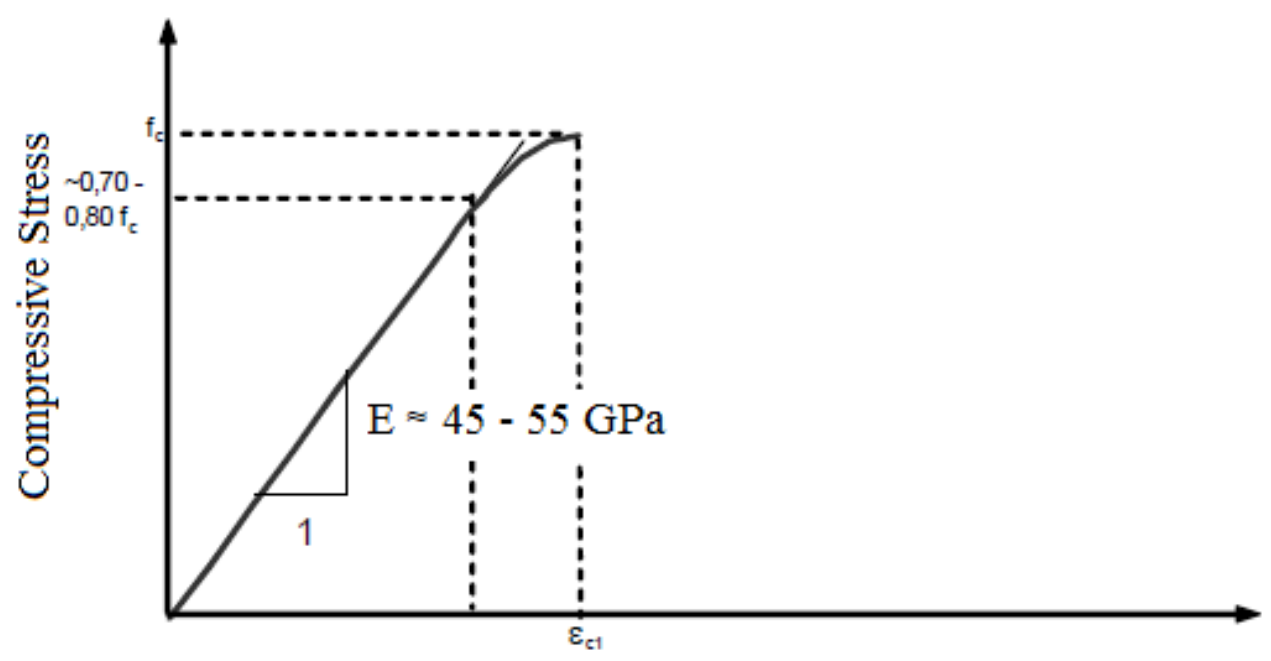

Strain

Figure 2.2: Stress-Strain Curve for UHPC without Fibers [16]

Unlike UHPC, UHP-FRC failure is ductile where a descending branch can be developed after failure by the effect of the fibres (Figure 2.3). The slope of the descending branch depends on fiber content, fiber aspect ratio (length/diameter) and fiber orientation [1, 16]. In general, fibers do not have significant influence on compression strength of UHP-FRC. However, improvement of compressive strength by $15 \%$ was reported for $2.5 \%$ of fibers content by volume fraction [16]. Nielsen, [17] also observed an increase of 5-10\% in average compressive strength for fiber content of $4 \%$ by volume fraction. 


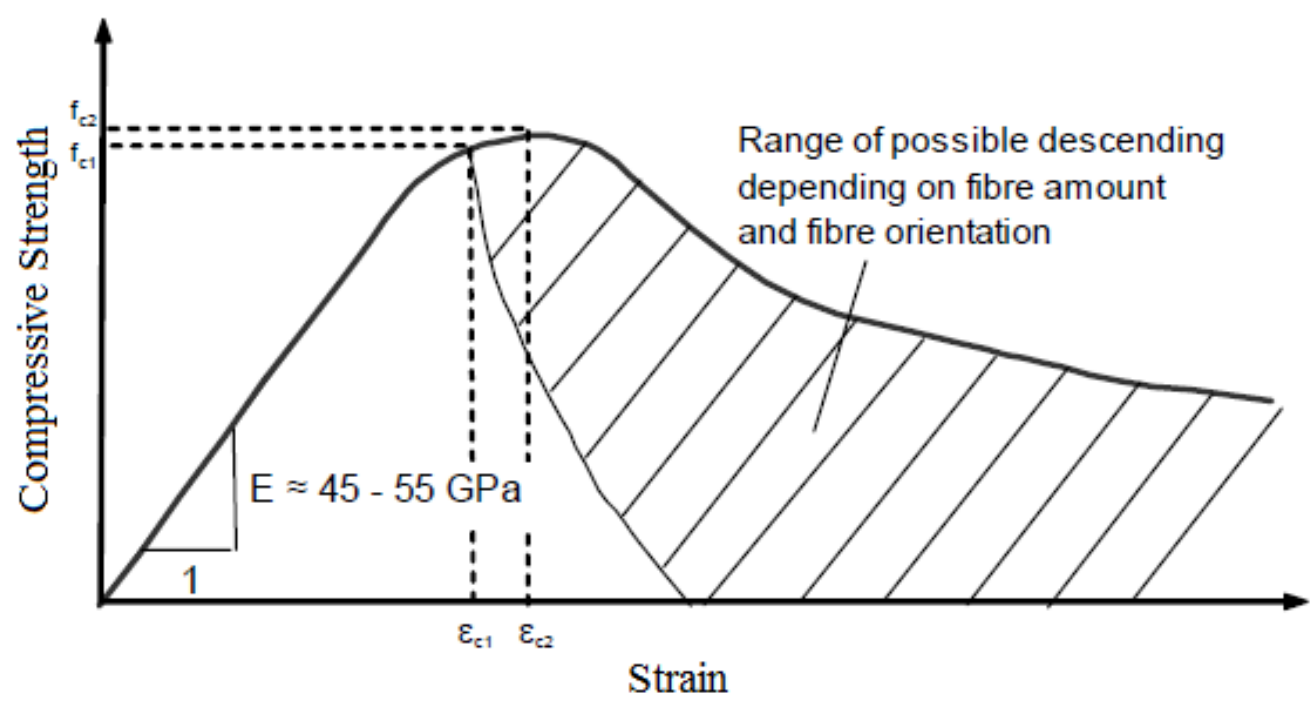

Figure 2.3: Stress-Strain Curve for UHP-FRC (1\% - 2.5\%) [16]

\subsubsection{Compressive Strength Testing}

Compressive strength testing of UHP-FRC is often completed by either using a modified version of ASTM C39 - Standard Test Method for Compressive Strength of Cylindrical Concrete or ASTM C109 - Standard Test Method for Compressive Strength of Hydraulic Cement Mortars using 50-mm Cube Specimens. The ASTM C39 test method is modified to include an increased load rate of $1 \mathrm{MPa} /$ second due to the high compressive strength response of UHP-FRC [10].

Many studies conducted to investigate the difference of cylinder and cube specimens on the measured compressive strength. In their investigation Graybeal and Davis [18] reported that 50 $\mathrm{mm}, 70 \mathrm{~mm}$, and $100 \mathrm{~mm}$ cubes exhibited compressive strengths up to approximately 7 percent greater than those observed from $75 \times 150 \mathrm{~mm}$ and $100 \times 200 \mathrm{~mm}$ cylinders.

Graybeal [12] also indicated that loading rates between 0.24 and $1.7 \mathrm{MPa} /$ seconds had no significant influence on the measured mechanical properties of UHP-FRC, such as, compressive strength, modulus of elasticity, and Poisson's ratio. 


\subsubsection{Tensile Strength (Direct Tension Test)}

The tensile strength of UHPC (without fibres) is between 7 and $10 \mathrm{MPa}$ while, the tensile strength of UHP-FRC is in the range between 7 and $15 \mathrm{MPa}$ [16]. Because of the fibers influence, the behaviour of UHP-FRC becomes ductile and tensile strength is sustained after first cracking. Therefore, the result of UHP-FRC tensile strength usually reports the first cracking strength along with peal port-cracking strength $[10,16]$. The tensile stress-strain response of UHP-FRC with $2 \%$ steel fibers by volume is illustrated in by Graybeal et al. [19] and is shown in Figure 2.4.

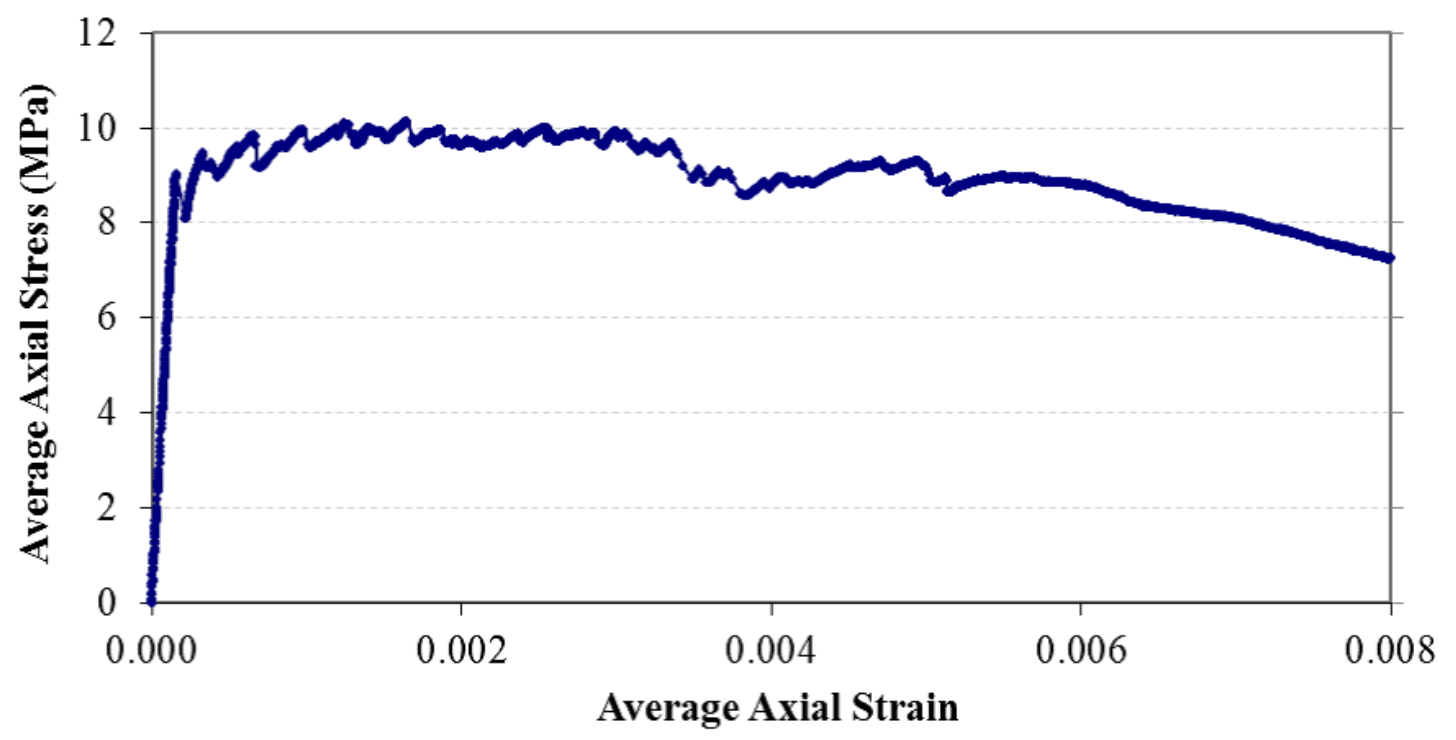

Figure 2.4: Tensile Stress-Strain of UHP-FRC by Graybeal et al. [19]

A proposed idealized tensile stress-strain by Graybeal and Baby [20] is shown in Figure 2.5. The proposed graph is a conceptual illustration of the pre-cracking and post-cracking tensile stressstrain response of strain-hardening UHP-FRC.

The behavior is divided into four phases as follow [10, 20]:

- Phase I is the elastic behavior region.

- Phase II exhibits multiple close cracking form in the UHP-FRC matrix. The cracks occur individually as the stress in the matrix exceeds the matrix cracking strength. 
- Phase III is the phase that existing cracks begin to widen since additional cracking between those is unlikely.

- Phase IV begins when an existing crack has reached their strain limit and the fibers bridging that crack begin to pull out of the matrix. In a strain-hardening fiberreinforced concrete, the fiber bridging strength where localization occurs is greater than the cracking strength where multi-cracking occurs.

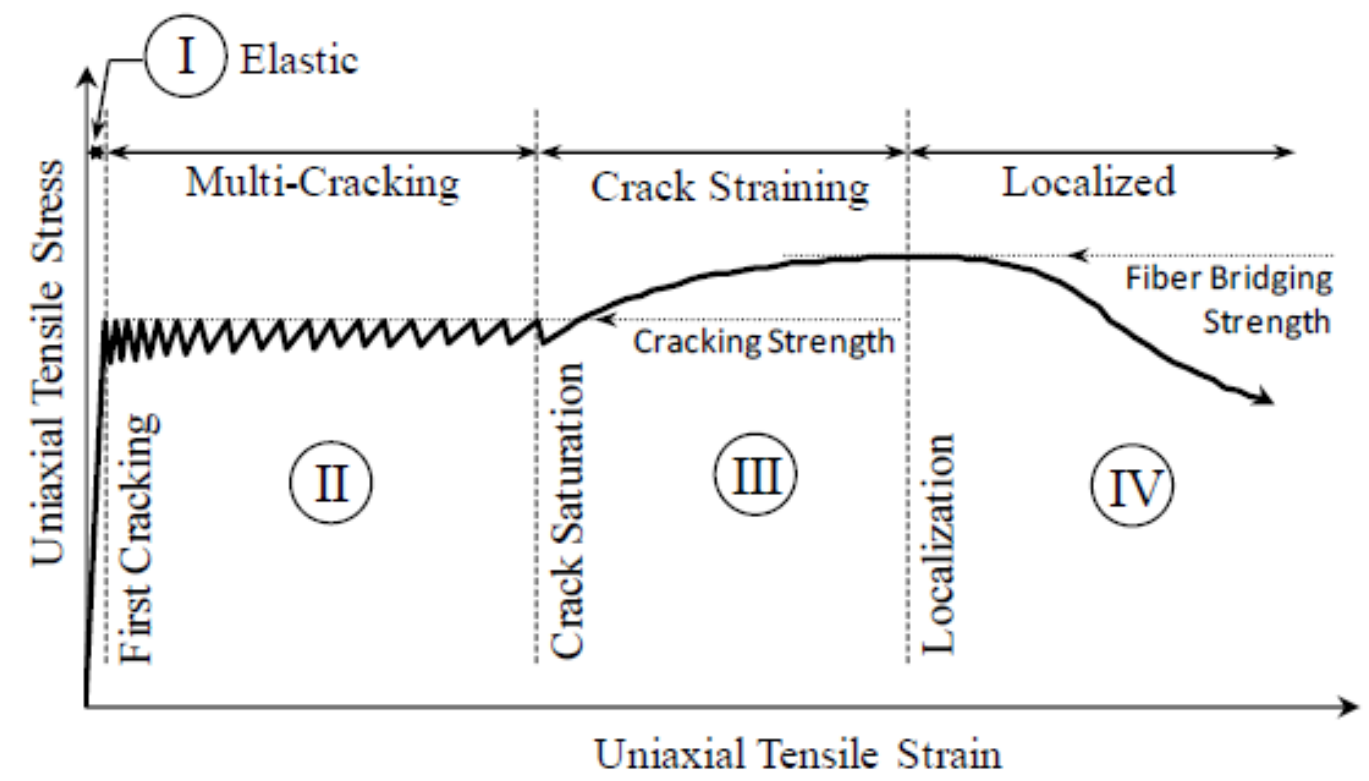

Figure 2.5: Idealized Uniaxial Tensile Response of UHP-FRC [20]

\subsubsection{Modulus of Rupture Test, $f_{r}$}

Standard tensile test methods, such as, ASTM C293 - Standard Test Method for Flexural Strength of Concrete (Using center point loading) and ASTM C496 - Standard Test Method for Splitting Tensile Strength of Cylindrical Concrete Specimens could be used for evaluation of the first cracking strength of UHP-FRC, however it might not be appropriate for evaluation of the post cracking response of it [12]. The reason is that in these methods there are assumptions in mechanical behaviours that are not consistent with strain-hardening fiber reinforced concretes, and as a result they are likely to overestimate the tensile strength of the UHP-FRC [10]. 
Graybeal [21] has proposed a modified version of ASTM C496 which requires monitoring the firs cracking of the UHP-FRC during the test and calculating the splitting tensile strength based on the observed cracking load (first crack).

There are different ways of measuring tensile strength of UHP-FRC such as, split tensile test, direct tension test and etc. In his research, Graybeal [12] measured the tensile strength of UHPC using flexural prisms, split cylinders, mortar briquettes, and direct tension tests of cylinders. Form these tests he indicated a first tensile cracking strength of approximately 9.0 MPa for steam-cured specimens and approximately 6.2 MPa without any heat treatment. The modulus of rapture values for first cracking was between ranges of 9.0 to $10.3 \mathrm{MPa}$, depending on the method of steam curing.

In this study, Graybeal [18] realized that the tensile strength $\left(f_{r}\right)$ of UHPC is related to the measured compressive strength $\left(f^{\prime} c\right)$ and introduced the following equation.

$$
\begin{gathered}
f_{r}=0.65 \sqrt{f^{\prime} c} \text { or } 0.69 \sqrt{f^{\prime} c} \text { in MPa unit For steam curing } \\
f_{r}=0.56 \sqrt{f^{\prime} c} \text { in MPa unit For untreated specimens }
\end{gathered}
$$

\subsubsection{Modulus of Elasticity, $\mathrm{E}_{\mathrm{c}}$}

Because of its dense structure, UHP-FRC has a higher modulus of elasticity than normal and high strength concrete [16]. UHP-FRC does not require any specific modifications to the standard ASTM C469 test method for static modulus of elasticity [10].

The UHPC modulus of elasticity $\left(\mathrm{E}_{\mathrm{c}}\right)$ equation for the value of compressive strength $\left(f^{\prime} c\right)$ ranging "between" 38 to $193 \mathrm{MPa}$ is given as follows by Graybeal [18]:

$$
\mathrm{E}_{\mathrm{c}}=3840 \sqrt{f^{\prime} c} \text { in MPa unit }
$$




\subsection{Dynamic Properties of UHP-FRC}

This section introduces strain rate effect on concrete under both compression and tension. The discussion in this section is focused on the influence of strain rate effect on mechanical properties of UHP-FRC taking into account of the experimental technique related to this study.

\subsubsection{Strain Rate Response of Concrete}

It's a well-known and accepted fact that the dynamic behavior of concrete materials is strain-rate dependent [22]. In compare to statically behaviour, concrete exhibits increase in strength, higher strain capacity and fracture energy when subjected to higher loading rate [23]. Many concrete structures which are required to resist extreme dynamic and impact loading such as, nuclear power stations could be affected by high strain rates coming from different sources [24]. Typical strain rates values for different loading condition is illustrated in Figure 2.6.

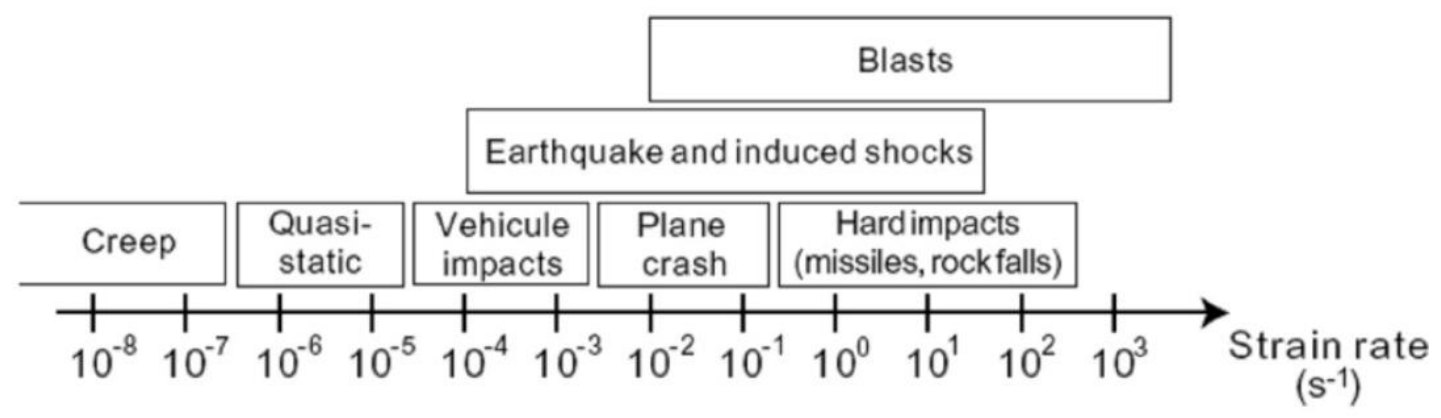

Figure 2.6: Various Load Cases with Corresponding Strain Rates [24]

The understanding of concrete behaviour under wide range of strain rate is required to properly design the concrete structures subject to all type of loading, particularly those with very high loading rates (Blast). Many researchers investigated the loading rate effect on mechanical properties of concrete in compression, tension and flexure [24].

In the following sub-sections the influence of different strain rates (high and low) on the strength of concrete material (e.g. UHP-FRC) and proposed experimental techniques for measuring the strength is discussed. 


\subsubsection{Strain Rate Effect on the Strength of Concrete}

\subsubsection{Dynamic Increase Factor, DIF}

The effect of strain rate on the concrete compressive and flexural strength is measured and presented as a dynamic increase factor (DIF) versus strain rate, on a semi-log or log-log scale. DIF is defined as the ratio of the dynamic strength to quasi-static strength as following [24, 25].

$$
D I F=\frac{f_{c d}^{\prime}}{f_{c s}^{\prime}}
$$

The most comprehensive model for calculating strain rate enhancement of concrete both in tension and compression is presented by CEB Model Code (Comite Euro-International du Beton - Federation Internationale de la Precontrainte) [26].

$$
\begin{aligned}
& D I F=f_{c d} / f_{c s}=\left(\frac{\varepsilon^{\prime}}{\varepsilon_{s}}\right)^{1.026 \alpha} \quad \text { for } \varepsilon^{\cdot} \leq 30 \mathrm{~s}^{-1} \\
& D I F=f_{c d} / f_{c s}=\gamma\left(\frac{\varepsilon^{*}}{\varepsilon_{s}}\right)^{1 / 3} \quad \text { for } \varepsilon^{\cdot} \geq 30 \mathrm{~s}^{-1}
\end{aligned}
$$

Where,

$$
\begin{aligned}
& f_{c d}=\text { Dynamic peak stress }(\mathrm{MPa}) \\
& f_{c s}=\text { Static compressive strength }(\mathrm{MPa}) \\
& \varepsilon^{\cdot}=\text { Strain rate in the range of } 30 \times 10^{-6} \text { to } 300 \mathrm{~s}^{-1} \\
& \varepsilon_{s}=30 \times 10^{-6}(\text { Quasi-static strain rate) } \\
& \log \gamma=6.156 \alpha-2 \\
& \alpha=1 /\left(5+9 f_{c s} / f_{c o}\right) \\
& f_{c o}=10 \mathrm{MPa}
\end{aligned}
$$




\subsubsection{Strain Rate Properties of Concrete in Compression}

Many researches have conducted experimental studies focusing on the dynamic compressive behavior of concrete. Most of these studies have shown that the measured dynamic compressive strength is a function of strain rate and strength increase in compression is primarily a material property $[5,8,25]$.

Among these researches, Bishoff and Perry [27] conducted a research on compressive behavior of normal to high strength plain concrete at high strain rates based on the results of many test programmes. In this research they reviewed the most commonly used experimental techniques for compressive strength of plain concrete at high strain rates, and the dynamic compressive strength of the plain concrete under uniaxial loading.

It is usually suggested that, hydraulic testing machines to be used for static loading of concrete in compression at a strain rate near $10^{-5} \mathrm{~s}^{-1}$. Since hydraulic machine test has the ability to increase the oil flow rate with aid of fast pumps and valves they also might be used to load at strain rate as high as $10^{-1} \mathrm{~s}^{-1}$. It is noted that, when using hydraulic testing machine at high strain rates (dynamic), displacement control is preferred in order to achieve a stable failure [27].

The researchers also noted that, careful attention must be taken to the limitations that exist during the dynamic loading, such as, consideration of testing machine characteristics, stress-wave propagation effect, and uniformity of stress and strain along the specimen length, specimen geometry and strain-rate variation and frequency response of the measurement system [27].

In this research, Bishoff and Perry [27] observed an increase of about 25 to $30 \%$ in design compressive strength, $f^{\prime}$, during dynamic loading of concrete structures. While dynamic compressive strength found to be 85 to $100 \%$ higher than static strength. It was also observed that, not all researches agree at which strain rate the increase in strength becomes significant. The researchers mentioned this due to different test techniques, type of measurement, differences in mix design, specimens shape and size, and finally aspect ratio of the specimen's. Therefore, it has been suggested that care must be taken when comparing the results from different researches, and comparison of material properties may be carried out within a particular test program. 
It was also reported that poorer concrete, such as normal strength concrete, exhibits a larger increase in compressive strength under high strain-rate loading. On the other hand, failure in high strength concrete, occur though out a greater number of aggregate particle in compare to normal strength concrete. This results in greater proportionate increase strength for weaker concrete at higher strain rates, when the strength increases is gained partly by the propagation of cracks through the stronger aggregate particles [27].

Malgarzata [24] conducted a research on the influence of strain rate on concrete, and gathered a summary of available test data of different concrete type subjected to compressive and tensile strain rates (Figure $2.7-2.8$ ). In these figures most of the concrete material types including, UHPC and HSC are pointed.

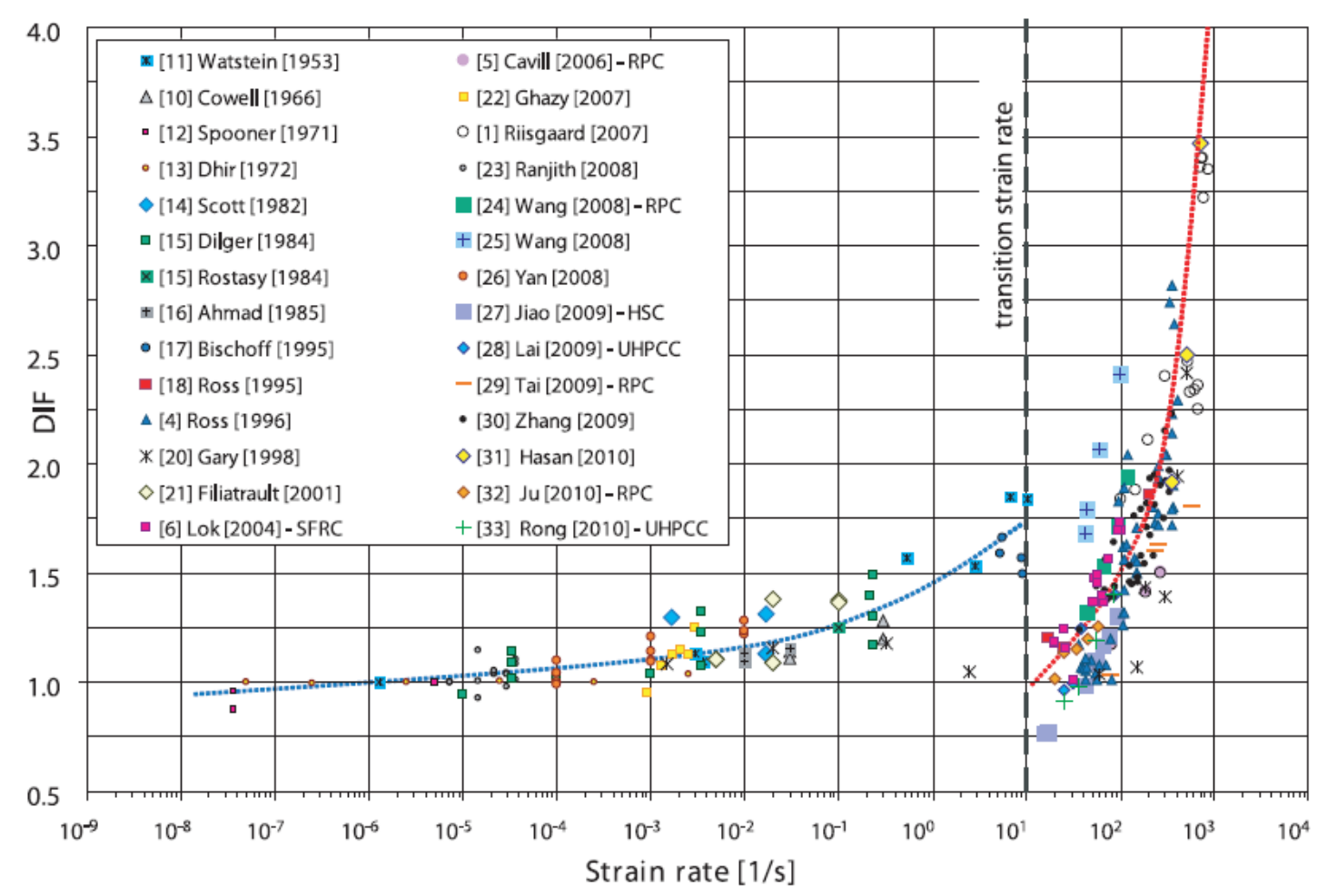

Figure 2.7: Strain Rate Effect on Compressive Strength of Different Concrete Types [24]

By analyzing the figure above one can observe that as the strain rate increase, concrete strength increases. Clearly the result cannot be approximate with one line and all range of strain rates should be investigated in two domains. In first region (before transition line) a slow increase in concrete strength is observed with DIF equal to 1.8. In the second region (after transition line) 
DIF increases significantly, with value of 3.5. The value of strain rate which causes this increase is called transition strain rate [24]. Different strain rate values for transition strain rate have been introduced by different researches (e.g. $10 \mathrm{~s}^{-1}, 60-80 \mathrm{~s}^{-1}$ ).

\subsubsection{Strain Rate Properties of Concrete in Tension}

Unlike the effort on investigation of concrete subjected to dynamic compression, less attention paid to the dynamic tensile behaviour of concrete. The main reason is that tests and measurement of the dynamic response of concrete in tension is much harder than in compression. However, all the available test results show that, the rate effect in tension is much higher than in compression [25]. The strain rate sensitivity of concrete in tension is illustrated by Malgarzata [24] and shown in Figure 2.8.

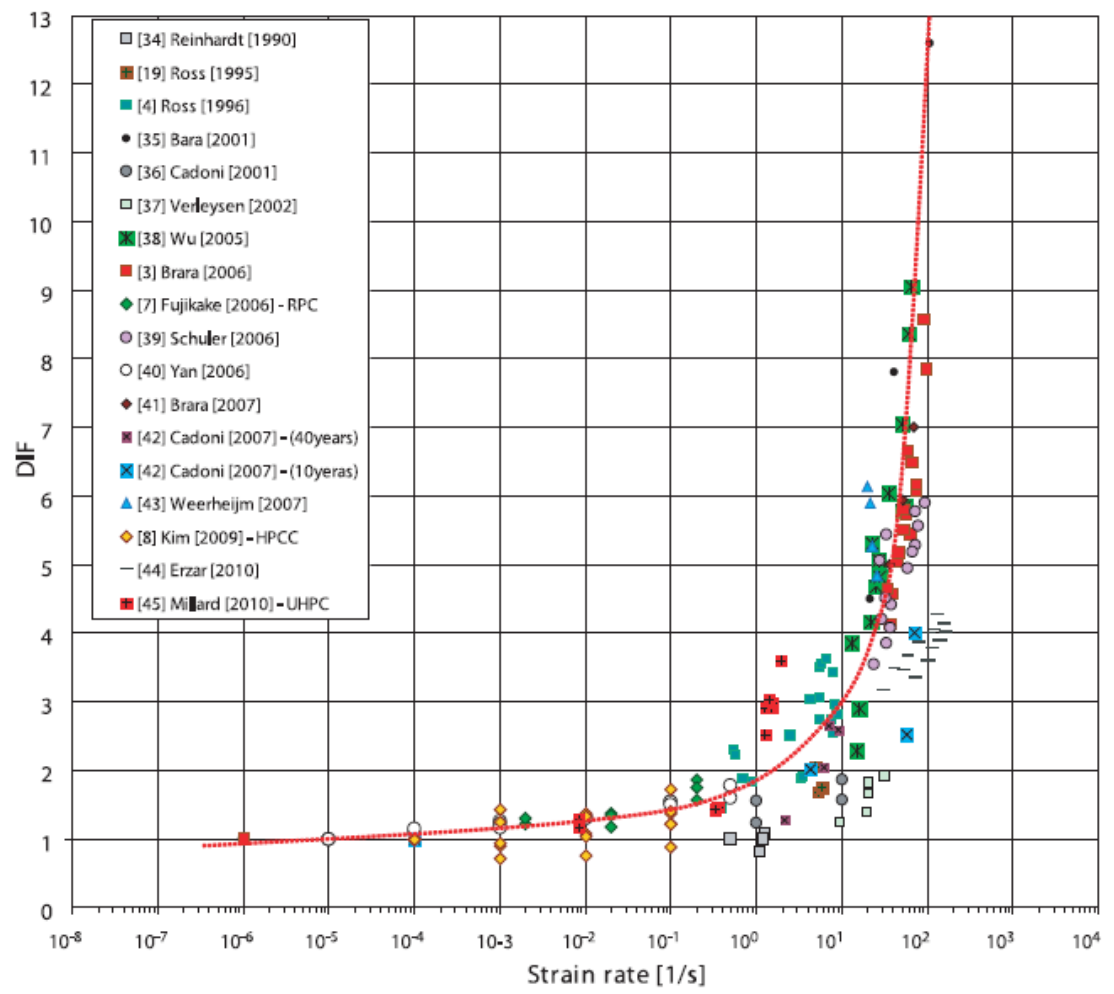

Figure 2.8: Strain Rate Effect on Tension Strength of Different Concrete Types [24]

The significant increase of strength (DIF equal to 13) in tension with increase of strain rate clearly can be seen. This increment confirms the earlier statement that the rate effect is much higher in tension than in compression. 


\subsubsection{Strain Rate Response of UHP-FRC}

Wille et al. [28] has reported that on the strain rate dependent tensile behavior of UHP-FRC with different fiber volume fractions at strain rates ranging from $10^{-4}$ to $10^{-1} \mathrm{~s}^{-1}$. In this study the researchers observed that strength and energy absorption capacity of UHP-FRC both increased with an increase in fiber volume fraction for a given strain rate. Gao et al. [5] investigated the strain rate dependency of fibre reinforced and plain UHPC for compressive and flexural strength. In this study the researchers used cylinder and prisms for compressive and flexural strength test respectively. Their investigation revealed that the flexural strength of UHPC shows higher DIF up to 3.5 at strain rate of $2 \mathrm{~s}^{-1}$, while UHP-FRC exhibits lower enhancement (DIF) at same rate with peak factor of 2.4. In this study the compressive strength enhancement value for UHPC and UHP-FRC reported as 1.2 at strain rate of $2 \times 10^{-3}$ and 1.3 at strain rate of $1 \times 10^{-3}$ respectively.

To date the experimental studies on the high strain rate behavior of UHP-FRC is very limited. Among the few examples are Millard et al. [3] who conducted flexural and shear high-speed loading tests of UHP-FRC using a drop-hammer testing apparatus for investigation of DIF. It has been found that the DIF of the flexural tensile strength rises from 1.0 at the strain rate of $1 \mathrm{~s}^{-1}$. on a slope of $1 / 3$ on a $\log$ (strain rate) versus $\log (\mathrm{DIF})$ plot. This study also revealed that there is no significant increase in shear strength at high strain rates.

Habel and Gauvereau [9] conducted series of drop weight tests at the University of Toronto to apply dynamic three-point-bending loading to UHP-FRC plates. In this study the researchers observed that strength and fracture energy of the dynamically loaded UHP-FRC plate's increases significantly when compared to quasi-static loading. Their analysis showed that the UHP-FRC strength increases with increasing of strain rate.

Bindiganavile et al. [4] investigated the impact response of UHP-FRC with fiber volume fraction of $0.75 \%$ and $6 \%$. The results of the study indicated that under quasi-static loading, UHP-FRC with $6 \%$ by volume of steel fibers was two to three times stronger in flexure and absorbed three times greater energy than those with $0.75 \%$ by volume of steel or polypropylene fiber. The researchers also reported that UHP-FRC with $6 \%$ by volume fraction is less stress-rate sensitive than conventional UHP-FRC with $0.75 \%$ by volume fraction. 
Behaviour of Ultra High Strength Concrete (UHSC) subjected to blast loading (at very high strain rate) investigated by $\mathrm{Ngo}$ et al. [29] and then the results compared to high strength concrete (HSC) and normal strength concrete (NSC). To do so, the researchers carried out series of impact test based on the split Hokinson pressure bar (SHPB) setup. In this study it has been observed that at high strain rates, the strength of the concrete can increase significantly. The researchers also reported the increase of compressive strength up to 1.5 times at the strain rate of about at strain of $267.4 \mathrm{~s}^{-1}$. It was found that UHSC is less rate sensitive than NSC and HSC. Based on their experimental program, a new strain rate dependent constitutive model has proposed by Ngo et al. This model applies for concrete under dynamic loading taking in to account the strain rate effect. This model is applicable to concrete strengths with strength range from 32 to $160 \mathrm{MPa}$ with a strain rate up to strain of $300 \mathrm{~s}^{-1}$. The DIF curves using the proposed model by Ngo et al. [29] are shown in figure 2.9.

$$
\begin{gathered}
D I F=f_{c d} / f_{c s}=\left(\frac{\varepsilon^{*}}{\varepsilon_{s}}\right)^{1.026 \alpha} \quad \text { for } \varepsilon^{*} \leq \varepsilon_{1} \\
D I F=f_{c d} / f_{c s}=\mathrm{A}_{1} \ln \left(\varepsilon^{*}\right)-\mathrm{A}_{2} \quad \text { for } \varepsilon^{\cdot} \geq \varepsilon_{1}
\end{gathered}
$$

$\alpha=1 /\left(20+f_{c s} / 2\right) ; \quad \varepsilon_{1}=0.0022 f_{c s}^{2}-0.1989 f_{c s}+46.137 ; \mathrm{A}_{1}=-0.0044 f_{c s}+0.9866 ;$ and $\mathrm{A}_{2}=-0.0128 f_{c s}+2.1396$,

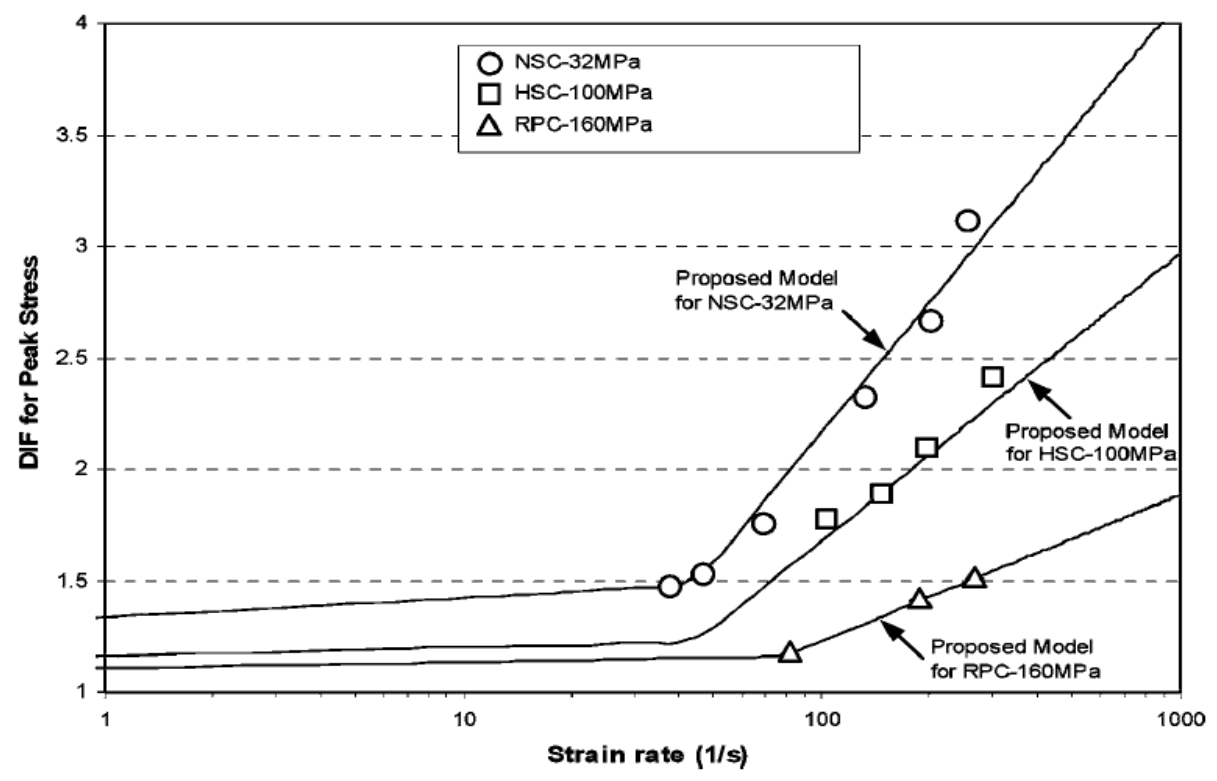

Figure 2.9: Proposed DIF Model for Peak Stress by Ngo et al. [29]. 


\subsection{Testing Methods for Concrete under High Strain Rates}

As previously mentioned, different setups for testing of concrete under high strain rate loading have been used in the past. Following is a survey of the most commonly used techniques which are related to this study.

\subsubsection{Drop Hammer Technique}

There is no standard approach or test to investigate the dynamic increase factor of UHP-FRC under flexural loading. Perhaps one of the most commonly used techniques for testing concrete under high strain rate is drop hammer technique which has been used by different researchers [3, 4, 9, 29 ]. In the following sub-sections different drop hammer setups used at different Universities is discussed in details.

\subsubsection{University of Toronto Drop Hammer Strain Rate Test}

Habel and Gauvereau [9] used the drop hammer facility at $U$ of $\mathrm{T}$ for a study on impact response of UHP-FRC. This facility consists of two drop weight of 10.2 and $20.6 \mathrm{~kg}$, and constant height drop of $1050 \mathrm{~mm}$ considered for the test. Plywood with length of $20 \mathrm{~mm}$ and thickness of $19 \mathrm{~mm}$ is used as load attenuator between drop weight and beam. In this test multiple drops were performed on all specimens to obtain complete fracture.

High speed camera operating at 1000 frames per second was used to calculate the speed of the drop weight at the instant of impact. The speed at impact was evaluated to $4.2 \mathrm{~m} / \mathrm{s}$ for the $10.3 \mathrm{~kg}$ and $4.3 \mathrm{~m} / \mathrm{s}$ for the $20.6 \mathrm{~kg}$ weight. Two accelerometers affixed to the drop weight for determination of the impact force. Also two load cells located underneath the steel rollers for measurement of the support reactions. The deflection is assessed with potentiometers.

The researchers performed total of thirteen tests to determine the dynamic behavior of UHPFRC. The maximum strain rates observed in this test was $2 \mathrm{~s}^{-1}$, that was confirmed by the strain gauge measurement. Maximum deflection for the plates impacted with $10.3 \mathrm{~kg}$ weight was between 4.1 to $5.7 \mathrm{~mm}$ and for $20.6 \mathrm{~kg}$ weight was always greater than $6.5 \mathrm{~mm}$ [9]. 


\subsubsection{RMIT University Drop Hammer Strain Rate Test}

The schematic drawing of the drop hammer facility at RMIT is shown in the Figure 2.10. This facility where used by Millard et al. [3] for investigation of dynamic enhancement of UHP-FRC, comprised a $30 \mathrm{~kg}$ cylindrical steel with a length of $2.0 \mathrm{~m}$ and diameter of $50 \mathrm{~mm}$. The lower end of the bar is hemispherical and the top end incorporates a steel ring that is used to raise the bar. The hammer is guided by four bolts which they placed within the tracks. The transmission bar positioned centrally on top of the beam specimens to transfer the impact force from hammer. The length of the transmission bar was $500 \mathrm{~mm}$ and same diameter as drop hammer was used (50 $\mathrm{mm}$ ). A $15 \mathrm{~mm}$ fiberboard used on top of the transmission bar to attenuate the force provided by the drop hammer.

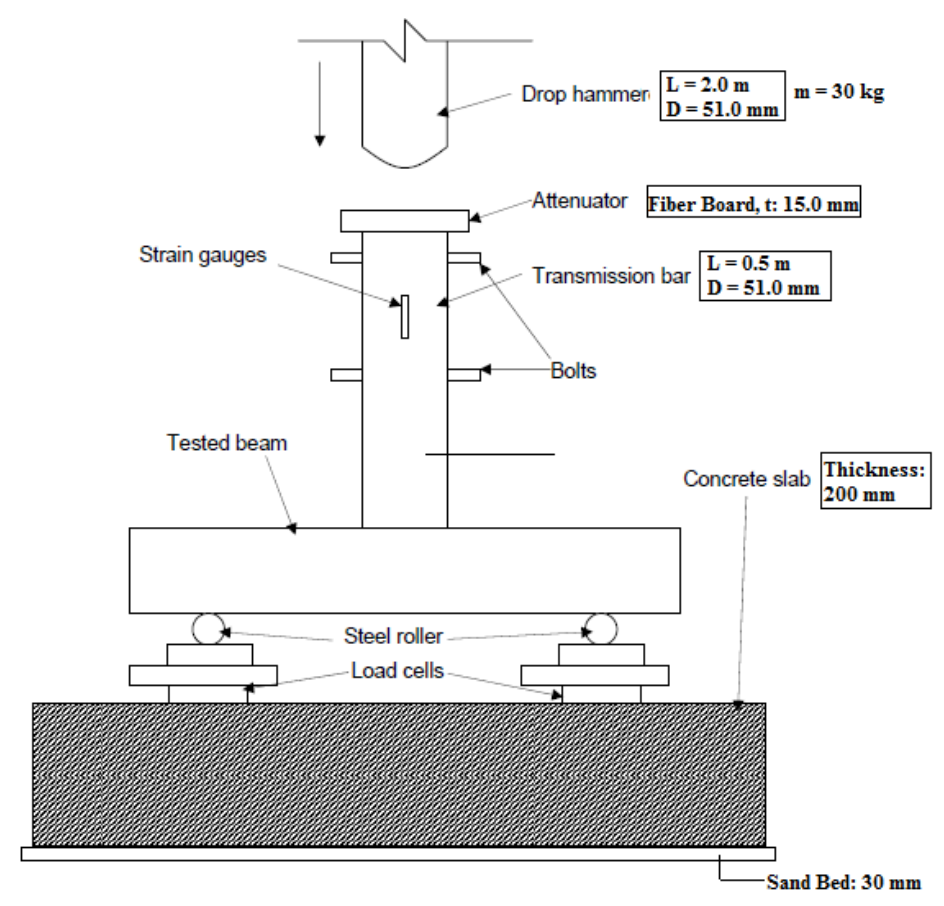

Figure 2.10: Drop-Hammer Test Setup Developed by RMIT [3]

A pair of strain gauges was attached parallel to the bar's longitudinal axis on opposite sides to get strain rates. Steel rollers with diameter of $25 \mathrm{~mm}$ were used to act as support for beams. Load cells placed under each supports to get one set of data from impact experiment. A concrete slab (200 mm thick) located on a $30 \mathrm{~mm}$ sand bed to reduce noise in the support load and transmission bars. An accelerometer attached to the concrete slab to record an insight into the operation of the rig. 
Drop weight facility was used for the investigating of the flexural strength of UHP-FRC under impact loading. $280 \times 70 \times 70 \mathrm{~mm}$ beams were used for flexural test with span of $210 \mathrm{~mm}$. Three different drop heights of 400, 600 and $1600 \mathrm{~mm}$ were used. The maximum strain rates observed in this test was at $4.01 \mathrm{~s}^{-1}$ for a drop height of $1600 \mathrm{~mm}$ with DIF of 2.53 [3].

The main advantages of the RMIT drop hammer facility are elimination of the high speed camera and simple setup. Because of its relatively simple setup this approach not only reduces the experiment cost tremendously, but open opportunities for more research in this area. The drop hammer facility developed for this study was inspired by RMIT drop hammer facility.

\subsubsection{University of Liverpool Drop Hammer Strain Rate Test}

The set up for the Liverpool University is similar to RMIT setup with few changes. A lighter hammer (23.3) $\mathrm{kg}$ was used, which required the maximum release height of $2.0 \mathrm{~m}$ to ensure failure of each specimen. In this test the impact force was calculated using Laser Doppler Anemometer ( $L D A)$ instead of transmission bar. LDA used to measure the velocity of the drop hammer as well. In addition a high speed camera was used to evaluate the beam displacement against time.

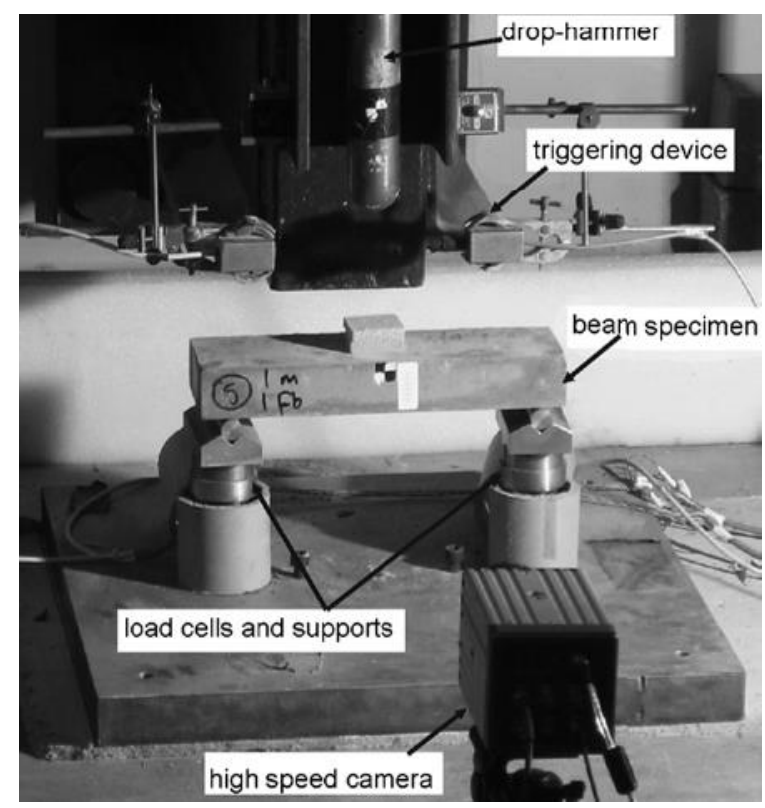

Figure 2.11: Liverpool University Drop-Hammer Test Facility [3] 
In this study strain rates could be calculated either from an applied load or from measured deflection. The load used for calculating the strain rate was load obtains from the support cells. A maximum flexural tensile strength of 54-68 $\mathrm{MPa}$ observed for $6 \%$ steel fiber by concrete volume. The Maximum strain rate achieved was $1.66 \mathrm{~s}^{-1}$ achieved [3].

\subsubsection{UBC Drop Hammer Strain Rate Test}

For the impact tests, University of British Columbia has designed and built an instrumented drop-weight impact test machine [4]. This machine is capable of dropping $60 \mathrm{~kg}$ mass from height up to $2.5 \mathrm{~m}$ on to a beam. Bindiganvile et al. [4] performed impact test with the mentioned machine for impact response of UHS-FRCC with up to $6 \%$ by volume of steel fiber.

In this experiment the researchers used four drop-heights of 200, 500, 750 and $1000 \mathrm{~mm}$ to investigate the impact behavior of these materials under a wide range of stress rates. For the flexural toughness testing beam specimens with dimension of $100 \times 100 \times 350 \mathrm{~mm}$ were used. For each mixture minimum of three beams were tested at various drop heights with on a clear span of $300 \mathrm{~mm}$.

In their research they reported the increase of the peak loads as well as the flexural strength with increase of drop-height of the hammer. Also specimens showed stiffer response at higher drop heights which indicates an increase in the elastic modulus of the material with an increase in the applied stress [4].

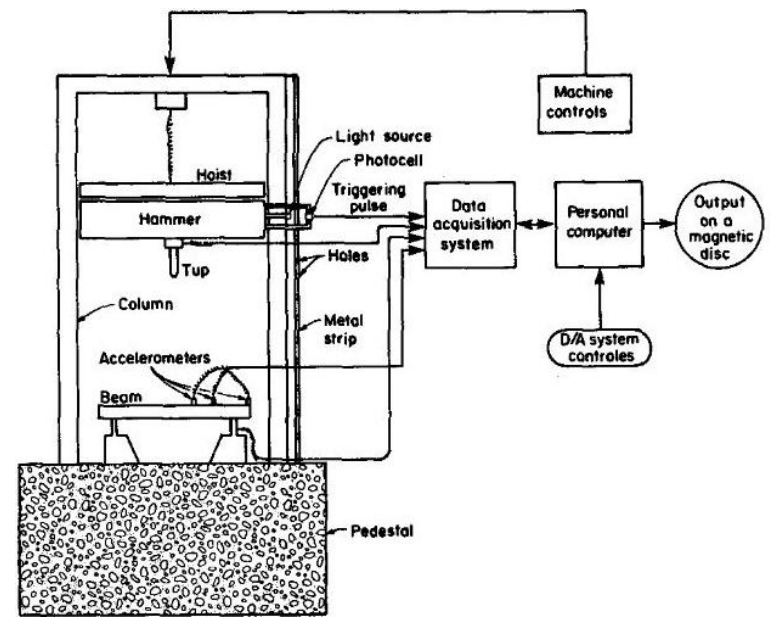

Figure 2.12: UBC Drop-Hammer Test Facility [30] 


\subsubsection{Split Hopkinson Pressure Bar (SHPB)}

The Split Hopkinson Pressure Bar (SHPB) configuration has been widely used to measure dynamic strength increase of concrete at high-strain rates in the range of $10 \mathrm{~s}^{-1}$ to $10^{3} \mathrm{~s}^{-1}$. The basic setup of the SHPB system is shown in Figure 2.12.

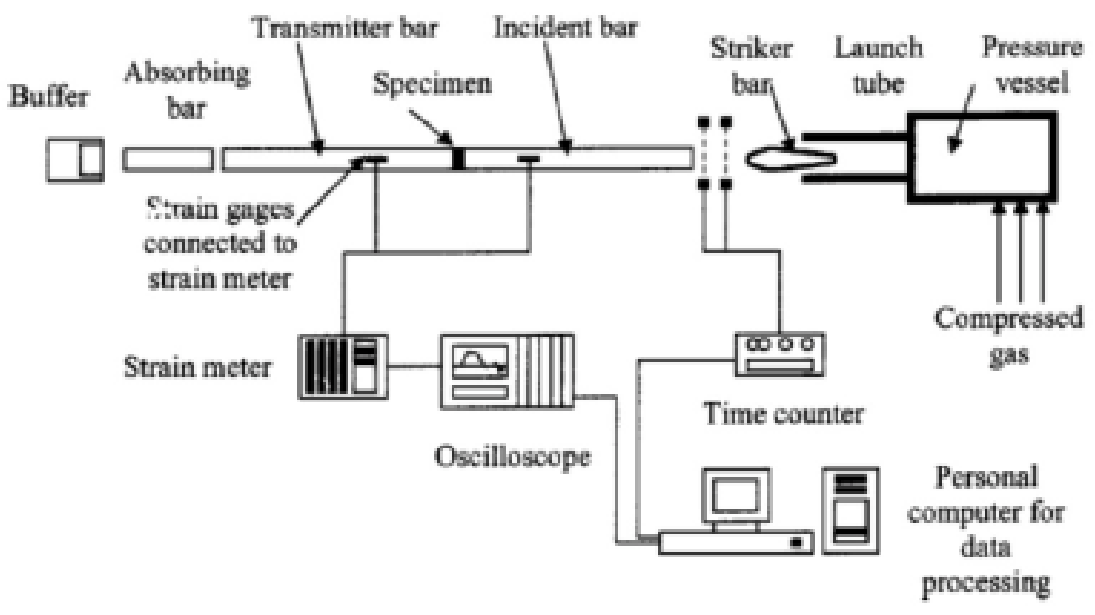

Figure 2.13: Typical Setup for a SHPB Device [24]

Riisgaard et al. [31] used SPHB for evaluating dynamic increase factor for high performance concrete in compression. In this study it is reported that the compressive of HPC increases from $100 \mathrm{MPa}$ to $340 \mathrm{MPa}$ at strain rate of approximately-700 s $\mathrm{s}^{-1}$. The researchers also reported the increase of compressive strength for UHPC from $160 \mathrm{MPa}$ to $400 \mathrm{MPa}$ at a strain rate of $600 \mathrm{~s}^{1}$. 


\section{Chapter 3 \\ EXPERIMENTAL PROGRAM}

The designed experimental investigation program is aimed to develop understanding of different concrete materials response to low and high strain rates. This chapter presents details about the mixture compositions, mixing procedure, test specimens and testing procedure for each series of composites. In the final section development and construction of drop hammer frame setup for impact test is discussed in details.

\subsection{Mixture Proportions}

Four different types of concrete are considered for the present study. In this section mixture proportions for each concrete type is discussed.

\subsubsection{UHP-FRC and EHP-FRC}

Ultra High Performance Fiber Reinforced Concrete (UHP-FRC) for the present study was provided by Lafarge Company, while Extra High Performance Fiber Reinforced Concrete (EHPFRC) was provided by Holcim Ltd. In the following table the material composition of UHP-FRC and EHP-FRC with $2 \%$ steel fiber is given according to Lafarge and Holcim Company mix design respectively.

Table 3.1: Mixture proportions for UHP-FRC and EHP-FRC

\begin{tabular}{|c|c|c|c|c|}
\hline \multirow[b]{2}{*}{ Composite } & \multicolumn{4}{|c|}{ Constituent, $\mathrm{kg} / \mathrm{m}^{3}$} \\
\hline & *Blend & $* *$ Admixture & Water & Fiber, $v_{f}=2 \%$ \\
\hline UHP-FRC & 2174 & 60.7 & 109 & 156 \\
\hline EHP-FRC & 2048 & 29.65 & 166 & 235 \\
\hline
\end{tabular}

*Blend contains; Cement, Silica Fume and Fine Sand

**Admixture contains; HRWR and Superplasticizer 


\subsubsection{EHS-FRC and HSC}

The Extra High Strength Fiber Reinforced Concrete (EHS-FRC) mix was done based on proposed mix designs from literature and produced from locally available materials in Ontario at Ryerson University. The water/cement ratio was 0.23. In The following table material composition for the EHS-FRC used in current study is given.

Table 3.2: Mixture proportions for EHS-FRC

\begin{tabular}{ccc}
\hline Constituent & Type & Bulk Density $\left(\mathbf{k g} / \mathbf{m}^{3}\right)$ \\
\hline Portland Cement & Type I & 1040 \\
Silica Sand & Size $<0.5 \mathrm{~mm}$ & 650 \\
Silica Fume & Grey SF & 165 \\
HRWR & Polycarboxylate & 46 \\
Steel Fibers (2\%) & Straight (1/d: 10/0.2 mm) & 156 \\
Water & - & 240 \\
\hline
\end{tabular}

Ready mix HSC with minimum aggregate size of $14 \mathrm{~mm}$ and silica fume was provided by an existing concrete plant in Ontario and it was transported to Ryerson University laboratory by a concrete mixer truck.

\subsection{Mixing Procedure}

In general mixing time of the UHP-FRC and EHP-FRC are higher than conventional concrete. Because the number of ingredient is higher and the fineness of particles is more than NSC, it is important that all particles are uniformly to avoid fine particle form chunk. Therefore, it is recommended that all dry compositions such as, Silica Fume, Sand and Cement should be mixed first for 10 minutes $[1,10]$. In the current study mixing procedure for UHP-FRC, EHP-FRC and EHS-FRC was same, because of the similarity of the mixture proportion and material characterization. In the following page mixing procedure of EHP-FRC by Holcim Ltd. is described as an example. 
The first step for mixing the UHP-FRC, EHP-FRC and EHS-FRC was weighting the materials packages (pails and jugs) using digital scale. Mixing procedure for EHP-FRC by Holcim Ltd. with $2 \%$ fiber by volume fraction is as follows.

1. In the first step, all the blend (binder) materials were placed in the mixture and mixed for 2 minutes.

2. After 2 minutes, $85 \%$ of water volume and $50 \%$ of the admixture were added to the batch over 2 minutes span, and mixed for 10 minutes.

3. After 10 minutes, rest of water and admixture incorporated to the batch and mixed for additional 5 minutes.

4. At 15 minutes of the total mixing time, steel fibers were gradually added into the mix over 3 minutes span, and let mixing product to mix for another 5 minutes.

5. Once the material became homogenous (at 20 minutes of mixing), a sample obtained and tested for flow. In case of UHP-FRC and EHP-FRC the mix discharged for casting when flow test is around $190 \mathrm{~mm}$ to $205 \mathrm{~mm}$ at 20 drops. The flow table test used for flow test, and $162.5 \mathrm{~mm}$ achieved without any drops, the slump flow test for EHP-FRC is shown in Figure 4.1.

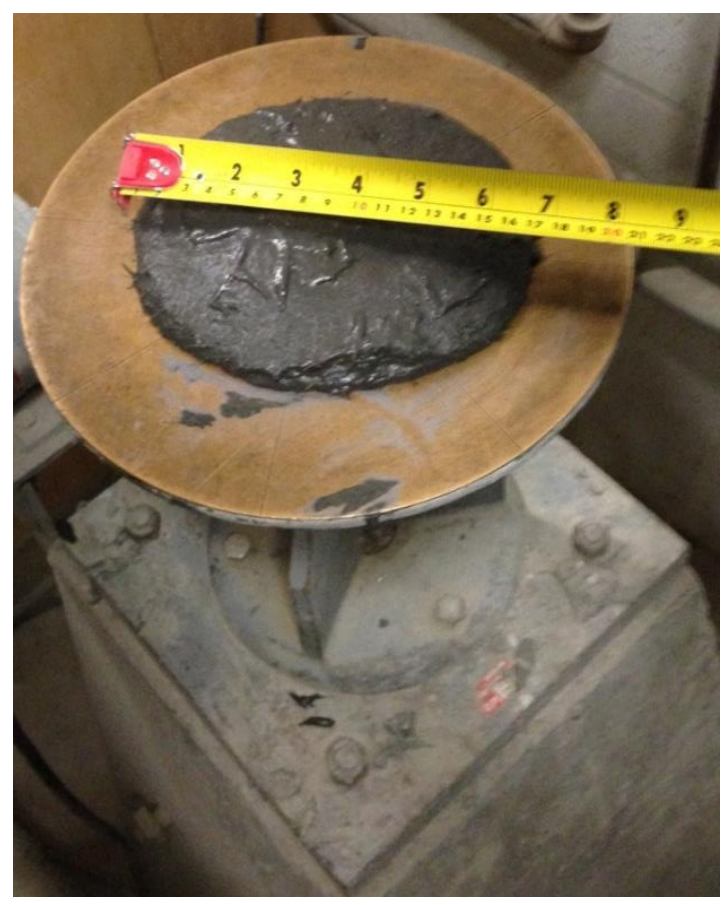

Figure 3.1: Slump Flow Test for EHP-FRC 


\subsection{Casting and Curing}

Each mix consisted of twenty six prisms of $100 \times 100 \times 400 \mathrm{~mm}$ size and at least forty cylinders of $100 \mathrm{~mm}$ in diameter by $200 \mathrm{~mm}$ height. For all mixes after mixing, the fresh concretes (all types) were transferred in to wooden formwork constructed with plywood for prisms, and plastic moulds for cylinder specimens. Before casting moulds were sprayed with oil lubricant before placing of concrete so that the concrete doesn't adhere to the plywood during de-moulding. The prepared moulds for prisms and cylinders right before casting are shown in Figure 3.2.

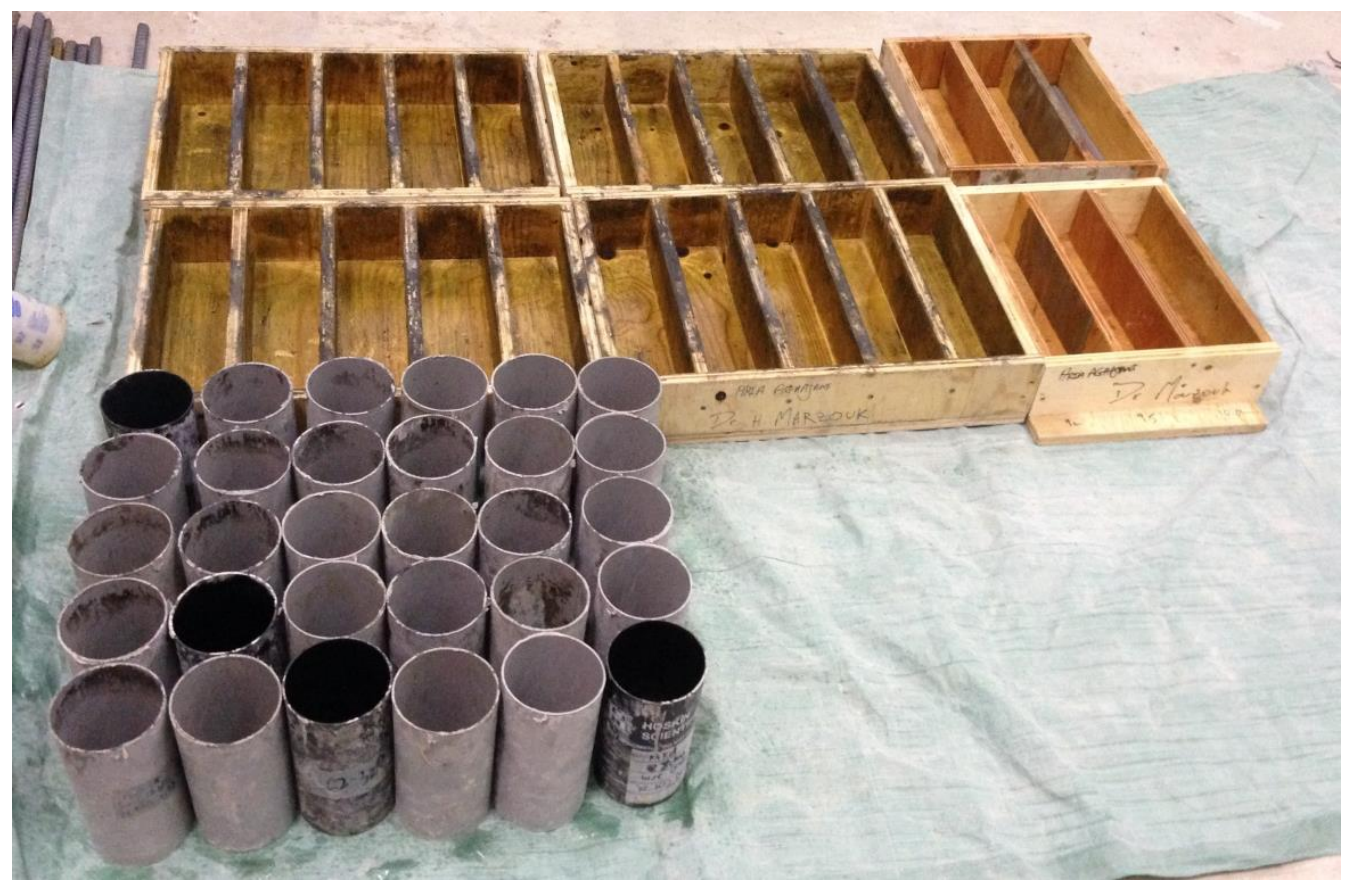

Figure 3.2: Prepared Moulds for Casting

Because of the steel fibre reinforcement orientations, internal vibration of UHP-FRC, EHP-FRC and EHS-FRC was avoided. Instead, limited vibration by compacting bar applied for the release of entrapped air. The specimens after casting were demoulded after interval of 72 hours to avoid any cracking. In case of HSC which had no fibers, internal vibration used more frequently to release entrapped air and to properly compact the materials. All the specimens were given proper finishing ensuring the uniformity of the surface. 
During the first three days the samples were covered with damp burlap and direct curing applied three times a day. Covered samples with burlap are shown in Figure 3.3.

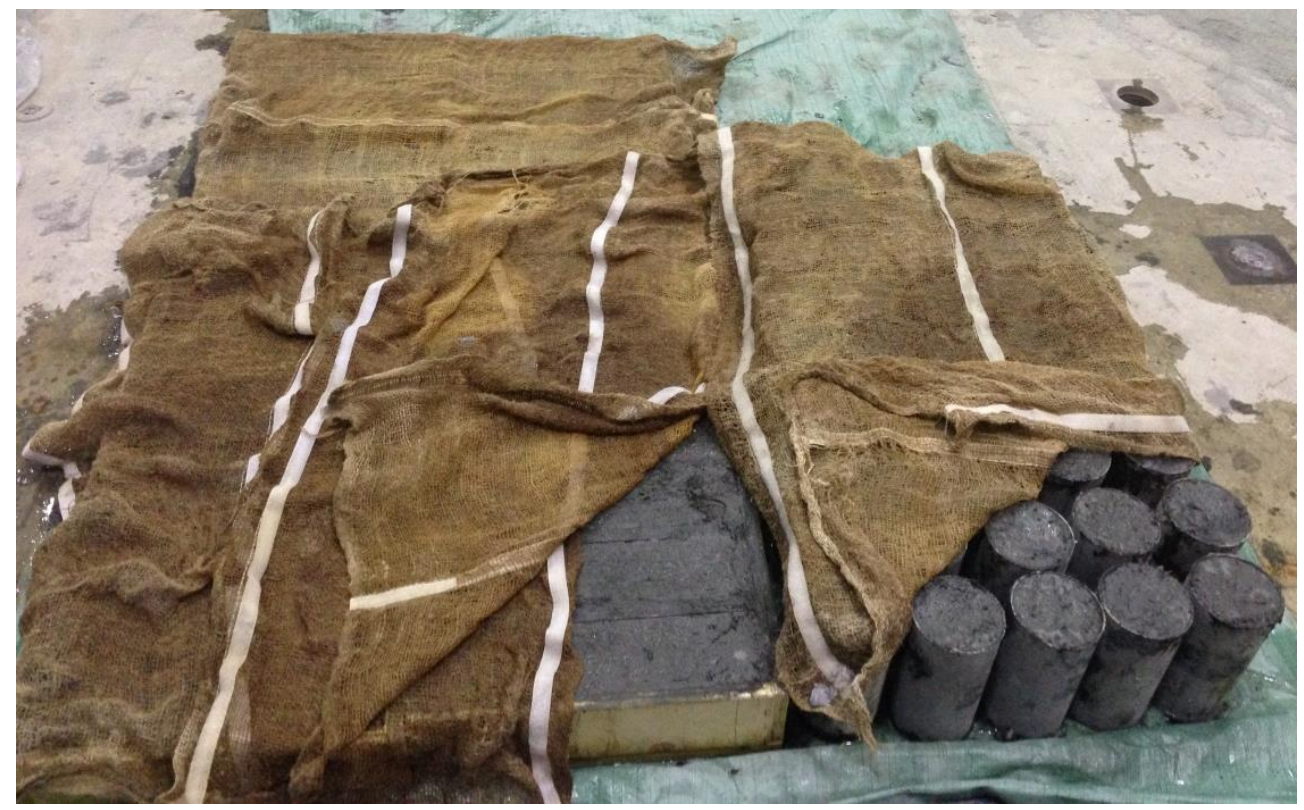

Figure 3.3: Covered Samples with Damp Burlap During First Three Days

After three days and once the specimens were demoulded, they were transferred to curing room and kept there until 24 hours before testing (25 days). Both prisms and cylinder samples in curing room are shown in Figure 3.4.

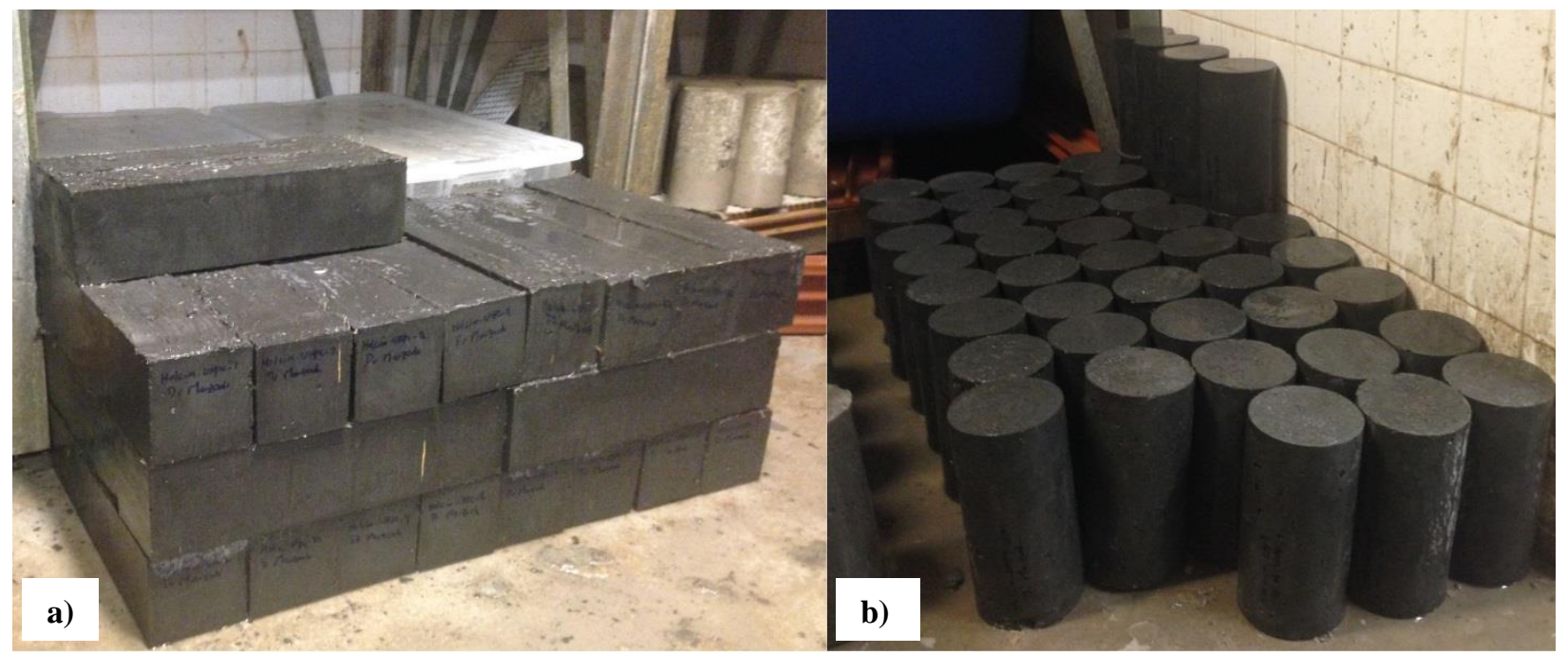

Figure 3.4: Specimens in the Curing Room: a) Prisms, b) Cylinders 


\subsection{Compressive Strength Test}

The compressive tests for each of UHP-FRC, EHP-FRC, EHS-FRC and HSC discussed in this section were all completed in accordance to the ASTM C39 standard test method for cylinders. Throughout the entire study on DIF for compressive strength and material characterization, more than 100 compression specimens were tested.

The basic compression test on each composite was the ASTM C39 test on a 100-mm diameter with 200-mm height cylinder. The cylinders were prepared for testing after demoulding, using a grinder to ensure the end planeness of the specimens. Figure 3.5 and 3.6 shows a picture of the end grinding procedure and cylinder specimens before and after grinding.

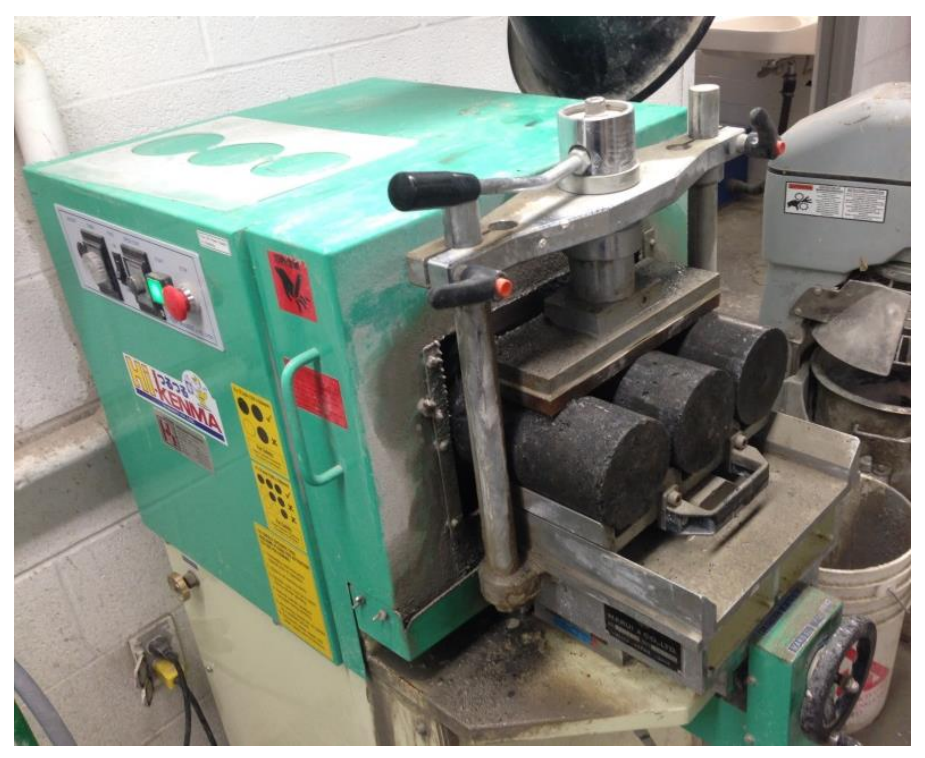

Figure 3.5: Cylinders in the Grinder

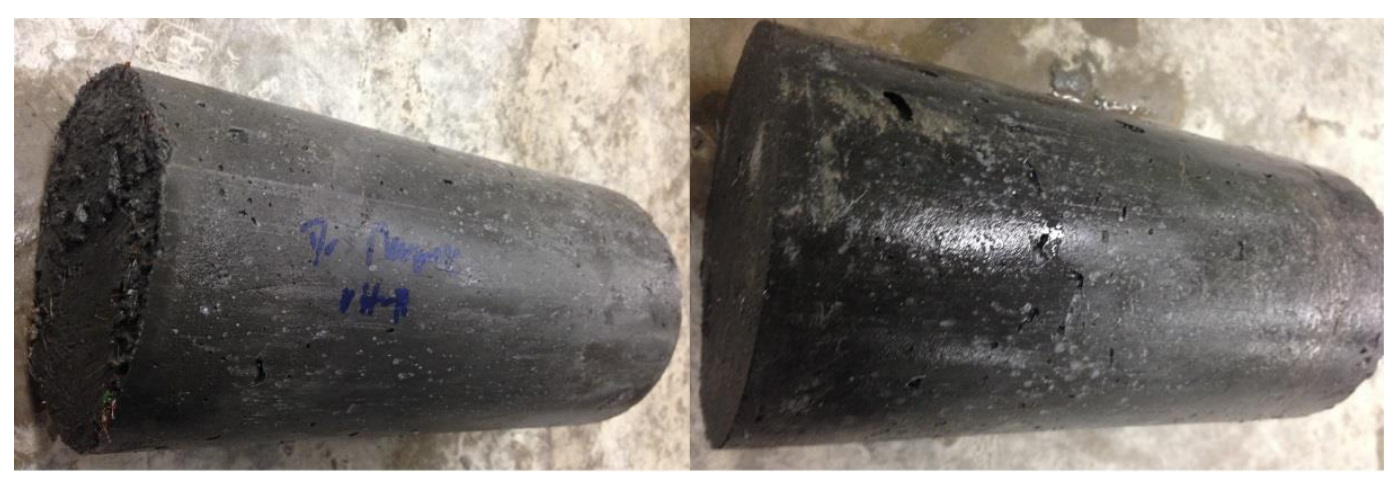

Figure 3.6: Cylinder Specimens Before and After Grinding 
The compressive strength of each composite was recorded at 7, 14, 21 and 28 day. The average reading of tested three cylinders was recorded as the compressive strength at respective age. The compression test is carried out in compression testing machine of $1500 \mathrm{kN}$ capacity. The peak strength is recorded after the specimens fail to resist any more loads. The values are recorded and compressive strength is calculated using the equation 7 . The compressive strength of each series at different ages is given in Table 3.3.

$$
f^{\prime} c=\frac{\operatorname{Load}(\mathrm{P})}{\text { Cross Sectional Area (A) }}
$$

Table 3.3: Compressive Strength of each Composite at Different Age

\begin{tabular}{|c|c|c|c|c|}
\hline \multirow{2}{*}{ Composite } & \multicolumn{4}{|c|}{ Compressive Strength $\left(\mathrm{N} / \mathrm{mm}^{2}\right)$} \\
\cline { 2 - 5 } & 7 Days & 14 Days & 21 Days & 28 Days \\
\hline UHP-FRC & - & - & - & $>150$ \\
\hline EHP-FRC & 91.25 & 110.42 & 110.87 & 112.31 \\
\hline EHS-FRC & 87.02 & 109.53 & 110.3 & 111.01 \\
\hline HSC & 41.19 & 48.68 & 50.32 & 53.48 \\
\hline
\end{tabular}

\subsubsection{Modulus of Elasticity}

There are different approaches for calculating the elastic modulus of high performance concrete materials. However, because the contribution of constituent in each matrix is unique, all the parameter that influences the value of $\mathrm{E}_{\mathrm{c}}$ is not directly related to $f^{\prime} c$.

In this study for the accuracy of the results, modulus of elasticity is calculated from stress-strain curve of each composite. Graphically we can define modulus of elasticity as a slope of the linear portion of the stress-strain diagram. From hooks low $\mathrm{E}_{\mathrm{c}}$ is defined as;

$$
\mathrm{E}=\frac{\sigma}{\varepsilon}
$$

Where, $\mathrm{E}=$ Modulus of elasticity $(\mathrm{MPa}), \sigma=40 \%$ of peak stress $(\mathrm{MPa}), \varepsilon=$ strain 


\subsubsection{Compressive Strength under Quasi-static and Dynamic Loading}

Concrete cylinders of $100 \mathrm{~mm}$ in diameter by $200 \mathrm{~mm}$ in depth were used in compression tests. Both low (quasi-static) and high (dynamic) strain rate for cylindrical experiments were conducted in MTS machine due to its ability to withstand greater force.

All the compression tests were conducted by MTS 815 test system which had a capacity of 4500 $\mathrm{kN}$ in compression and $2200 \mathrm{kN}$ in tension. In Figure 3.7 MTS 815 test system with cylindrical specimen is shown.

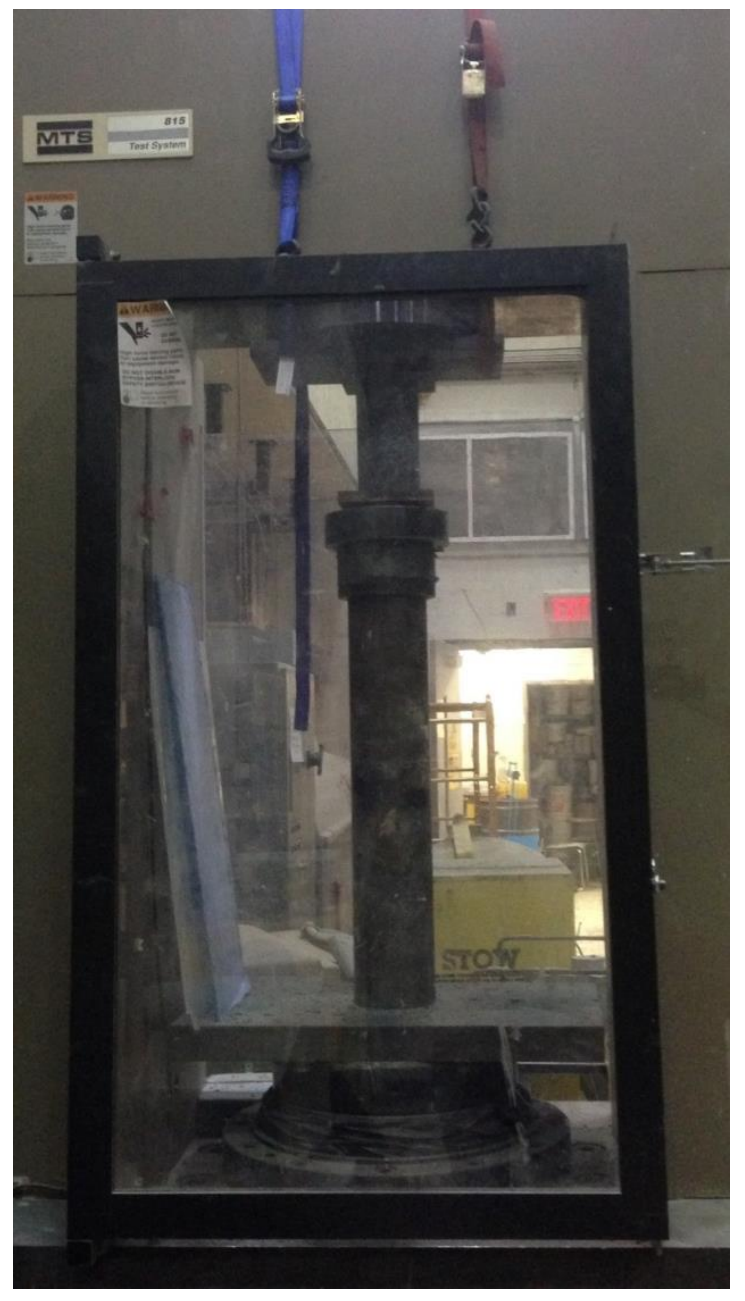

Figure 3.7: MTS Test Machine for Compression Tests 
From the literature, the quasi-static loading rate varied from $10^{-8}$ to $10^{-5}$ [24]. The required strain rates were converted to displacement rate form equation (9). Then the nominal displacement rates were set through the software on the controlling PC. The displacement rates range from $0.36 \mathrm{~mm} / \mathrm{min}$ (quasi-static) to $72 \mathrm{~mm} / \mathrm{min}$ (dynamic). These rates are given in Table 3.4.

$$
\Delta^{*}=\varepsilon^{*} \times \mathrm{L}
$$

Where,

$$
\begin{aligned}
& \Delta=\text { Displacement rate }(\mathrm{mm} / \mathrm{sec}) \\
& \varepsilon=\text { Strain rate }\left(\mathrm{s}^{-1}\right) \\
& \mathrm{L}=\text { Length of the specimens }(\mathrm{mm})
\end{aligned}
$$

Table 3.4: Displacement and Strain Rates for Compressive Strength

\begin{tabular}{|c|c|c|c|c|c|}
\hline \multicolumn{3}{|c|}{ Quasi-Static Range } & \multicolumn{3}{c|}{ Dynamic Range } \\
\hline $\begin{array}{c}\text { No } \\
\text { Specimens }\end{array}$ & $\begin{array}{c}\text { Displacement } \\
\text { Rate }(\mathrm{mm} / \mathrm{min})\end{array}$ & $\begin{array}{c}\text { Strain Rate } \\
\left(\mathrm{s}^{-1}\right)\end{array}$ & $\begin{array}{c}\text { No } \\
\text { Specimens }\end{array}$ & $\begin{array}{c}\text { Displacement } \\
\text { Rate }(\mathrm{mm} / \mathrm{min})\end{array}$ & $\begin{array}{c}\text { Strain Rate } \\
\left(\mathrm{s}^{-1}\right)\end{array}$ \\
\hline 3 & 0.36 & $30 \times 10^{-6}$ & 2 & 16.2 & $1.35 \times 10^{-3}$ \\
\hline 2 & 1.62 & $135 \times 10^{-6}$ & 2 & 36 & $3 \times 10^{-3}$ \\
\hline 2 & 3.60 & $300 \times 10^{-6}$ & 2 & 72 & $6 \times 10^{-3}$ \\
\hline
\end{tabular}

Once all the tests were done with the corresponding strain rates, Dynamic Increase Factor was calculated for each composite series from equation (10). Static compressive strength $\left(f_{c s}^{\prime}\right)$ is calculated from the average of three tested specimens under quasi-static strain rate $\left(30 \times 10^{-6} \mathrm{~s}^{-1}\right)$. On the other hand, dynamic peak stress $\left(f_{c d}^{\prime}\right)$ is calculated from the average of two tested specimens under other given ranges $\left(135 \times 10^{-6}\right.$ to $\left.6 \times 10^{-3}\right)$.

$$
D I F=\frac{f_{c d}^{\prime}}{f_{c s}^{\prime}}
$$

Where, $f_{c d}^{\prime}=$ Dynamic peak stress $(\mathrm{MPa})$, $f^{\prime}{ }_{c s}=$ Static compressive strength $(\mathrm{MPa})$, 


\subsection{Flexural Strength Test}

The Flexural strength test for each composite discussed in this section was completed in accordance to the ASTM C1609-12 standard test method for flexural performance of fiberreinforced concrete (using beam with third-point loading). Throughout the entire study on DIF for flexural strength over 85 prisms were tested.

For the flexural strength test, prisms of $100 \times 100 \times 400 \mathrm{~mm}$ were tested under three-bendingloading for all composite series. From the three-point bending flexural test, flexural stress (modulus of rupture) was calculated from equation (11).

$$
\sigma_{f}=\frac{3 \mathrm{PL}}{2 \mathrm{bd}^{2}}
$$

Where,

$$
\begin{aligned}
& P=\text { Load at the fracture point }(N), \\
& L=\text { Clear span }(\mathrm{mm}), \\
& b=\text { Width of the tested beam, } \\
& d=\text { depth of the tested beam }
\end{aligned}
$$

\subsubsection{Flexural Strength under Quasi-static Loading}

Concrete prism $(100 \times 100 \times 400 \mathrm{~mm})$ specimens used in flexural strength test of UHP-FRC, EHP-FRC, EHS-FRC and HSC composites. The flexural strength test for prism specimens under quasi-static loading were conducted by MTS test machine.

MTS 793 test system used in this experiment with capacity of $100 \mathrm{kN}$ in flexure. The MTS 793 test machine for quasi-static tests is shown in Figure 3.8. 


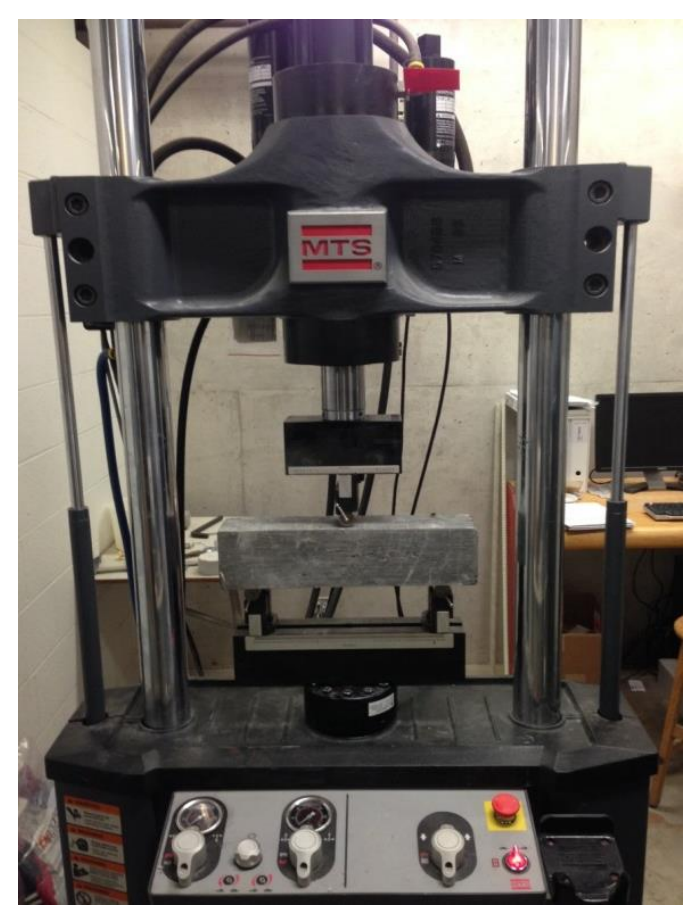

Figure 3.8: Flexural Test in the MTS Machine

The clear span of the beams was $300 \mathrm{~mm}$ which is three times the depth $(\mathrm{d}=100 \mathrm{~mm})$. The beams were tested on their side relative to the casting orientation. The beams with their span and test directions is shown in the Figure 3.9. As is shown in the figure below there was sufficient clearance under the beam to allow specimens to break completely.

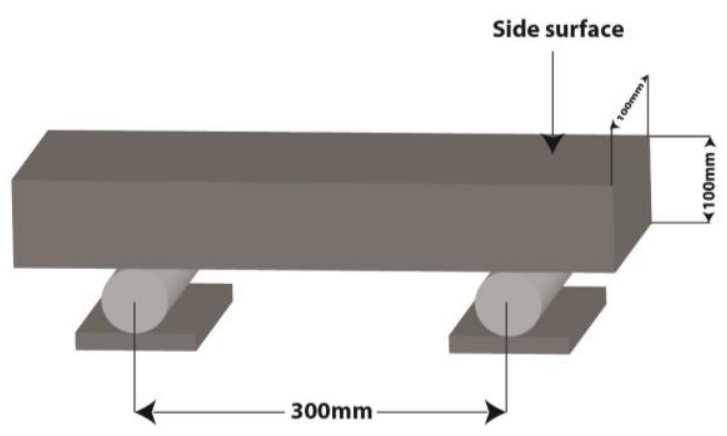

Figure 3.9: Test Direction and Span of Prisms

The quasi-static strain rate range was $1 \times 10^{-6}$ to $20 \times 10^{-6}$. Like compressive strength test, the required strain rates were converted to displacement rate form equation (9) and then the displacement rates were set through the software on the controlling PC. The strain rates with corresponding displacement for quasi-static range are given in Table 3.5. 
The DIF for flexural strength tests was evaluated same as those specimens in compressive strength test, where static compressive strength is calculated from the average of three tested specimens under quasi-static strain rate basis. Finally, the dynamic peak stress is calculated from the average of two tested specimens under other given ranges.

Table 3.5: Quasi-static Strain Rates for Flexural Strength

\begin{tabular}{|c|c|c|}
\hline \multicolumn{3}{|c|}{ Quasi-Static Range } \\
\hline No Specimens & $\begin{array}{c}\text { Displacement } \\
\text { Rate (mm/min) }\end{array}$ & Strain Rate $\left(\mathrm{s}^{-1}\right)$ \\
\hline 3 & 0.013 & $1 \times 10^{-6}$ \\
\hline 2 & 0.129 & $10 \times 10^{-6}$ \\
\hline 2 & 0.257 & $20 \times 10^{-6}$ \\
\hline
\end{tabular}

\subsubsection{Flexural Strength under Dynamic (Impact) Loading}

The flexural strength test under dynamic (impact) loading conducted with a drop weight rig with weight of $37.5 \mathrm{~kg}$. Various heights of 400, 600 and $800 \mathrm{~mm}$ used to achieve different strain rates. The drop hammer facility built at Ryerson University for the impact test (dynamic loading) is shown in Figure 3.10. In the following sub-section the development of the drop hammer facility is discussed in details.

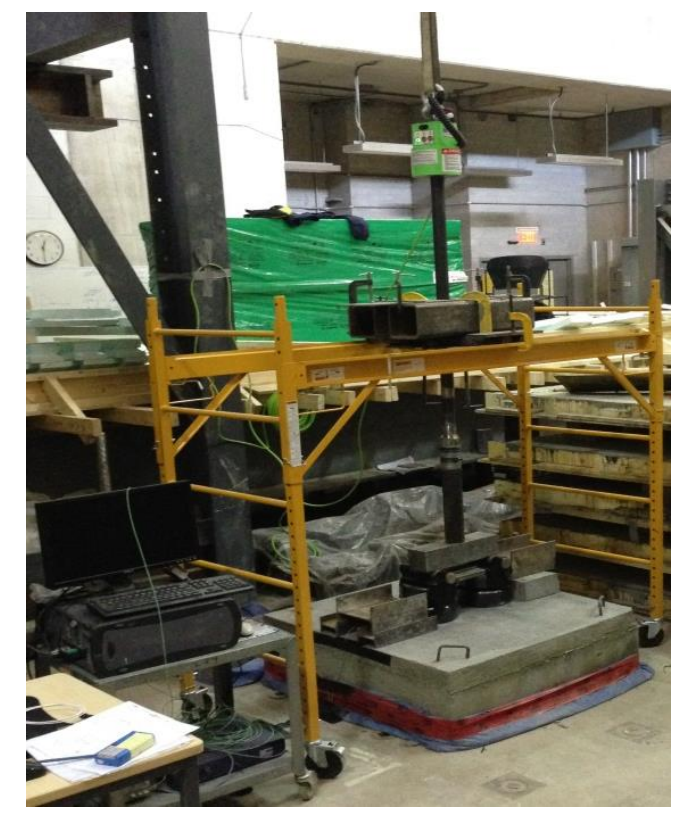

Figure 3.10: Drop Hammer Facility Built at Ryerson University 
The corresponding loading was obtained from load cells and strain rate calculated form loading rates assuming Engineers' the flexural bending formula as given in equation 12. The number of the test specimens and corresponding strain rates are given in Table 3.4.

$$
\sigma=\frac{\mathrm{M} \cdot \mathrm{y}}{\mathrm{I}} \Rightarrow \frac{\mathrm{PL} / 4 \mathrm{~d} / 2}{\mathrm{bd}^{3} / 12}
$$

and stress rate is $\left(\sigma^{*}\right)$ :

$$
\sigma^{\cdot}=\varepsilon^{*} \times \mathrm{E}
$$

Finally by substitution:

$$
\varepsilon^{\cdot}=\frac{3 \mathrm{PL}}{2 \mathrm{Ebd}^{2}}
$$

Where,

$$
\begin{aligned}
& \varepsilon^{\cdot}=\text { Strain rate per second }\left(\mathrm{s}^{-1}\right) \\
& \mathrm{P}=\text { Loading rate }(\mathrm{kN} / \mathrm{s}) \\
& \mathrm{L}=\text { Clear Span }(\mathrm{mm}) \\
& \mathrm{b}=\text { With of the Specimens }(\mathrm{mm}) \\
& \mathrm{d}=\text { Depth of the Specimens }(\mathrm{mm})
\end{aligned}
$$

Table 3.6: Flexural Strength Strain rates

\begin{tabular}{|c|c|}
\hline \multicolumn{2}{|c|}{ Dynamic Range } \\
\hline No Specimens & Drop Height $(\mathrm{mm})$ \\
\hline 2 & 400 \\
\hline 2 & 600 \\
\hline 2 & 800 \\
\hline
\end{tabular}




\subsection{Development of Drop Hammer Facility}

For the investigation of the properties of the composites under dynamic (impact) loading a drop hammer rig was constructed at Ryerson University. The drop hammer facility contains a concrete platform, steel frame, drop hammer weight with $38 \mathrm{~kg}$, magnetic release, two load cells, two accelerometers attached to drop weigh and a data acquisition system. This section fully describes its instrumentation, construction and modifications for achieving reliable data. Furthermore, the detail drawing and complete summary of the drop hammer facility is provided in Appendix A.

The facility is a 2 meters high steel frame with load carrying capacity of $500 \mathrm{~kg}$ which carries a $37.5 \mathrm{~kg}$ drop hammer weight from top. Two steel HSS sections are attached to top the frame to hold the drop hammer weight. An electrical-magnetic release is provided on the top of drop hammer, for achievement of the desired height and release of the weight. The drop hammer weight is raised with crane until desired heights were achieved. In Figure 3.11 drop hammer weight, electrical magnetic release and crane is shown.

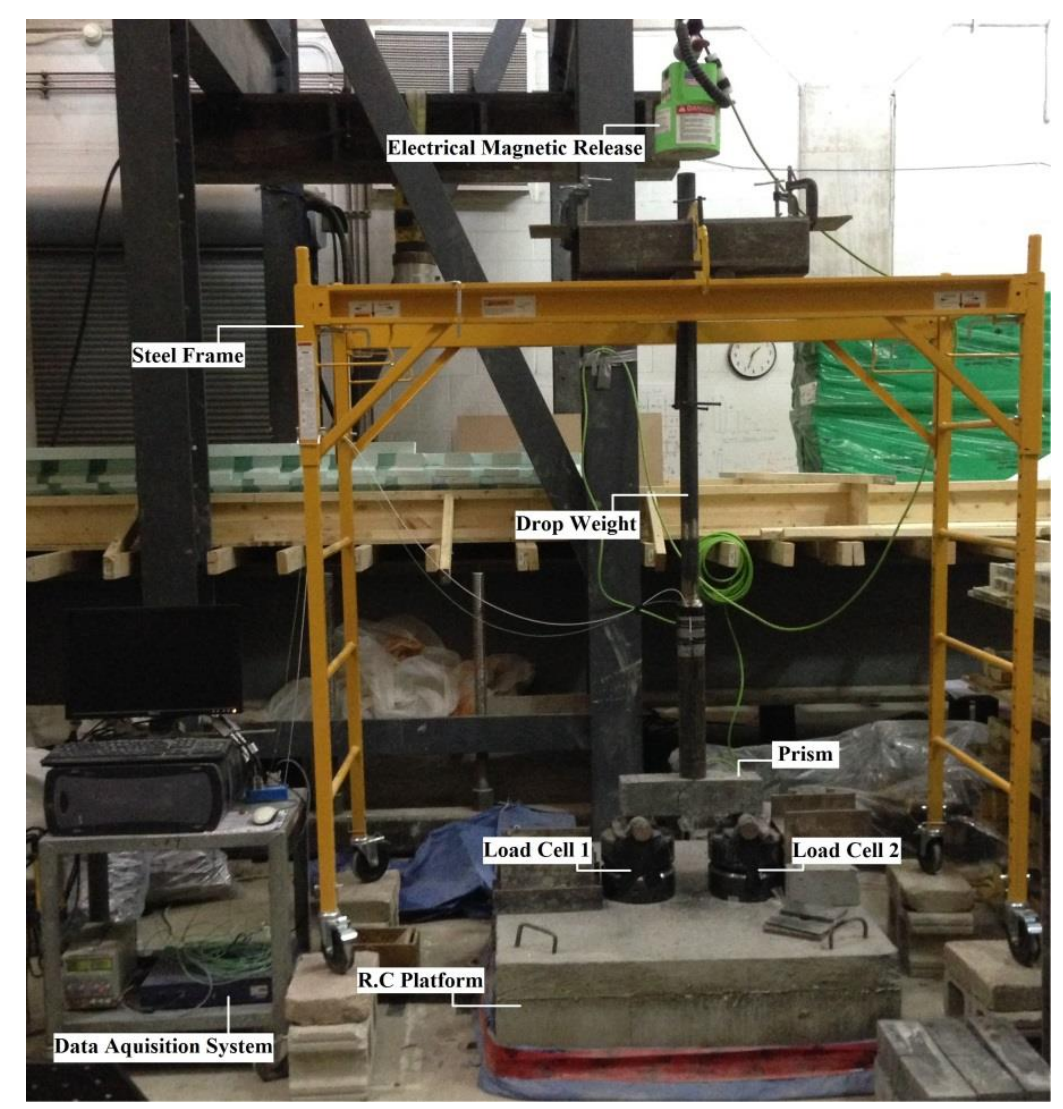

Figure 3.11: Drop Hammer Facility and Accessories 


\subsubsection{Drop Hammer Weight and Magnetic Release}

To get the desired weight for the drop hammer, two cylindrical steel rods were welded together. The bottom weight had a weight of $19.5 \mathrm{~kg}$ and $1.2 \mathrm{~m}$ long with a diameter of $50 \mathrm{~mm}$, and the top weight had a weight of $18.5 \mathrm{~kg}$ and $0.55 \mathrm{~m}$ long with a diameter of $70 \mathrm{~mm}$. The total weight of the drop hammer was 38.0, which is the sufficient weight to break UHP-FRC, EHP-FRC and EHS-FRC composites at minimum drop height of $400 \mathrm{~mm}$. For HSC drop height of $200 \mathrm{~mm}$ found to be sufficient to get a complete break.

As mentioned earlier, for rising and releasing the drop hammer weight from desired heights (400, $600,800 \mathrm{~mm}$ ), an electrical magnet was provided on the top of drop hammer. Crane was used for raising the drop hammer to reach the desired height. It worth mentioning that due to safety, release of the drop hammer from electrical magnet was done by remote control. In Figure 3.12 drop hammer weight and electrical magnet are shown.

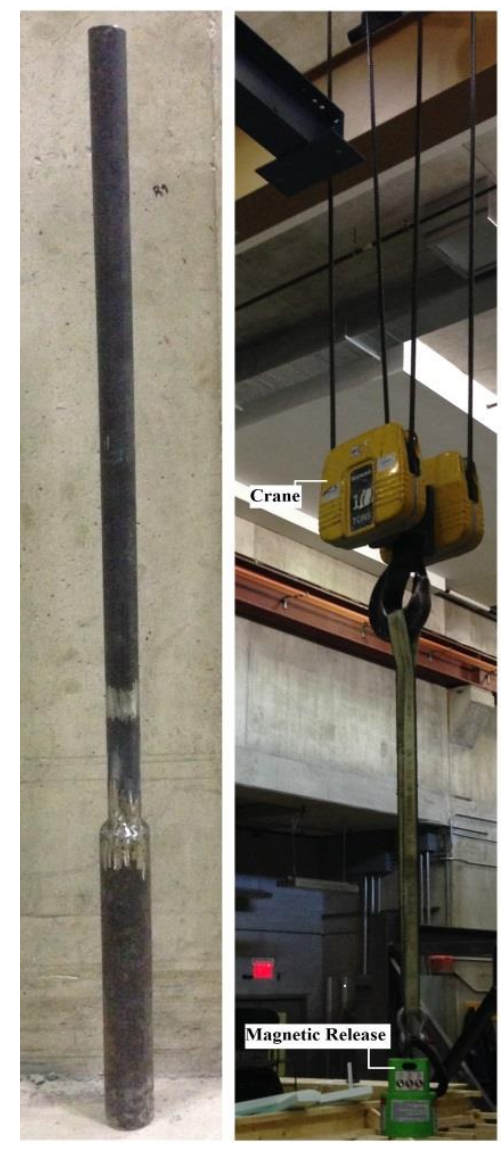

Figure 3.12: Drop Hammer Weight and Electrical Magnet 


\subsubsection{Concrete Platform}

A concrete slab was considered as platform in order to enhance the stability of the specimens and control stress waves due to impact. The dimensions were $1.05 \times 1.05 \times 0.4 \mathrm{~m}$ and it was cast using high strength concrete. As shown in Figure 3.13 four diagonal steel rebar's was included to resist shrinkage at early stages of casting and enhance the impact resistance. Also four hangers were provided at each corner for placing the platform at the desired location.

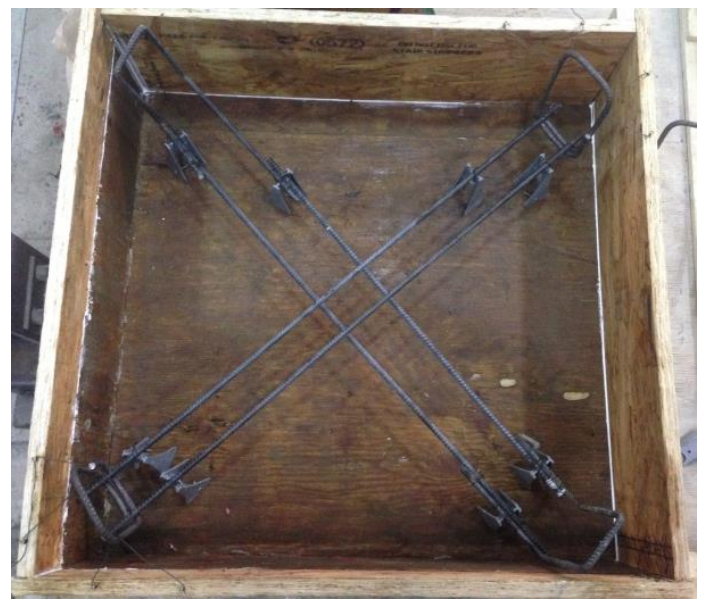

Figure 3.13: Steel Rebar's and Hanger for Concrete Platform

In order to absorb the vibration due to impact and minimize the quantity of noise in the acquired data; $50 \mathrm{~mm}$ fine sand is used as support system. The fine sand first placed as the support and then the platform carried on top with crane (See Figure 3.14).

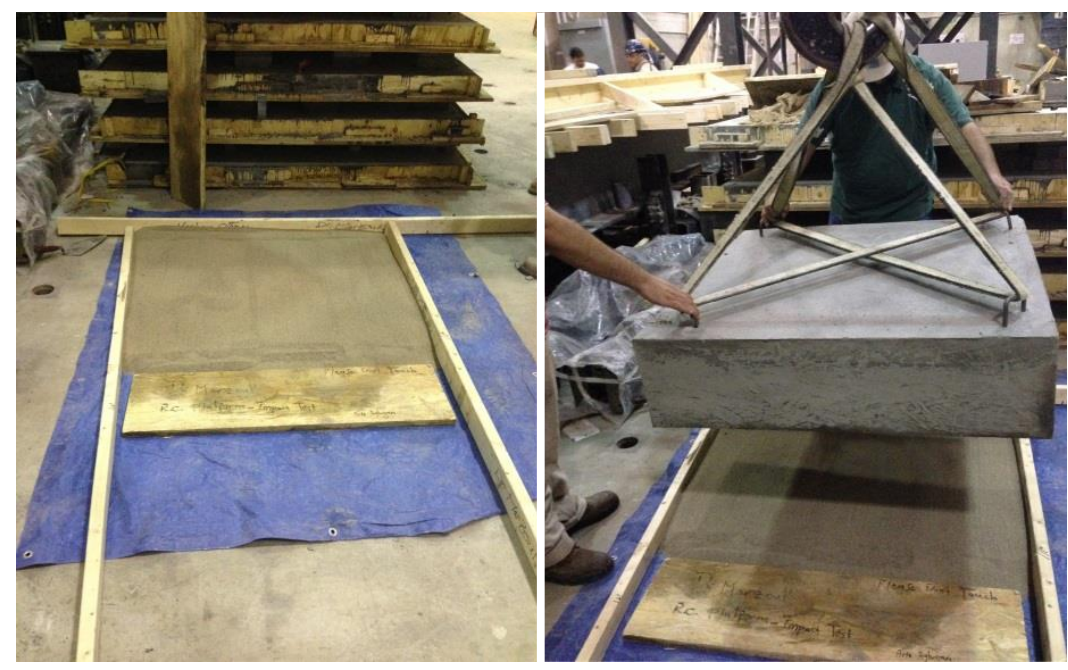

Figure 3.14: Placement of Sand and Concrete Platform 
To not lose the sand during the test, a plastic matt was placed underneath it. After placing the platform on top of the sand, spirit level was used to ensure that the platform is level and fully supported. Finally, after the platform was seating completely on sand and its alignment was measured, the matt was wrapped tightly around it with use of duct type. This procedure is shown in Figure 3.15.

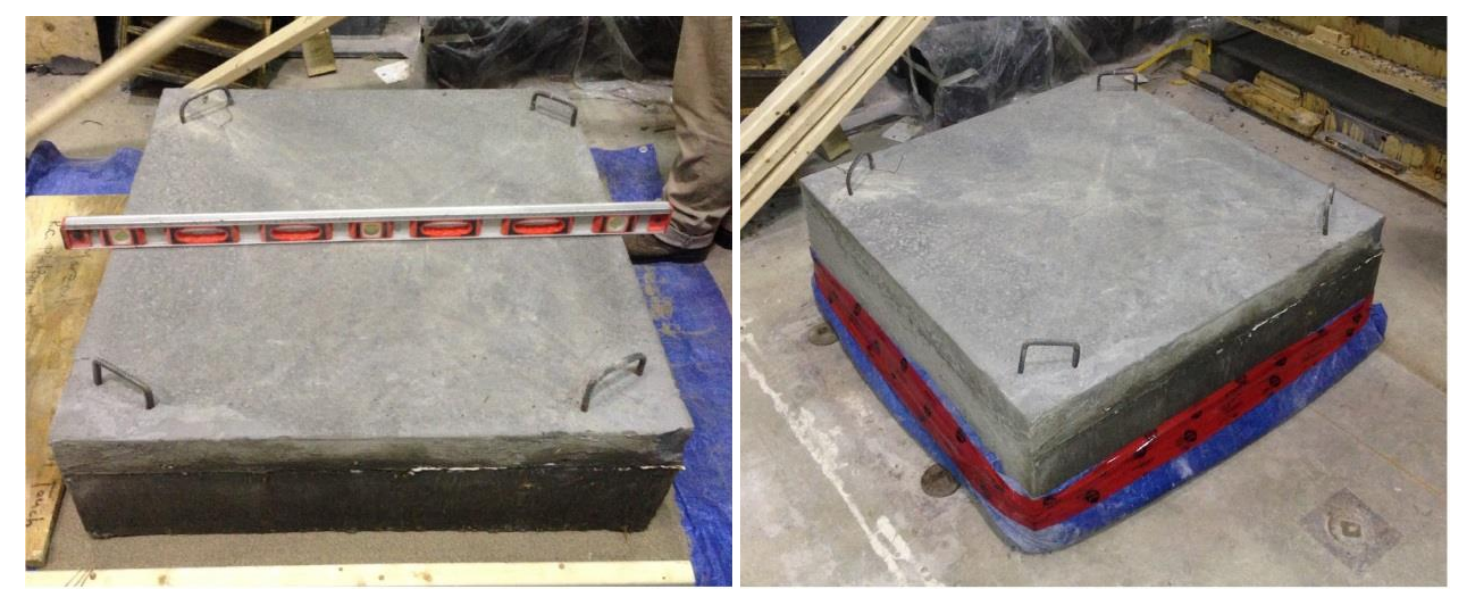

Figure 3.15: Preparation of Concrete Platform

\subsubsection{Ryerson University Drop Hammer Test Setup Instrumentation}

\subsubsection{Dynamic Load Cells}

Two dynamic load cells were provided under each support for calculation of the crush reaction form the impact at different drop heights. Load cells were sheltered by two steel covers; one underneath and one above. In order to avoid movement of the load cells, the cells were held in place by fixing the two heavy steel cover together with bolts and applied pre-compression. For the protection of the cables two steel I-section used as shield. A steel roller with height of $8 \mathrm{~cm}$ was placed on each steel cover to act as supports for prisms. Steel rollers also were tight to the steel covers with duct tape to avoid movement due to impact. The position of the load cells, load covers and steel roller are shown in Figure 3.16 - 3.18. 


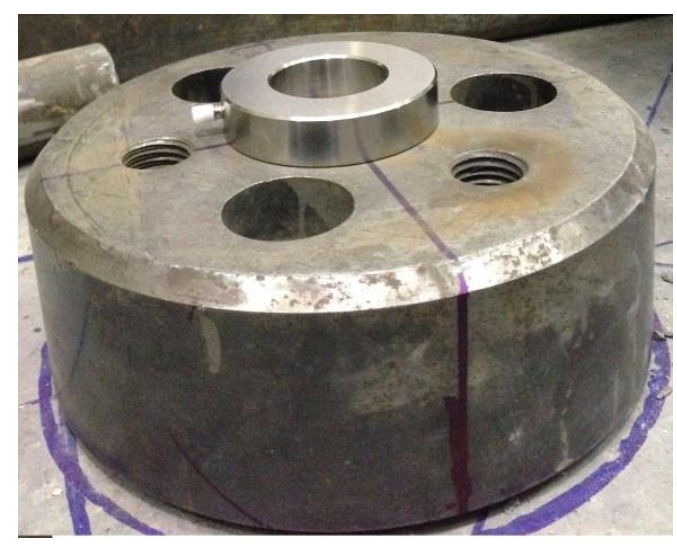

Figure 3.16: Location of the Dynamic Load Cell on Steel Cover

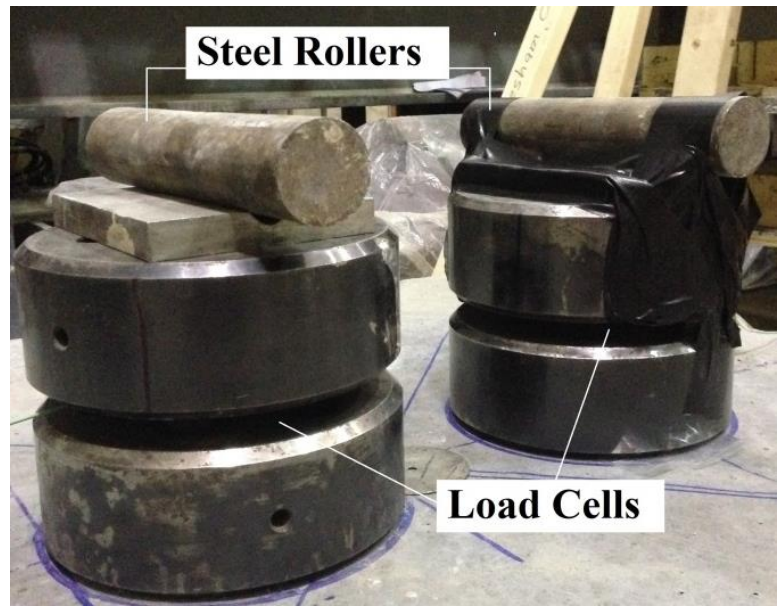

Figure 3.17: Position of the Dynamic Load Cells, Steel Rollers and Steel Covers

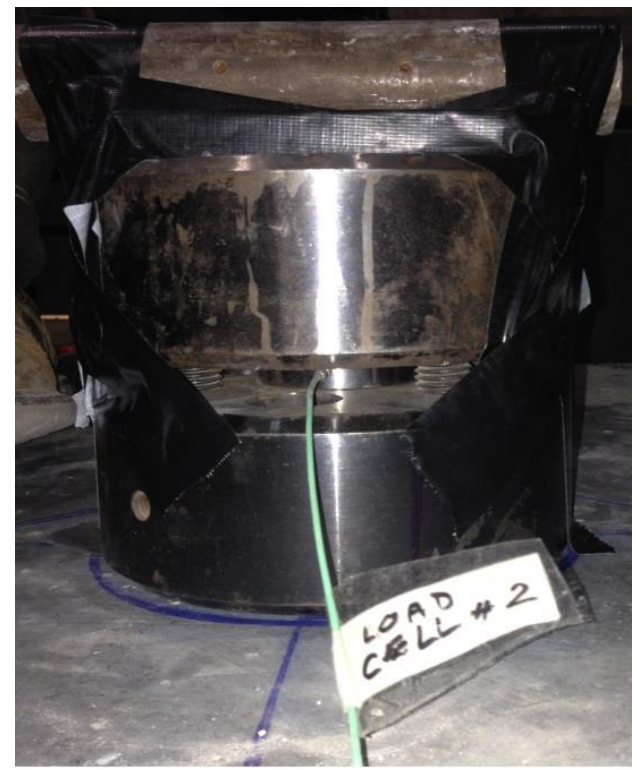

Figure 3.18: Settled Dynamic Load Cell Between Steel Covers 


\subsubsection{Accelerometers}

For the validation of the test results two accelerometer were attached to the drop weight. The accelerometers were capable of measuring acceleration along the single axis of motion. The accelerometers were capable of measuring acceleration of $\pm 5,000 \mathrm{~g}$ and $\pm 500 \mathrm{~g}$. Both accelerometers were plugged to data acquisition system. Position of the accelerometers on drop weight is shown in Figure 3.19.

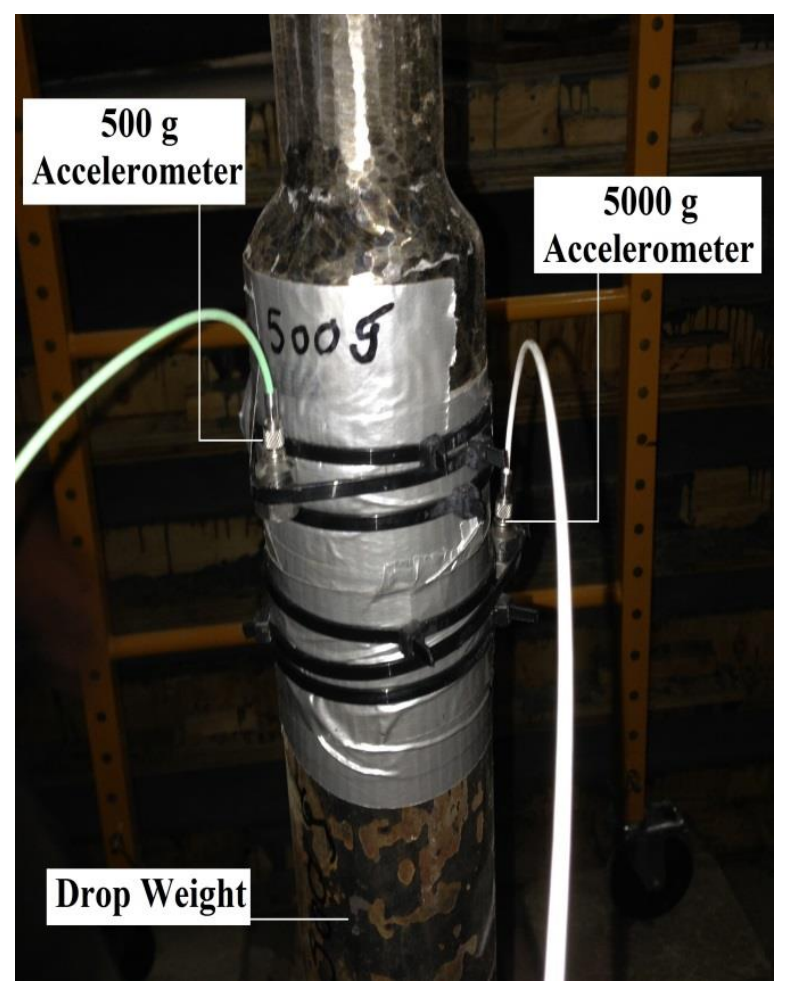

Figure 3.19: Position of the Accelerometers on Drop Weight

In order to reduce the noise, rubber were used and wrapped with duct tape underneath of the accelerometers. Figure 3.20 shows the rubber on drop weight before mounting the accelerometer.

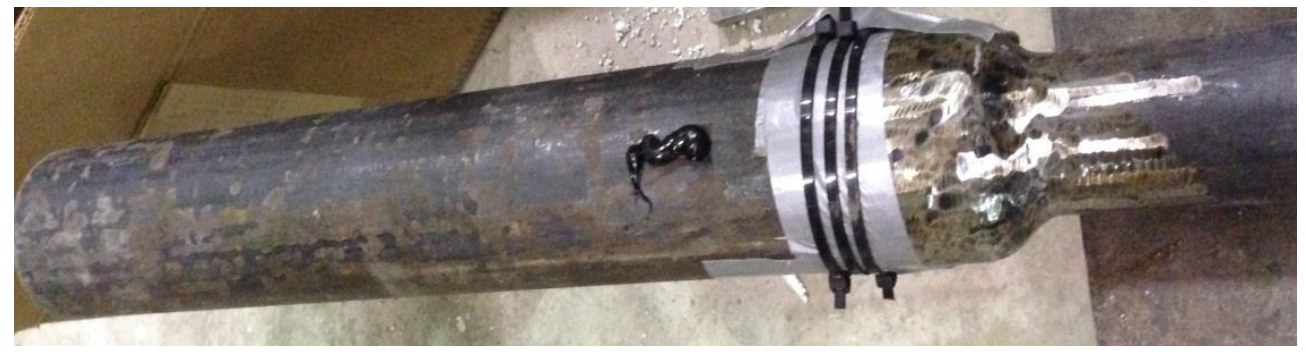

Figure 3.20: Applied Rubber on Drop WeightBefore Mounting Accelerometer 


\subsubsection{Data Acquisition System}

The two load cells and two accelerometers were connected to the dynamic data acquisition system. ECON Model MI-7004 dynamic analyzer (8) channel signal analyzer, complete with 300 MHZ sampling IEPE sensors that capture of data, playback, shock recording, analysis and ManuWare Software. The data was recorded by a PC through the high frequency (up to $10 \mathrm{MHz}$ ) data acquisition system. The software ManuWare (MW) was used for data acquisition and one channel was defined in the software for each instrument, therefore total of four set of data were received after each test. After extracting the data's, Excel program was used for analyzing the data and draw graphs. The data acquisition system and PC is shown in Figure 3.21.

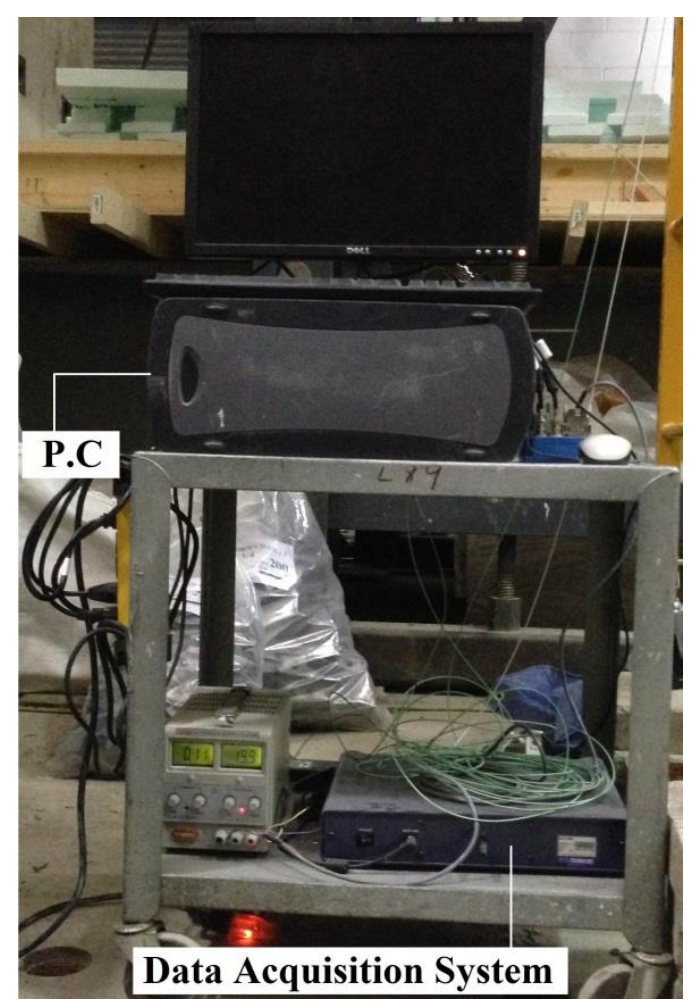

Figure 3.21: Dynamic Data Acquisition System and PC 


\section{Chapter 4}

\section{RESULTS ANALYSIS AND DISCUSSION}

\subsection{Introduction}

This chapter will discuss the results obtained from the experimental program for different concrete composites. Compressive and flexural strength tests conducted at different strain rates for the evaluation of dynamic increase factor (DIF) of each composite. The evaluated DIF compared to each other to indicate which concrete composite have a better response to high strain rate and which one has less strain rate sensitivity.

\subsection{Compression Tests}

\subsubsection{Compressive Strength}

The compressive strength of each composite was recorded at 7, 14, 21, 28 and 56 day. The average reading of tested three cylinders was recorded as the compressive strength at each age. The compression test is carried out in compression testing machine of $1500 \mathrm{kN}$ capacity. The peak strength is recorded after the specimens fail to resist any more loads. The compressive strength of each series at different ages is given in Table 4.1. It should be noted that, all the tests for HSC material were conducted after 56 days where material reached its maximum strength.

Table 4.1: Compressive Strength of each Composite at Different Age

\begin{tabular}{|c|c|c|c|c|c|}
\hline \multirow{2}{*}{ Composite } & \multicolumn{5}{|c|}{ Compressive Strength $\left(\mathrm{N} / \mathrm{mm}^{2}\right)$} \\
\cline { 2 - 6 } & 7 Days & 14 Days & 21 Days & 28 Days & 56 Days \\
\hline UHP-FRC & - & - & - & $>150$ & - \\
\hline EHP-FRC & 91.25 & 110.42 & 110.87 & 112.31 & - \\
\hline EHS-FRC & 87.02 & 109.53 & 110.3 & 111.01 & - \\
\hline HSC & 41.19 & 48.68 & 55.32 & 63.48 & 83.46 \\
\hline
\end{tabular}




\subsubsection{Stress - Strain Behaviour}

The stress-strain behaviour of each composite was recorded by uniaxial loading with MTS815 test machine on cylindrical specimens. The displacement rate of $0.005 \mathrm{~mm} / \mathrm{min}$ applied to each specimen, and test was preceded till the load dropped to more than $50 \%$ of peak load. The difference in the stress-strain response of each composite is tabulated in Table 4.2.

Table 4.2: Stress-Strain Response of Concrete Composites

\begin{tabular}{|c|c|c|c|c|c|}
\hline Composite & $\begin{array}{c}\text { Peak Stress } \\
(\mathrm{MPa})\end{array}$ & $\begin{array}{c}\text { Strain at Peak } \\
\text { Load, } \varepsilon_{\mathrm{o}}\end{array}$ & $\begin{array}{c}40 \% \text { Stress, } \\
0.4 f^{\prime}{ }_{c}(\mathrm{MPa})\end{array}$ & $\begin{array}{c}\text { Strain at } \\
0.4 f^{\prime}{ }^{\prime}\end{array}$ & $\begin{array}{c}\text { Elastic Modulus } \\
(\mathrm{GPa})\end{array}$ \\
\hline UHP-FRC & $>150$ & - & - & - & 50 \\
\hline EHP-FRC & 111.65 & 0.00328 & 44.57 & 0.00126 & 35.27 \\
\hline EHS-FRC & 112.635 & 0.00345 & 45.06 & 0.00117 & 37.79 \\
\hline HSC & 87.456 & 0.002501 & 34.98 & 0.00113 & 30.83 \\
\hline
\end{tabular}

The ascending and descending portion of the stress strain response of cylindrical specimens for each composite are plotted in Figure 4.1.

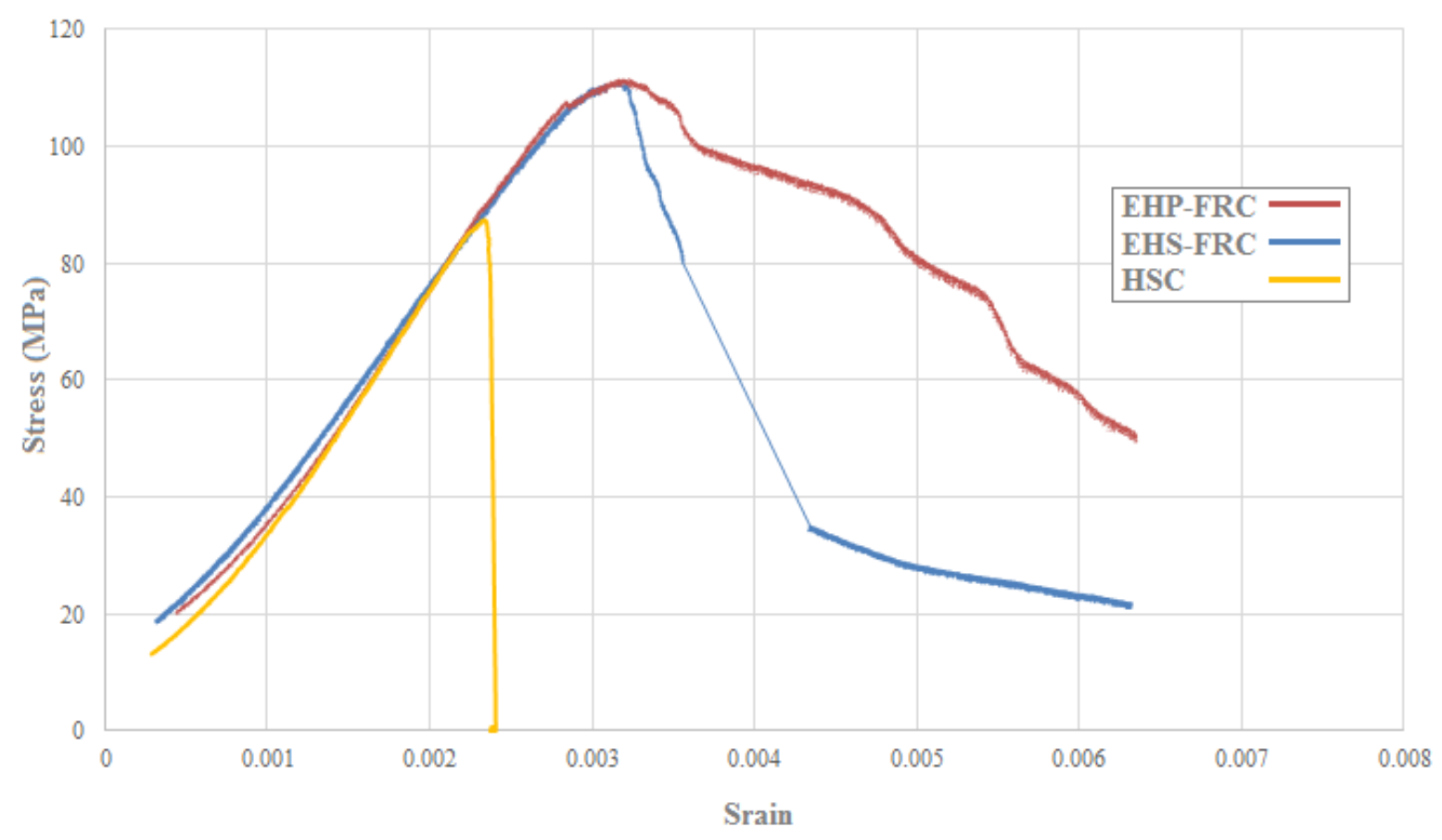

Figure 4.1: Stress - Strain Curve for all Composites 
In Figures 4.2 to 4.4 concrete specimens after compressive strength test under quasi-static loading rate is shown.

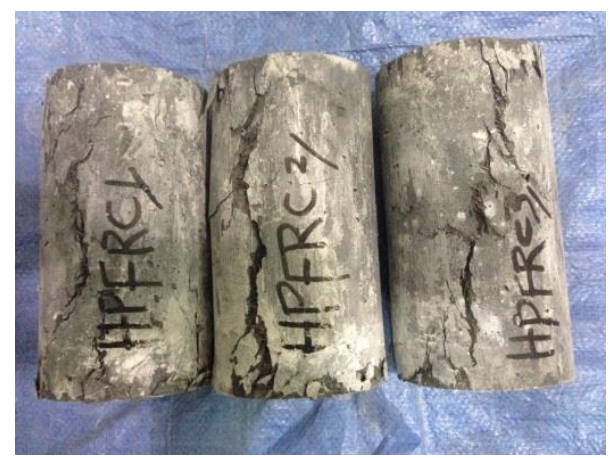

Figure 4.2: EHP-FRC Cylinders After Compressive Test

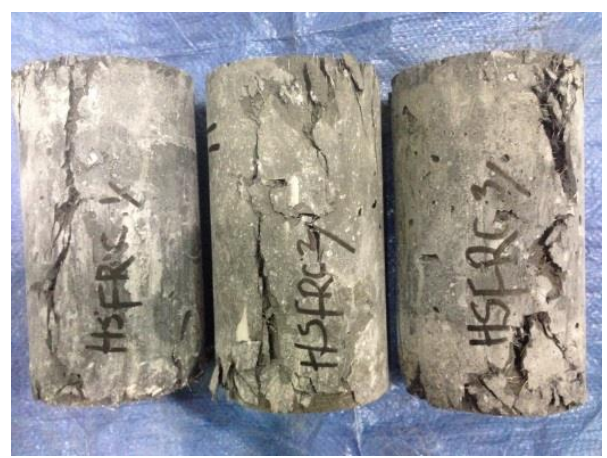

Figure 4.3: EHS-FRC Cylinders After Compressive Test

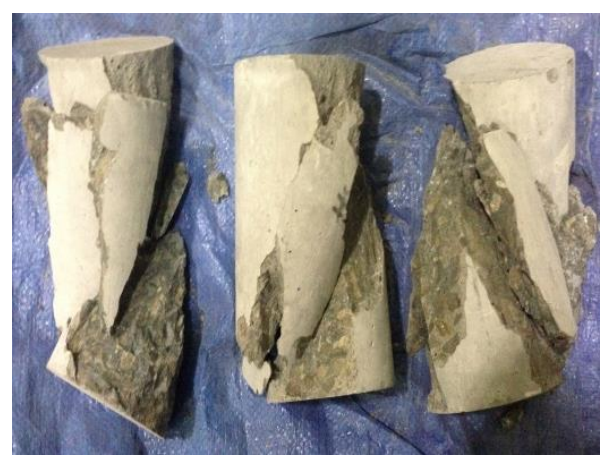

Figure 4.4: HSC Cylinders After Compressive Test 


\subsubsection{Quasi-static Tests}

Concrete cylinders of $100 \mathrm{~mm}$ in diameter by $200 \mathrm{~mm}$ in depth were used in compression quasistatic tests. Cylindrical samples were loaded in MTS-815 test system. The test results in quasistatic domain with different strain rate range for all composites are tabulated in Table 4.3 respectively.

Table 4.3: Quasi-static Compressive Strength Test Results for all Composites

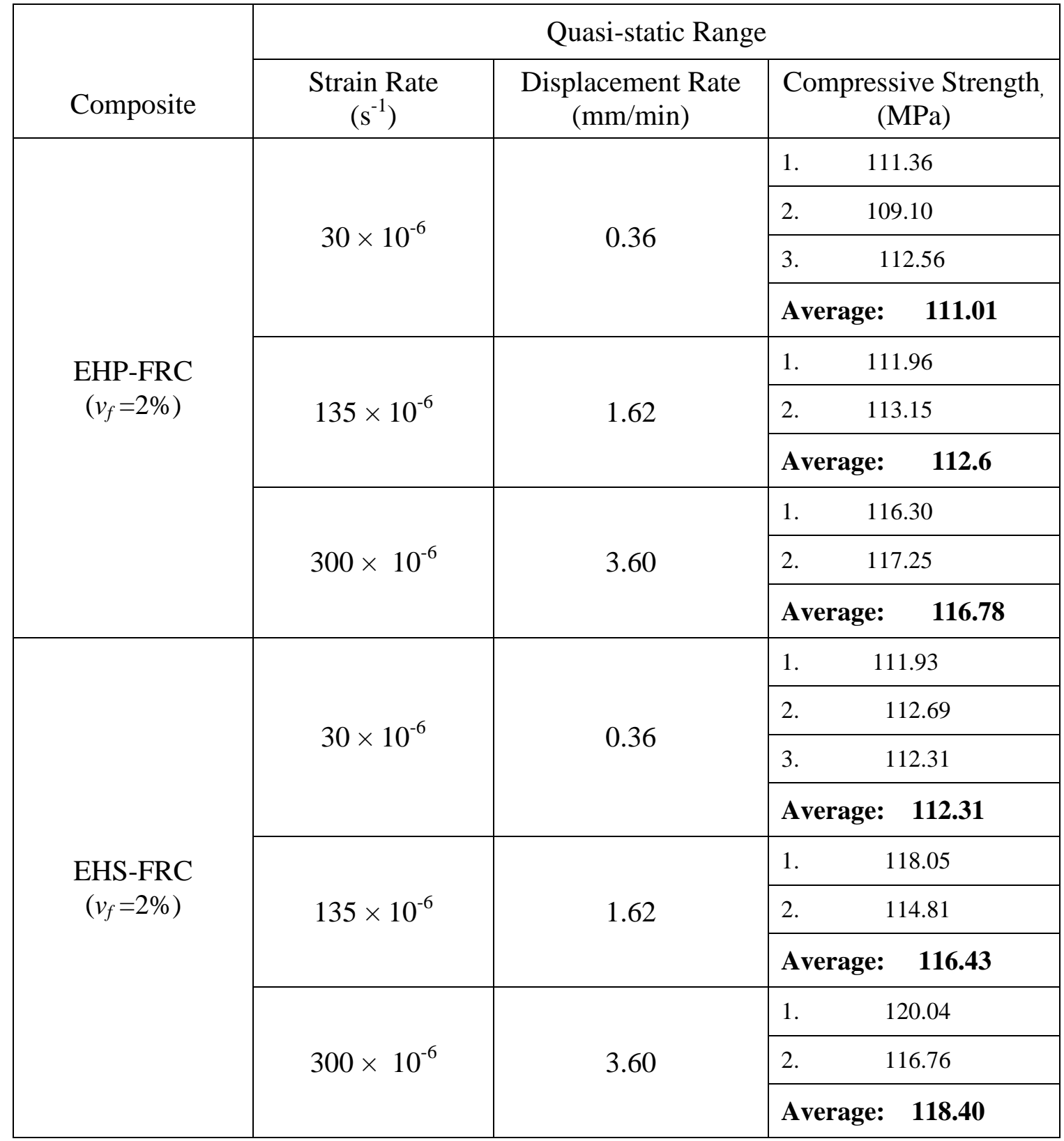


Table 4.3: Quasi-static Compressive Strength Test Results for all composites (continued)

\begin{tabular}{|c|c|c|c|}
\hline \multirow[b]{2}{*}{ Composite } & \multicolumn{3}{|c|}{ Quasi-static Range } \\
\hline & $\begin{array}{l}\text { Strain Rate } \\
\qquad\left(\mathrm{s}^{-1}\right)\end{array}$ & $\begin{array}{c}\text { Displacement Rate } \\
(\mathrm{mm} / \mathrm{min})\end{array}$ & $\begin{array}{c}\text { Compressive Strength, } \\
(\mathrm{MPa})\end{array}$ \\
\hline \multirow{10}{*}{$\begin{array}{c}\text { HSC } \\
\text { (No Fibers) }\end{array}$} & \multirow{4}{*}{$30 \times 10^{-6}$} & \multirow{4}{*}{0.36} & 83.12 \\
\hline & & & 80.21 \\
\hline & & & 87.15 \\
\hline & & & Average: $\quad \mathbf{8 3 . 4 6}$ \\
\hline & \multirow{3}{*}{$135 \times 10^{-6}$} & \multirow{3}{*}{1.62} & 85.22 \\
\hline & & & 88.12 \\
\hline & & & Average: $\quad 86.67$ \\
\hline & \multirow{3}{*}{$300 \times 10^{-6}$} & \multirow{3}{*}{3.60} & 1. $\quad 86.23$ \\
\hline & & & 88.97 \\
\hline & & & Average: $\quad 87.6$ \\
\hline
\end{tabular}

Dynamic Increase Factor for all three composites in quasi-static region are shown in Figure 4.5.

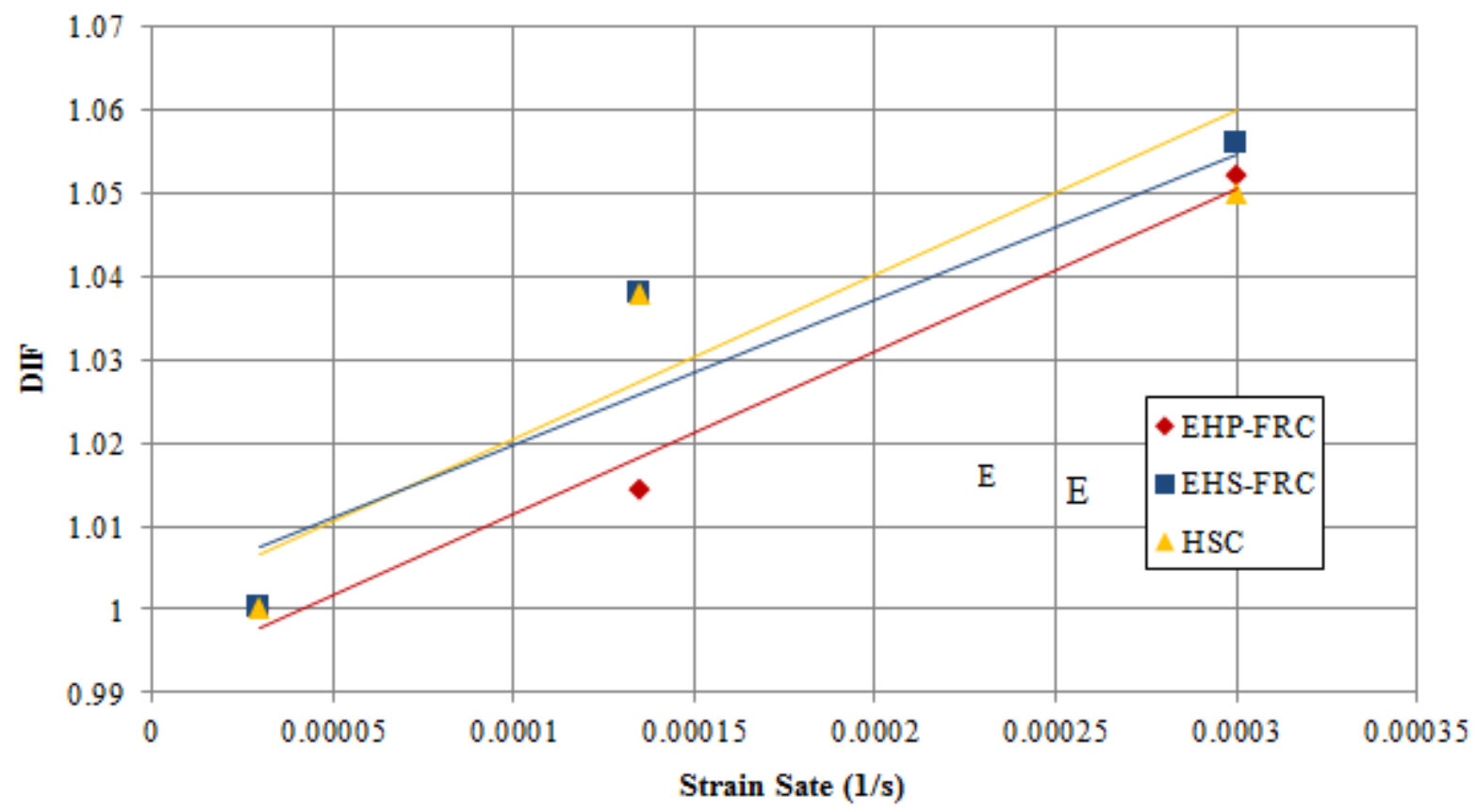

Figure 4.5: DIF in Quasi-Static Region 


\subsubsection{Dynamic Tests}

Concrete cylinders of $100 \mathrm{~mm}$ in diameter by $200 \mathrm{~mm}$ in depth were used in compression dynamic tests. Cylindrical samples were loaded in MTS-815 test system. The test results in dynamic domain with different strain rate range for all composites are tabulated in Table 4.4.

Table 4.4: Dynamic Compressive Strength Test Results for all Composites

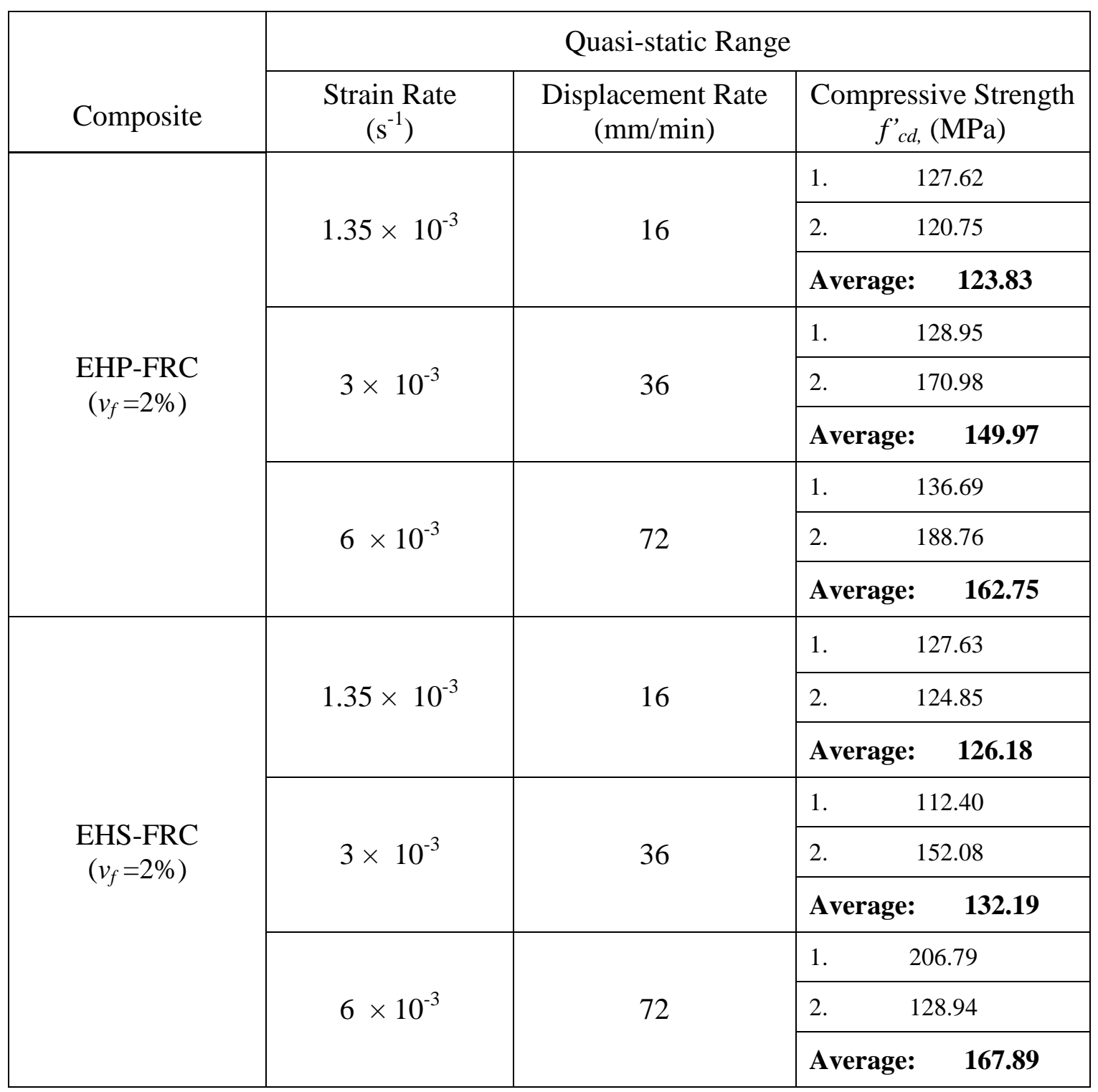


Table 4.4: Dynamic Compressive Strength Test Results for all Composites (continued)

\begin{tabular}{|c|c|c|c|}
\hline & & Quasi-static Ran & \\
\hline Composite & $\begin{array}{l}\text { Strain Rate } \\
\left(\mathrm{s}^{-1}\right)\end{array}$ & $\begin{array}{l}\text { Displacement Rate } \\
(\mathrm{mm} / \mathrm{min})\end{array}$ & $\begin{array}{c}\text { Compressive Strength } \\
f^{\prime}{ }_{c d,}(\mathrm{MPa})\end{array}$ \\
\hline \multirow{9}{*}{$\begin{array}{c}\text { HSC } \\
\text { (No Fibers) }\end{array}$} & \multirow{3}{*}{$1.35 \times 10^{-3}$} & \multirow{3}{*}{16} & 1. $\quad 100.2$ \\
\hline & & & 97.12 \\
\hline & & & Average: $\quad \mathbf{9 8 . 6 6}$ \\
\hline & \multirow{3}{*}{$3 \times 10^{-3}$} & \multirow{3}{*}{36} & 115.32 \\
\hline & & & 118.23 \\
\hline & & & Average: 116.78 \\
\hline & \multirow{3}{*}{$6 \times 10^{-3}$} & \multirow{3}{*}{72} & 130.23 \\
\hline & & & 138.43 \\
\hline & & & Average: 134.33 \\
\hline
\end{tabular}

Dynamic Increase Factor for all three composites in dynamic region are shown in Figure 4.6.

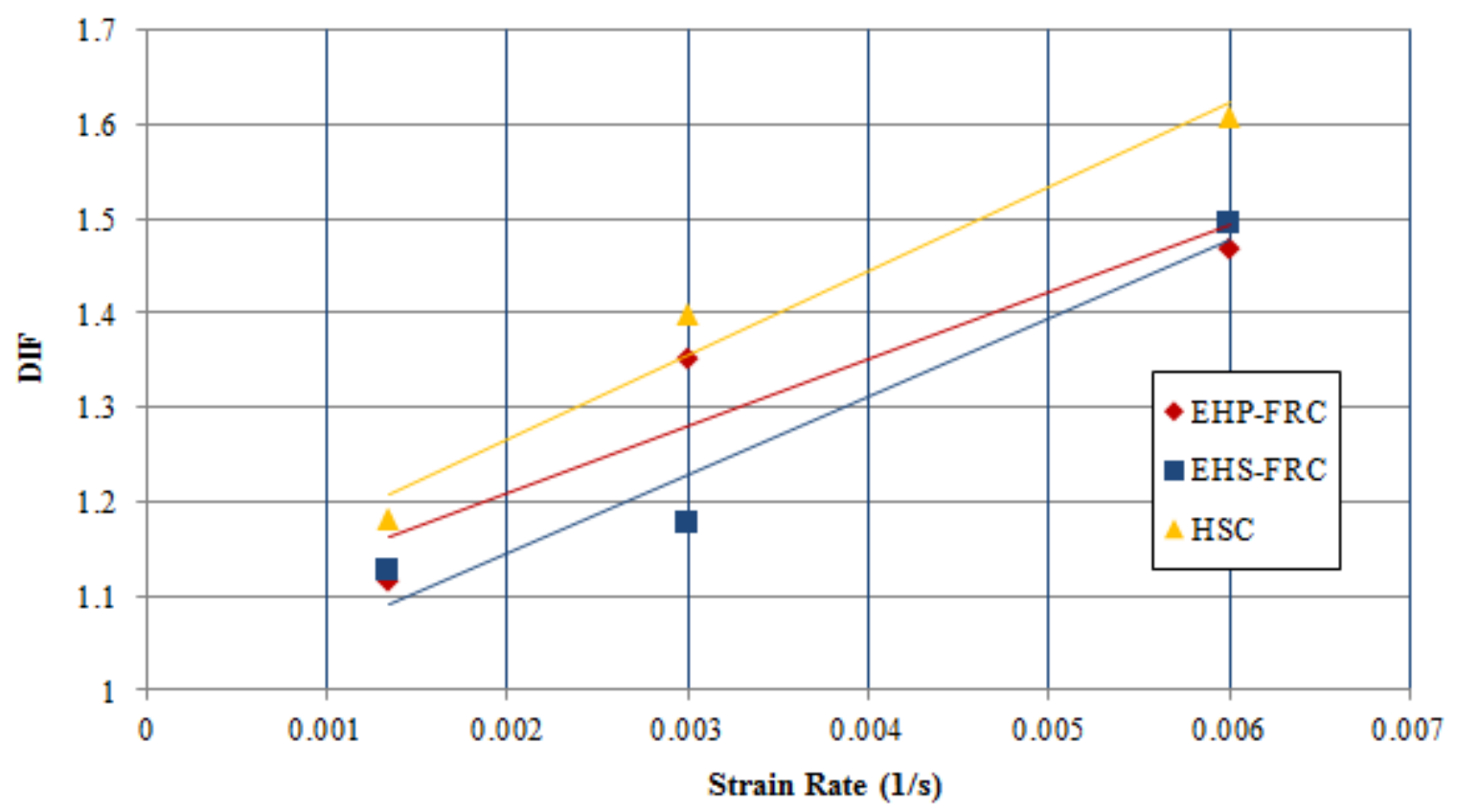

Figure 4.6: DIF in Dynamic Region 


\subsubsection{Dynamic Increase Factor, DIF}

Dynamic Increase Factor (DIF) for each composite is calculated by taking the ratio of static compressive strength $\left(f_{c s}{ }_{c s}\right)$ under quasi-static strain rate $\left(30 \times 10^{-6} \mathrm{~s}^{-1}\right)$ over dynamic peak stress $\left(f_{c d}^{\prime}\right)$ under other given ranges $\left(135 \times 10^{-6}\right.$ to $\left.6 \times 10^{-3}\right)$. The dynamic compressive strength of each composite is given in Table 4.5.

Table 4.5: Dynamic Compressive Strength of Concrete Composites

\begin{tabular}{|c|c|c|c|c|}
\hline Composite & & Rate $\left(s^{-1}\right)$ & Strength (MPa) & DIF \\
\hline \multirow{6}{*}{ EHP-FRC } & \multirow{3}{*}{ 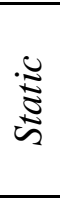 } & $30 \times 10^{-6}$ & $f_{c s}^{\prime}=111.01$ & 1.00 \\
\hline & & $135 \times 10^{-6}$ & $f_{c d}^{\prime}=112.6$ & 1.014 \\
\hline & & $300 \times 10^{-6}$ & $f_{c d}^{\prime}=116.78$ & 1.052 \\
\hline & \multirow{3}{*}{ 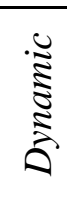 } & $135 \times 10^{-3}$ & $f_{c d}^{\prime}=123.83$ & 1.115 \\
\hline & & $3 \times 10^{-3}$ & $f_{c d}^{\prime}=149.97$ & 1.351 \\
\hline & & $6 \times 10^{-3}$ & $f_{c d}^{\prime}=162.75$ & 1.467 \\
\hline \multirow{6}{*}{ EHS-FRC } & \multirow{3}{*}{ 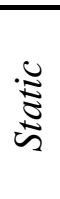 } & $30 \times 10^{-6}$ & $f_{c s}^{\prime}=112.13$ & 1.00 \\
\hline & & $135 \times 10^{-6}$ & $f_{c d}^{\prime}=116.43$ & 1.038 \\
\hline & & $300 \times 10^{-6}$ & $f_{c d}^{\prime}=118.40$ & 1.056 \\
\hline & \multirow{3}{*}{ 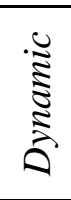 } & $135 \times 10^{-3}$ & $f_{c d}^{\prime}=126.18$ & 1.125 \\
\hline & & $3 \times 10^{-3}$ & $f_{c d}^{\prime}=132.19$ & 1.177 \\
\hline & & $6 \times 10^{-3}$ & $f_{c d}^{\prime}=167.89$ & 1.495 \\
\hline \multirow{6}{*}{ HSC } & \multirow{3}{*}{$\underset{\tilde{\Xi}}{\stackrel{\Xi}{\Xi}}$} & $30 \times 10^{-6}$ & $f_{c s}^{\prime}=83.46$ & 1.00 \\
\hline & & $135 \times 10^{-6}$ & $f_{c d}^{\prime}=86.67$ & 1.038 \\
\hline & & $300 \times 10^{-6}$ & $f_{c d}^{\prime}=87.6$ & 1.05 \\
\hline & \multirow{3}{*}{ 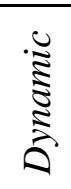 } & $1.35 \times 10^{-3}$ & $f^{\prime}{ }_{c d}=98.66$ & 1.18 \\
\hline & & $3 \times 10^{-3}$ & $f_{c d}^{\prime}=116.78$ & 1.399 \\
\hline & & $6 \times 10^{-3}$ & $f_{c d}^{\prime}=134.34$ & 1.609 \\
\hline
\end{tabular}


In the Figure 4.7 dynamic increase factor versus strain rate for compressive strength is plotted for each concrete composite.

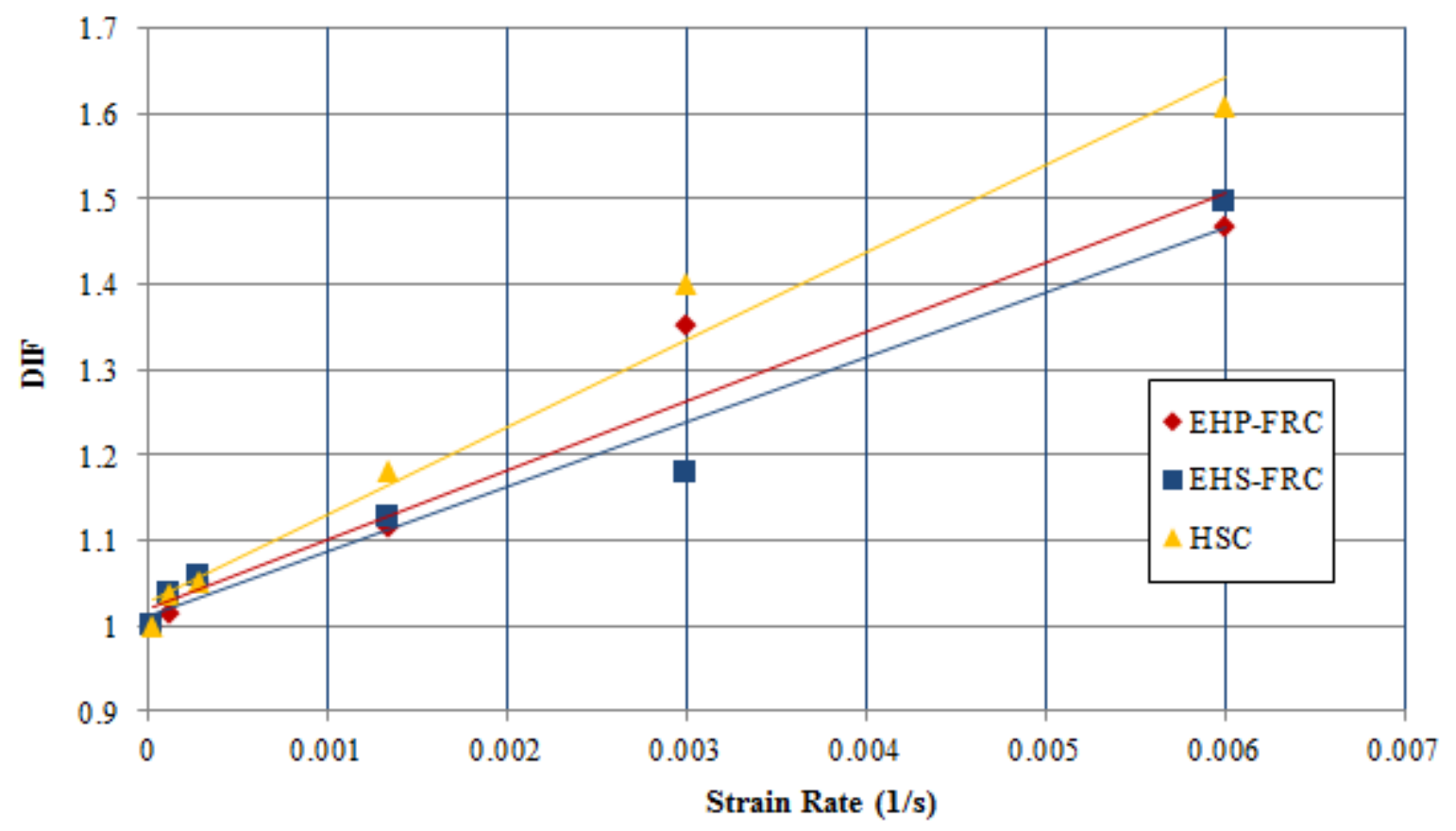

Figure 4.7: DIF for Compressive Strength

\subsection{Flexural Tests}

\subsubsection{Flexural Tensile Strength}

For all flexural strength tests, prism specimens of $100 \times 100 \times 400 \mathrm{~mm}$ were used. For flexural strength test under quasi-static loading MTS 793 test machine was used. Prisms were tested under three-bending-loading for all composite series.

From the three-point bending flexural test, force, displacement and modulus of rupture for UHPFRC, EHP-FRC, EHS-FRC and HSC were calculated these values are tabulated in Table 4.6 for each composite. 
Table 4.6: Flexural strength of UHP-FRC, EHP-FRC, EHS-FRC and HSC

\begin{tabular}{|c|c|c|c|}
\hline Composite & $\begin{array}{c}\text { Peak Load } \\
(\mathrm{kN})\end{array}$ & $\begin{array}{c}\text { Modulus of } \\
\text { Rupture }(\mathrm{MPa})\end{array}$ & $\begin{array}{c}\text { Deflection at } \\
\text { peak load }(\mathrm{mm})\end{array}$ \\
\hline UHP-FRC & 40.422 & 18.19 & - \\
\hline EHP-FRC & 27.09 & 12.19 & 0.868 \\
\hline EHS-FRC & 44.58 & 20.06 & 1.18 \\
\hline HSC & 17.84 & 8.028 & - \\
\hline
\end{tabular}

The flexural load displacement plots for EHP-FRC, EHS-FRC and HSC under quasi-static loading at displacement rate of $0.013 \mathrm{~mm} / \mathrm{min}$ is shown in Figure 4.8. For each series three prisms were tested at mentioned displacement rate and the average value used as quasi-static strength. The tested prisms for EHP-FRC, EHS-FRC and HSC are shown in Figure 4.8.

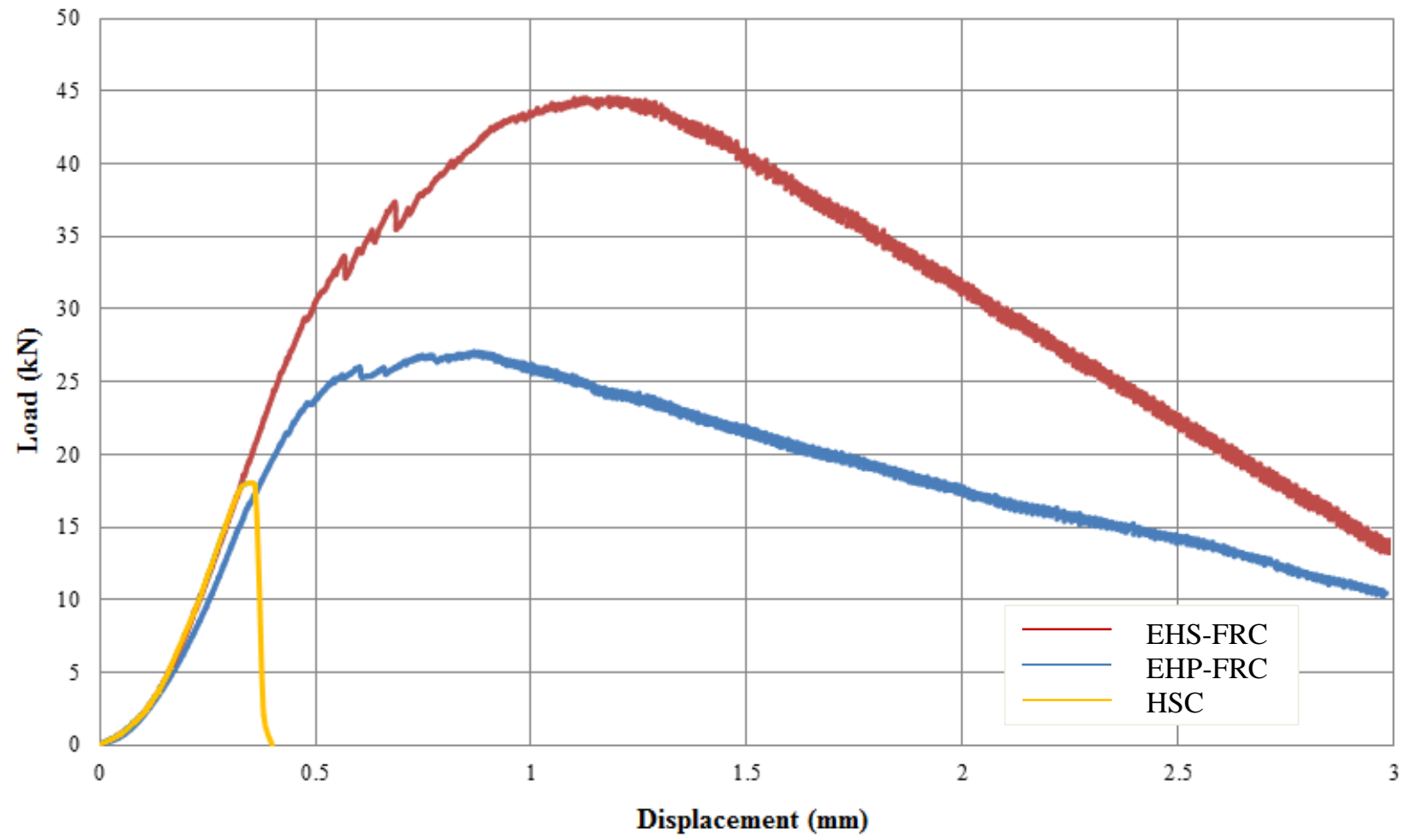

Figure 4.8: Flexural Performance of EHP-FRC, EHS-FRC and HSC 


\subsubsection{Quasi-static Tests}

Concrete prism $(100 \times 100 \times 400 \mathrm{~mm})$ specimens were used in flexural quasi-static tests. Prism samples were loaded in MTS 793 test system. The test results in quasi-static domain with different strain rate range for EHP-FRC and EHS-FRC are tabulated in Table 4.7. Note that, since the dynamic enhancement in quasi-static region found to be minimal from EHP-FRC and EHS-FRC test, these tests for the other two materials were skipped.

Table 4.7: Quasi-static Flexural Strength Test Results for EHP-FRC and EHS-FRC

\begin{tabular}{|c|c|c|c|}
\hline \multirow[b]{2}{*}{ Composite } & \multicolumn{3}{|c|}{ Quasi-static Range } \\
\hline & $\begin{array}{l}\text { Strain Rate } \\
\left(\mathrm{s}^{-1}\right)\end{array}$ & $\begin{array}{l}\text { Displacement Rate } \\
(\mathrm{mm} / \mathrm{min})\end{array}$ & $\begin{array}{l}\text { Compressive Strength } \\
(\mathrm{MPa})\end{array}$ \\
\hline \multirow{10}{*}{$\begin{array}{c}\text { EHP-FRC } \\
\left(v_{f}=2 \%\right)\end{array}$} & \multirow{4}{*}{$1 \times 10^{-6}$} & \multirow{4}{*}{0.013} & 1. 12.19 \\
\hline & & & 11.51 \\
\hline & & & 11.43 \\
\hline & & & Average: $\quad 11.47$ \\
\hline & \multirow{3}{*}{$10 \times 10^{-6}$} & \multirow{3}{*}{0.129} & 12.01 \\
\hline & & & 11.29 \\
\hline & & & Average: 11.65 \\
\hline & \multirow{3}{*}{$20 \times 10^{-6}$} & \multirow{3}{*}{0.257} & 12.03 \\
\hline & & & 13.21 \\
\hline & & & Average: 12.62 \\
\hline \multirow{10}{*}{$\begin{array}{c}\text { EHS-FRC } \\
\left(v_{f}=2 \%\right)\end{array}$} & \multirow{4}{*}{$1 \times 10^{-6}$} & \multirow{4}{*}{0.013} & 1. 20.06 \\
\hline & & & 19.53 \\
\hline & & & 3. $\quad 19.12$ \\
\hline & & & Average: 19.57 \\
\hline & \multirow{3}{*}{$10 \times 10^{-6}$} & \multirow{3}{*}{0.129} & 19.94 \\
\hline & & & 20.81 \\
\hline & & & Average: $\quad 20.38$ \\
\hline & \multirow{3}{*}{$20 \times 10^{-6}$} & \multirow{3}{*}{0.257} & 20.94 \\
\hline & & & 21.47 \\
\hline & & & Average: $\quad 21.21$ \\
\hline
\end{tabular}




\subsubsection{Impact Tests}

Prism $(100 \times 100 \times 400 \mathrm{~mm})$ specimens were used in flexural dynamic (impact) tests. For dynamic loading (impact) drop hammer weight apparatus as discussed in previous chapter was used. After each drop, load versus time graph extracted from data acquisition system, then loading rates and corresponding strain rates were calculated.

When evaluating loading rates from load cell data the shape of the curve (time-load) was like a parabola. In this case the loading rate is obtained by dividing the peak load by the overall time from the start of the impact to the peak loading. The peak forces and loading rates were calculated from the output of the two load cells in the flexural experiments. The time versus load curve for EHP-FRC under impact loading at drop height of $800 \mathrm{~mm}$ is shown in Figure 4.9 as an example. Calculated loading rates and corresponding strain rates for all composites at different drop heights is tabulated in Tables 4.8 to 4.11 .

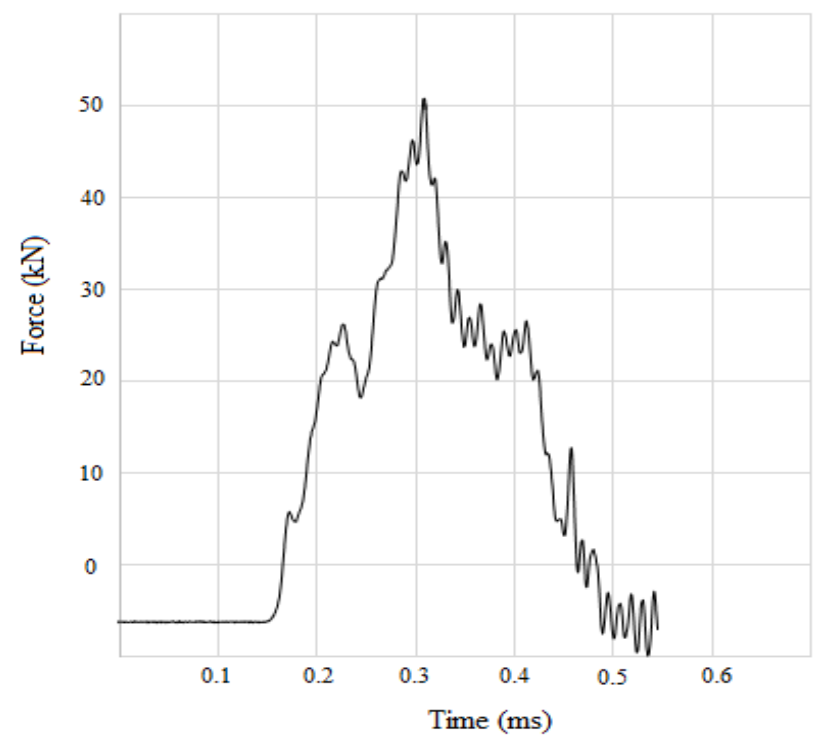

Figure 4.9: Typical Force - Time Curve Extracted From Load Cells

Form the graph: $\mathrm{F}=51.32 \mathrm{kN}, \mathrm{t}=0.0003613 \mathrm{sec}$

$$
\mathrm{P}=\frac{\mathrm{F}}{\mathrm{t}}=>\frac{51.32}{3.613 \times 10^{-4}}=142125.66 \mathrm{kN} / \mathrm{s}
$$

Then, Strain rate is: $\quad \varepsilon=\frac{3 \mathrm{PL}}{2 \mathrm{Ebd}^{2}}=>\frac{3 \times 142125.66 \times 300}{2 \times 35.27 \times 100 \times 100^{2}}=1.81 \mathrm{~s}^{-1}$ 
Table 4.8: Loading Rates and Strain Rates for UHP-FRC

\begin{tabular}{|c|l|l|c|l|l|}
\hline $\begin{array}{c}\text { Drop } \\
\text { Height } \\
(\mathrm{mm})\end{array}$ & $\begin{array}{c}\text { Peak Force } \\
(\mathrm{kN})\end{array}$ & \multicolumn{1}{|c|}{$\begin{array}{c}\text { Stress } \\
(\mathrm{MPa})\end{array}$} & $\begin{array}{c}\text { Impact Time } \\
(\mathrm{ms})\end{array}$ & $\begin{array}{c}\text { Load Rating } \\
(\mathrm{kN} / \mathrm{s})\end{array}$ & \multicolumn{1}{|c|}{$\begin{array}{c}\text { Strain Rate } \\
\left(\mathrm{s}^{-1}\right)\end{array}$} \\
\hline \multirow{3}{*}{600} & 1.61 .32 & 1.27 .59 & 0.4199 & 1.143574 .744 & 1.1 .29 \\
\cline { 2 - 7 } & 2.60 .28 & 2.27 .13 & 0.4199 & 2.146040 .846 & 2.1 .32 \\
\cline { 2 - 7 } & Ave: $\mathbf{6 0 . 8 1}$ & Ave: $\mathbf{2 7 . 3 6}$ & $\mathbf{0 . 4 1 9 9}$ & Ave: $\mathbf{1 4 4 8 0 7 . 7 9}$ & Ave: $\mathbf{1 . 3 1}$ \\
\hline \multirow{3}{*}{800} & 1.65 .56 & 1.29 .51 & 0.1935 & 1.338812 .66 & 1.3 .05 \\
\cline { 2 - 7 } & 2.73 .05 & 2.32 .91 & 0.1935 & 2.377524 .05 & 2.3 .39 \\
\cline { 2 - 7 } & Ave: $\mathbf{6 9 . 3 1}$ & Ave: $\mathbf{3 1 . 1 8}$ & $\mathbf{0 . 1 9 3 5}$ & Ave: $\mathbf{3 5 8 1 6 8 . 3 6}$ & Ave: 3.22 \\
\hline
\end{tabular}

Table 4.9: Loading Rates and Strain Rates for EHP-FRC

\begin{tabular}{|c|l|l|c|l|c|}
\hline $\begin{array}{c}\text { Drop } \\
\text { Height } \\
(\mathrm{mm})\end{array}$ & $\begin{array}{c}\text { Peak Force } \\
(\mathrm{kN})\end{array}$ & \multicolumn{1}{|c|}{$\begin{array}{c}\text { Stress } \\
(\mathrm{MPa})\end{array}$} & $\begin{array}{c}\text { Impact Time } \\
(\mathrm{ms})\end{array}$ & $\begin{array}{c}\text { Load Rating } \\
(\mathrm{kN} / \mathrm{s})\end{array}$ & $\begin{array}{c}\text { Strain Rate } \\
\left(\mathrm{s}^{-1}\right)\end{array}$ \\
\hline \multirow{4}{*}{400} & 1.43 .56 & 1.19 .60 & 0.68336 & 1.63743 .85 & 1.0 .81 \\
\cline { 2 - 7 } & 2.42 .075 & 2.18 .93 & 0.68336 & 2.61570 .76 & 2.0 .78 \\
\cline { 2 - 7 } & Ave: $\mathbf{4 2 . 8 2}$ & Ave: $\mathbf{1 9 . 2 6}$ & $\mathbf{0 . 6 8 3 3 6}$ & Ave: $\mathbf{6 2 6 5 7 . 3 1}$ & Ave: $\mathbf{0 . 7 9 9}$ \\
\hline \multirow{3}{*}{600} & 1.50 .4616 & 1.22 .71 & 0.458 & 1.110178 .16 & 1.1 .40 \\
\cline { 2 - 7 } & 2.45 .16 & 2.20 .32 & 0.458 & 2.98602 .62 & 2.1 .26 \\
\cline { 2 - 7 } & Ave: $\mathbf{4 7 . 8 1}$ & Ave: $\mathbf{2 1 . 5 2}$ & $\mathbf{0 . 4 5 8}$ & Ave: $\mathbf{1 0 4 3 9 0 . 3 9}$ & Ave: $\mathbf{1 . 3 3}$ \\
\hline \multirow{4}{*}{800} & 1.51 .35 & 1.23 .11 & 0.3613 & 1.142125 .66 & 1.1 .81 \\
\cline { 2 - 7 } & 2.50 .42 & 2.22 .69 & 0.3613 & 2.139547 .47 & 2.1 .78 \\
\cline { 2 - 7 } & Ave: $\mathbf{5 0 . 8 8}$ & Ave: $\mathbf{2 2 . 8 9}$ & $\mathbf{0 . 3 6 1 3}$ & Ave: $\mathbf{1 4 0 8 3 6 . 5 6}$ & Ave: $\mathbf{1 . 7 9}$ \\
\hline
\end{tabular}


Table 4.10: Loading Rates and Strain Rates for EHS-FRC

\begin{tabular}{|c|l|l|c|l|c|}
\hline $\begin{array}{c}\text { Drop } \\
\text { Height } \\
(\mathrm{mm})\end{array}$ & $\begin{array}{c}\text { Peak Force } \\
(\mathrm{kN})\end{array}$ & \multicolumn{1}{|c|}{$\begin{array}{c}\text { Stress } \\
(\mathrm{MPa})\end{array}$} & $\begin{array}{c}\text { Impact Time } \\
(\mathrm{ms})\end{array}$ & $\begin{array}{c}\text { Load Rating } \\
(\mathrm{kN} / \mathrm{s})\end{array}$ & $\begin{array}{c}\text { Strain Rate } \\
\left(\mathrm{s}^{-1}\right)\end{array}$ \\
\hline \multirow{3}{*}{400} & 1.61 .55 & 1.27 .69 & 0.664 & 1.92698 .19 & 1.1 .103 \\
\cline { 2 - 7 } & 2.56 .77 & 2.25 .54 & 0.664 & 2.85496 .985 & 2.1 .018 \\
\cline { 2 - 7 } & Ave: $\mathbf{5 9 . 1 6}$ & Ave: $\mathbf{2 6 . 6 2}$ & $\mathbf{0 . 6 6 4}$ & Ave: $\mathbf{8 9 0 9 7 . 5 9}$ & Ave: $\mathbf{1 . 0 6 1}$ \\
\hline \multirow{4}{*}{600} & 1.74 .63 & 1.33 .58 & 0.5469 & 1.136465 .53 & 1.1 .62 \\
\cline { 2 - 7 } & 2.68 .28 & 2.30 .735 & 0.5469 & 2.124861 .95 & 2.1 .48 \\
\cline { 2 - 7 } & Ave: $\mathbf{7 1 . 4 6}$ & Ave: $\mathbf{3 2 . 1 6}$ & $\mathbf{0 . 5 4 6 9}$ & Ave: $\mathbf{1 3 0 6 6 3 . 7 4}$ & Ave: $\mathbf{1 . 5 5}$ \\
\hline \multirow{3}{*}{800} & 1.88 .69 & 1.39 .91 & 0.3906 & 1.227065 .79 & 1.2 .71 \\
\cline { 2 - 7 } & 2.80 .83 & 2.36 .37 & 0.3906 & 2.206954 .68 & 2.2 .46 \\
\cline { 2 - 7 } & Ave: $\mathbf{8 4 . 7 6}$ & Ave: $\mathbf{3 8 . 1 4}$ & $\mathbf{0 . 3 9 0 6}$ & Ave: $\mathbf{2 1 7 0 1 0 . 2 4}$ & Ave: $\mathbf{2 . 5 8}$ \\
\hline
\end{tabular}

Table 4.11: Loading Rates and Strain Rates for HSC

\begin{tabular}{|c|l|l|c|l|c|}
\hline $\begin{array}{c}\text { Drop } \\
\begin{array}{c}\text { Height } \\
(\mathrm{mm})\end{array}\end{array}$ & $\begin{array}{c}\text { Peak Force } \\
(\mathrm{kN})\end{array}$ & \multicolumn{1}{|c|}{$\begin{array}{c}\text { Stress } \\
(\mathrm{MPa})\end{array}$} & $\begin{array}{c}\text { Impact Time } \\
(\mathrm{s})\end{array}$ & $\begin{array}{c}\text { Load Rating } \\
(\mathrm{kN} / \mathrm{s})\end{array}$ & $\begin{array}{c}\text { Strain Rate } \\
\left(\mathrm{s}^{-1}\right)\end{array}$ \\
\hline \multirow{3}{*}{200} & 1.43 .43 & 1.19 .5435 & 0.0022495 & 1.19306 .5125 & 1.0 .298 \\
\cline { 2 - 7 } & 2.52 .314 & 2.23 .5413 & 0.0022495 & 2.23255 .8345 & 2.0 .359 \\
\cline { 2 - 7 } & Ave: $\mathbf{4 7 . 8 7 2}$ & Ave: $\mathbf{1 . 5 4 2 4}$ & $\mathbf{0 . 0 0 2 2 4 9 5}$ & Ave: $\mathbf{2 1 2 8 1 . 1 7 3}$ & Ave: $\mathbf{0 . 3 2}$ \\
\hline \multirow{4}{*}{400} & 1.61 .54 & 1.27 .693 & 0.0010449 & 1.58896 .52311 & 1.0 .909 \\
\cline { 2 - 7 } & 2.57 .47 & 2.25 .8615 & 0.0010449 & 2.54998 .39985 & 2.0 .849 \\
\cline { 2 - 7 } & Ave: $\mathbf{5 9 . 5 0 5}$ & Ave: $\mathbf{2 6 . 7 7 5}$ & $\mathbf{0 . 0 0 1 0 4 4 9}$ & Ave: $\mathbf{9 1 6 1 2 . 3 9 6}$ & Ave: $\mathbf{0 . 8 7 9}$ \\
\hline \multirow{3}{*}{600} & 1.88 .4 & 1.39 .78 & 0.0005231 & 1.169978 .285 & 1.2 .625 \\
\cline { 2 - 7 } & 2.84 .22 & 2.37 .899 & 0.0005231 & 2.160993 .0944 & 2.2 .486 \\
\cline { 2 - 7 } & Ave: $\mathbf{8 6 . 3 1}$ & Ave: $\mathbf{3 8 . 8 3}$ & $\mathbf{0 . 0 0 0 5 2 3 1}$ & Ave: $\mathbf{1 6 5 4 8 5 . 6 9}$ & Ave: $\mathbf{2 . 5 5}$ \\
\hline
\end{tabular}




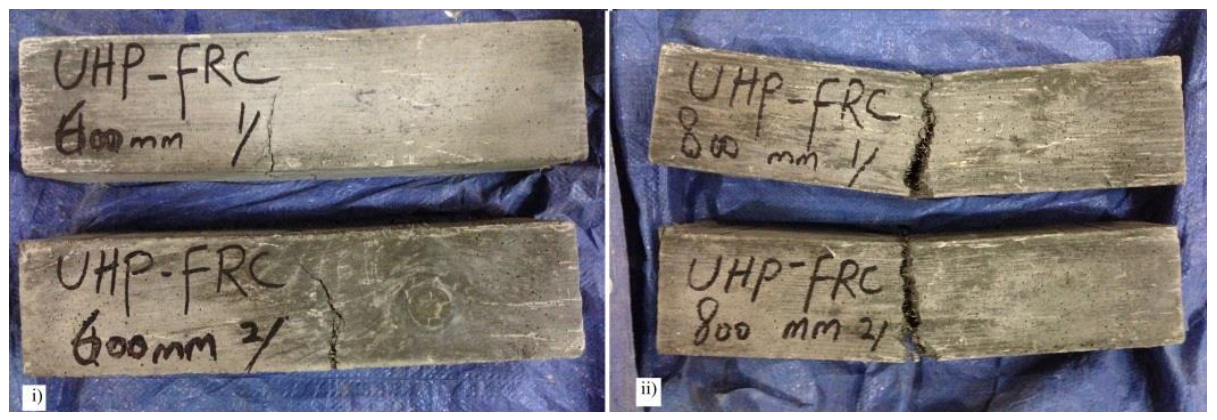

Figure 4.10: UHP-FRC Prisms After Impact Test; i) $600 \mathrm{~mm}$ and ii) $800 \mathrm{~mm}$
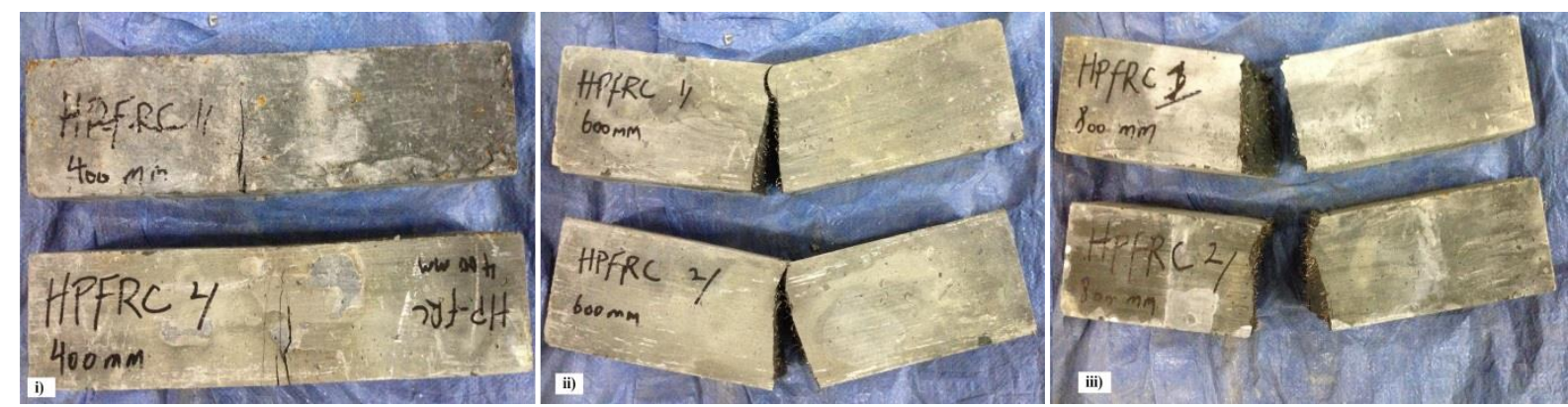

Figure 4.11: EHP-FRC Prisms After Impact Test; i) $400 \mathrm{~mm}$, ii) $600 \mathrm{~mm}$ and iii) $800 \mathrm{~mm}$
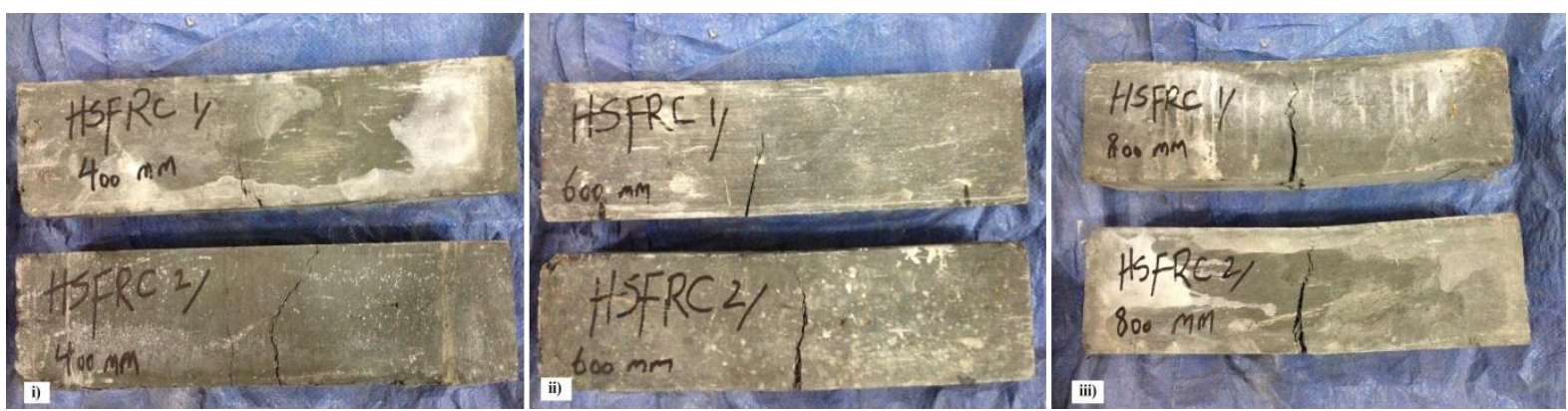

Figure 4.12: EHS-FRC Prisms after Impact Test; i) $400 \mathrm{~mm}$, ii) $600 \mathrm{~mm}$ and iii) $800 \mathrm{~mm}$
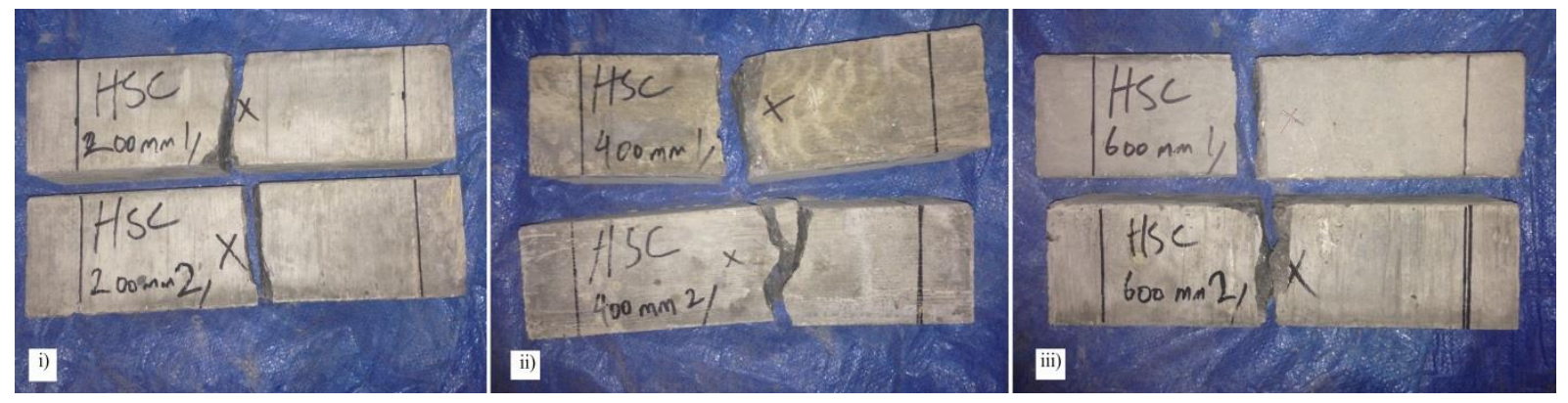

Figure 4.13: HSC Prisms After Impact Test; i) $200 \mathrm{~mm}$, ii) $400 \mathrm{~mm}$ and iii) $600 \mathrm{~mm}$ 
Different drop heights and their corresponding strain rates with are given in Tables 4.12.

Table 4.12: Dynamic Flexural Strength Test Results for all Composites

\begin{tabular}{|c|c|c|c|}
\hline \multirow[b]{2}{*}{ Composite } & \multicolumn{3}{|c|}{ Quasi-static Range } \\
\hline & $\begin{array}{l}\text { Drop Height } \\
(\mathrm{mm})\end{array}$ & $\begin{array}{c}\text { Strain Rate } \\
\quad\left(\mathrm{s}^{-1}\right)\end{array}$ & $\begin{array}{c}\text { Flexural Strength } \\
f_{c d,}^{\prime}(\mathrm{MPa})\end{array}$ \\
\hline \multirow{8}{*}{$\begin{array}{c}\text { UHP-FRC } \\
\left(v_{f}=2 \%\right)\end{array}$} & \multirow[b]{2}{*}{400} & \multirow[b]{2}{*}{ - } & 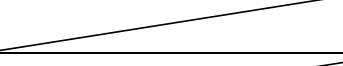 \\
\hline & & & ${ }_{2}$ \\
\hline & \multirow{3}{*}{600} & \multirow{3}{*}{1.31} & 1. $\quad 27.59$ \\
\hline & & & 2. $\quad 27.13$ \\
\hline & & & Average: $\mathbf{2 7 . 3 6}$ \\
\hline & \multirow{3}{*}{800} & \multirow{3}{*}{3.22} & 29.51 \\
\hline & & & 32.91 \\
\hline & & & Average: 31.18 \\
\hline \multirow{9}{*}{$\begin{array}{c}\text { EHP-FRC } \\
\left(v_{f}=2 \%\right)\end{array}$} & \multirow{3}{*}{400} & \multirow{3}{*}{0.79} & 19.60 \\
\hline & & & 2. $\quad 18.93$ \\
\hline & & & Average: 19.26 \\
\hline & \multirow{3}{*}{600} & \multirow{3}{*}{1.33} & 22.71 \\
\hline & & & 20.32 \\
\hline & & & Average: 21.52 \\
\hline & \multirow{3}{*}{800} & \multirow{3}{*}{1.79} & 23.11 \\
\hline & & & 22.69 \\
\hline & & & Average: $\mathbf{2 2 . 8 9}$ \\
\hline
\end{tabular}


Table 4.12: Dynamic Compressive Strength Test Results for all Composites (continued)

\begin{tabular}{|c|c|c|c|}
\hline \multirow[b]{2}{*}{ Composite } & \multicolumn{3}{|c|}{ Quasi-static Range } \\
\hline & $\begin{array}{l}\text { Drop Height } \\
\text { (mm) }\end{array}$ & $\begin{array}{c}\text { Strain Rate } \\
\left(\mathrm{s}^{-1}\right)\end{array}$ & $\begin{array}{c}\text { Flexural Strength } \\
f_{c d,}^{\prime}(\mathrm{MPa})\end{array}$ \\
\hline \multirow{9}{*}{$\begin{array}{c}\text { EHS-FRC } \\
\left(v_{f}=2 \%\right)\end{array}$} & \multirow{3}{*}{400} & \multirow{3}{*}{$` 1.061$} & 27.69 \\
\hline & & & 25.54 \\
\hline & & & Average: $\mathbf{2 6 . 6 2}$ \\
\hline & \multirow{3}{*}{600} & \multirow{3}{*}{1.55} & 1. $\quad 33.58$ \\
\hline & & & 2. $\quad 30.735$ \\
\hline & & & Average: 32.16 \\
\hline & \multirow{3}{*}{800} & \multirow{3}{*}{2.58} & 39.91 \\
\hline & & & 36.37 \\
\hline & & & Average: 38.14 \\
\hline \multirow{9}{*}{$\begin{array}{c}\text { HSC } \\
\text { (No Fiber) }\end{array}$} & \multirow{3}{*}{200} & \multirow{3}{*}{0.32} & 1. 19.5435 \\
\hline & & & 23.5413 \\
\hline & & & Average: $\mathbf{2 1 . 5 4 2 4}$ \\
\hline & & & 27.693 \\
\hline & 400 & 0.88 & 25.8615 \\
\hline & & & Ave: $\mathbf{2 6 . 7 7 5}$ \\
\hline & & & 39.78 \\
\hline & 600 & 2.55 & 37.899 \\
\hline & & & Ave: $\mathbf{3 8 . 8 3}$ \\
\hline
\end{tabular}




\subsubsection{Dynamic Increase Factor, DIF}

Dynamic Increase Factor (DIF) for each composite is calculated by taking the ratio of static compressive strength $\left(f_{c s}^{\prime}\right)$ under quasi-static strain rate $\left(1 \times 10^{-6} \mathrm{~s}^{-1}\right)$ over dynamic peak stress $\left(f_{c d}^{\prime}\right)$ under strain rates calculated from each drop. The dynamic flexural strength of each composite is given in Table 4.13 .

Table 4.13: Dynamic Flexural Strength of Concrete Composites

\begin{tabular}{|c|c|c|c|c|}
\hline Composite & & Rate $\left(\mathrm{s}^{-1}\right)$ & Strength (MPa) & DIF \\
\hline \multirow{6}{*}{ UHP-FRC } & \multirow{3}{*}{ 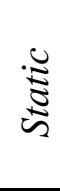 } & $1 \times 10^{-6}$ & $f^{\prime}{ }_{c s}=18.19$ & 1.00 \\
\hline & & $10 \times 10^{-6}$ & $f_{c d}^{\prime}=\mathrm{NA}$ & - \\
\hline & & $20 \times 10^{-6}$ & $f_{c d}^{\prime}=\mathrm{NA}$ & - \\
\hline & \multirow{3}{*}{ 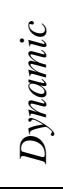 } & - & $f^{\prime}{ }_{c d}=\mathrm{NA}$ & - \\
\hline & & 1.31 & $f_{c d}^{\prime}=27.36$ & 1.43 \\
\hline & & 3.22 & $f_{c d}^{\prime}=31.18$ & 1.72 \\
\hline \multirow{6}{*}{ EHP-FRC } & \multirow{3}{*}{$\frac{\overrightarrow{\widetilde{J}}}{\tilde{\Xi}}$} & $1 \times 10^{-6}$ & $f_{c s}^{\prime}=11.47$ & 1.00 \\
\hline & & $10 \times 10^{-6}$ & $f_{c d}^{\prime}=11.65$ & 1.016 \\
\hline & & $20 \times 10^{-6}$ & $f^{\prime}{ }_{c d}=12.62$ & 1.100 \\
\hline & \multirow{3}{*}{ 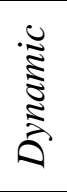 } & 0.79 & $f^{\prime}{ }_{c d}=19.26$ & 1.68 \\
\hline & & 1.33 & $f_{c d}^{\prime}=21.52$ & 1.88 \\
\hline & & 1.79 & $f^{\prime}{ }_{c d}=22.95$ & 2.00 \\
\hline \multirow{6}{*}{ EHS-FRC } & \multirow{3}{*}{ 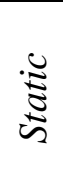 } & $1 \times 10^{-6}$ & $f_{c s}^{\prime}=19.57$ & 1.00 \\
\hline & & $10 \times 10^{-6}$ & $f_{c d}^{\prime}=20.38$ & 1.041 \\
\hline & & $20 \times 10^{-6}$ & $f^{\prime}{ }_{c d}=21.21$ & 1.084 \\
\hline & \multirow{3}{*}{ 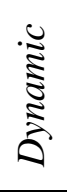 } & 1.061 & $f^{\prime}{ }_{c d}=26.62$ & 1.327 \\
\hline & & 1.55 & $f^{\prime}{ }_{c d}=32.16$ & 1.604 \\
\hline & & 2.58 & $f^{\prime}{ }_{c d}=38.14$ & 1.902 \\
\hline \multirow{6}{*}{ HSC } & \multirow{3}{*}{ 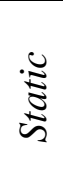 } & $1 \times 10^{-6}$ & $f_{c s}^{\prime}=9.39$ & 1.00 \\
\hline & & $10 \times 10^{-6}$ & $f_{c d}^{\prime}=\mathrm{NA}$ & - \\
\hline & & $20 \times 10^{-6}$ & $f_{c d}^{\prime}=\mathrm{NA}$ & - \\
\hline & \multirow{3}{*}{ 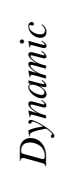 } & 0.32 & $f_{c d}^{\prime}=21.54$ & 2.29 \\
\hline & & 0.88 & $f_{c d}^{\prime}=26.78$ & 2.85 \\
\hline & & 2.55 & $f_{c d}^{\prime}=38.83$ & 4.135 \\
\hline
\end{tabular}


In the Figure 4.14 dynamic increase factor versus strain rate for flexural strength is plotted for each concrete composite.

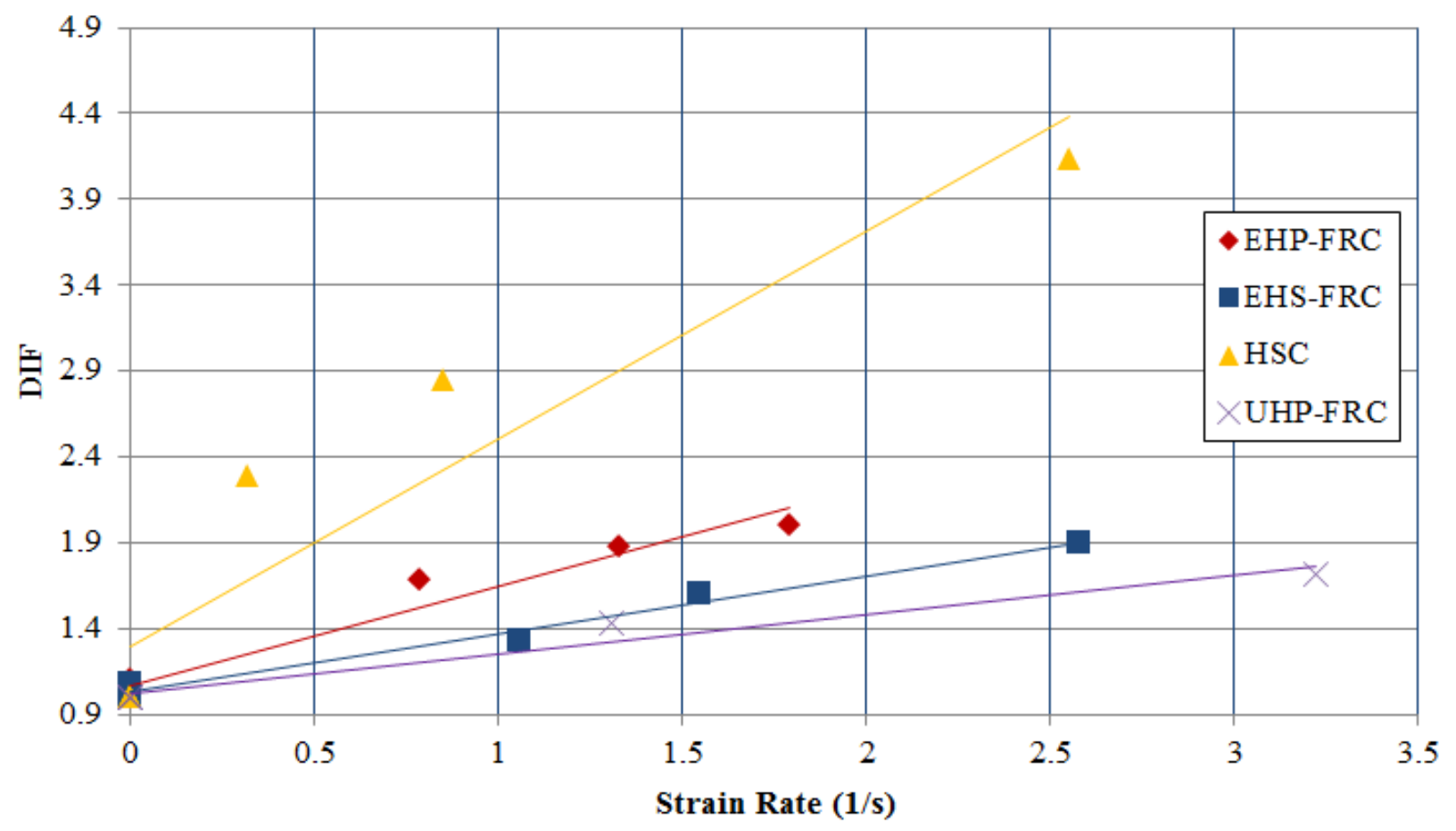

Figure 4.14: DIF versus Strain Rate for Flexural Tensile Strength

\subsection{Discussion of the Results}

In this chapter strain rates sensitivity of different concrete fiber composites and plain concrete are evaluated for both compressive and flexural tensile strength. For the compressive strength rate sensitivity, cylindrical specimens were used and the experiments carried out in the MTS machine for both quasi-static and dynamic strain rates. The tested cylinder specimens after compressive test in quasi-static range are shown in Figures $4.2-4.4$. As it can be seen in these figures, the specimens containing steel fibers are capable of resisting spalling after peak stress, that shows the ductility of the specimens. This could be confirmed through the stress-strain curve (see Figure 4.1) where gradual descending is seen after peak stress. On the other hand, HSC specimens without fiber showed no ductility and explosive spalling behaviour at all loading rates (See Figure 4.4). This could be seen in Figure 4.1 where HSC exhibits sudden descending after peak stress. Among the three concrete types, EHP-FRC exhibits a larger area under the graph which represents the higher ductility of this material. 
Test results of the quasi-static and dynamic compressive strength is given in Table 4.4 and 4.5 respectively. As it was expected, with greater strain rates, a larger increment in compressive strength is achieved. Overall, compressive strengths under dynamic loading are greater than under quasi-static loading. Figure 4.8 presents the relationship between strain rates and DIF. The results show that in both regions HSC without fiber exhibits higher sensitivity than the other two composites with steel fiber content. The DIF for HSC found to be 1.609 under a strain rate of $6 \times$ $10^{-3} \mathrm{~s}^{-1}$, while DIF under same strain rate for EHP-FRC and EHS-FRC are 1.467 and 1.495 respectively.

For the flexural tensile strength rate sensitivity, prism specimens were tested. For the quasi-static region, prisms tested in MTS machine under three-point bending loading. In this region maximum strain rate of $20 \times 10^{-6}$ was achieved with DIF of 1.1 . In flexural strength the increment of strength is minimal in quasi-static region using MTS testing machine.

In order to achieve high strain rates in dynamic region, prism specimens tested under impact loading using drop weight hammer facility. Different heights of 400, 600 and $800 \mathrm{~mm}$ used for composites containing fibers while drop heights of 200, 400, $600 \mathrm{~mm}$ were used for HSC without fiber. The tested prisms at different drop heights are shown in Figures 4.10 to 4.13.

As it can be seen in Figure 4.10, UHP-FRC exhibits an outstanding performance under impact loading. The prism specimens were partly connected under drop height of $800 \mathrm{~mm}$, and complete fracture did not occur. The UHP-FRC prisms experienced fiber pullout mode of failure.

In the case of EHP-FRC, drop weight had to rise to $800 \mathrm{~mm}$ to get the complete fracture. The failure mode of the EHP-FRC prisms was seen to be due to fiber pull out rather than fiber fracture. For EHS-FRC even $800 \mathrm{~mm}$ was not sufficient to completely break the specimens (See Figure 4.12). This confirms that EHS-FRC has higher toughness in comparison to EHP-FRC. This also can be seen in Figure 4.8 as the area under the graph of load - deflection curve for EHS-FRC is much greater than EHP-FRC. On the other hand, for HSC drop height of $200 \mathrm{~mm}$ was sufficient to get a complete fracture. The plain HSC exhibits a brittle failure under all drop heights and loading rates. 
Test results of the impact tests are given in Table 4.9 where high strain rates were achieved using drop weight facility. Notice that, for all composites the flexural strength increased as the height of drop hammer was increased. In Figure 4.14 the relationship between strain rate and DIF for UHP-FRC, EHP-FRC, EHS-FRC and HSC is shown. It is clear from this figure that, plain HSC exhibit much higher sensitivity than fiber reinforced composites. For HSC strain rate of $2.55 \mathrm{~s}^{-1}$ with the corresponding DIF of 4.155 was recorded. It should be noted that, while HSC is increasingly brittle under impact loading, fiber reinforced composites improve the impact loading and only in some cases become brittle where drop height increased at $800 \mathrm{~mm}$ (in case of EHP-FRC).

As it was expected UHP-FRC prisms exhibit much lower DIF under corresponding strain rates in comparison to other concrete composites, especially plain HSC. This can be seen in Figure 4.14, where UHP-FRC has much lower slope in DIF versus Strain rate graph rather than all other three materials. Maximum strain rate achieved is $3.22 \mathrm{~s}^{-1}$ at corresponding DIF of 1.72. This result confirms the low strain rate sensitivity of the UHP-FRC material.

The dynamic increase factor for EHP-FRC and EHS-FRC is relatively close to each other. However EHP-FRC has DIF of 2.00 at lower strain rate of $1.79 \mathrm{~s}^{-1}$ in comparison to the EHSFRC where exhibits DIF of 1.902 under strain rate of $2.58 \mathrm{~s}^{-1}$. In other words EHP-FRC is more sensitive to the strain rate than UHP-FRC and HS-FRC.

DIF in concrete can also be explained by the time taken for micro crack propagation in the matrix. In fibre reinforced composites, the fibers are capable of resisting the spread of the cracks by bridging and as a result exhibit much better performance in comparison to plain concrete.

In the present study, among all four concrete types UHP-FRC exhibit a much better performance under impact loading. UHP-FRC also exhibit less strain rate sensitivity than other concrete types. Therefore, UHP-FRC is the recommended material for structures subjected to impact or blast loading. 


\section{Chapter 5 \\ CONCLUSION}

This investigation was intended to determine the strain rate sensitivity of fiber reinforced ultrahigh performance concrete and plain high strength concrete. The experimental program is designed for both compressive and flexural strength test under quasi-static and dynamic loading. For the quasi-static tests MTS machine is used to achieve low strain rates, while for reaching higher strain rates a dynamic drop hammer weight facility was designed and constructed at Ryerson University. The results are used to evaluate dynamic increase factor to determine the strain rate sensitivity of each mix. The study of strain rate sensitivity is required to determine the performance of the concrete under dynamic loading such as, impact and blast loading.

\subsection{Research Findings}

For the compressive strength tests MTS machine is used for both quasi-static and dynamic region. Following are the major findings of compressive strength tests in quasi-static and dynamic region:

1. In the compressive strength tests as the strain rate is increased from quasi-static to dynamic range, the compressive strength is increased significantly.

2. The compressive strength exhibits higher strain rate sensitivity in HSC compared to EHPFRC and EHS-FRC, especially in the dynamic range.

3. Both EHP-FRC and EHS-FRC exhibit much better performance under higher loading rates rather than HSC.

4. No spalling is observed EHP-FRC and EHS-FRC even under strain rate of $0.006 \mathrm{~s}^{-1}$. On the other hand, HSC specimens show explosive spalling under all loading rates.

5. Although fibers bring ductility concrete material, but there are no positive effects on compressive strength under quasi-static and higher rate loading. 
In the flexural tensile strength tests MTS machine is used for quasi-static range while higher strain rates in dynamic region is achieved with use of drop weight hammer facility. Major findings in flexural tensile strength test for quasi-static and dynamic region are as follow:

1. The flexural strength DIF of plain HSC specimens is significantly greater than fiber reinforced concrete specimens.

2. The flexural tensile strength dynamic strength enhancement for fiber reinforced concrete found to be minimal in quasi-static region.

3. Strain hardening behavior subsists under high strain rates in both loading cases compression and tension for EHS-FRC.

4. Quasi-static and drop hammer tests had identical failure modes for all studied concrete classes.

5. Use of steel fiber in the concrete mix enhanced the flexural strength and impact behaviour of concrete significantly and don not exhibit brittleness even at high drop heights.

6. UHP-FRC exhibited much lower DIF under corresponding strain rate of $3.22 \mathrm{~s}^{-1}$, while EHP-FRC and EHS-FRC exhibited higher DIF of 2.00 and 1.9; respectively.

The test results of this investigation show that UHP-FRC material has much lower strain rate sensitivity. As result of its great performance under high loading rate and less sensitivity, UHPFRC is suggested for structures with application of impact or blast loading.

\subsection{Recommendation for Future Studies}

This study is expected to introduce new opportunities for graduate students at Ryerson University to investigate further into strain rate sensitivity and impact loading of concrete structures. Following recommendation can be made for future studies:

- For more accurate result and better validation of the results, drop hammer facility can be improved in the sense of instrumentation. 
- In order to get better statistical relationship more specimens with various fiber volume fractions should be tested.

- Strain rate sensitivity of Ultra High Performance Concrete with different fiber fraction can be evaluated to correlate the fiber content to strain rate sensitivity.

- Large-scale experiment on dynamic loading of UHPC such as, thin shells can be carried out to find the optimum percentage of fiber content. 


\section{REFERENCES}

[1] K. Wille, A. E. Naaman and G. J. Parra Montensinos, "Ultra-High Performance Concrete with Compressive Strength Exceeding 150 MPa: A Simpler Way," ACI Materials Journal, vol. 108, no. 1, pp. 46-54, 2011.

[2] S.T. Kang, Y. Lee, Y.D. Park and J.K. Kim, "Tensile fracture properties of an Ultra High Performance Fibre Reinforced Concrete (UHPFRC) with Steel Fibre,"Composite Structures, vol. 92 , no. 1 pp. 61-71, 2010.

[3] S. Millard, T. Molyneaux, S. Barnett and X. Gao, "Dynamic enhancemnet of blast-resistanct ultra high performance fibre-reinforced concrete under flexural and shea loading," International Journal of Imapact Engineering, vol. 37, no. 4 pp. 405-413, 2010.

[4] V. Bindiganavile, N. Banthia and B. Aarup, "Impact Response of Ultra-High-Strength Fibre-Reinforced Cement Composite," ACI Materials Journal, vol. 99, no. 6 pp. 543-548, 2002.

[5] X. Gao, T. Molyneaux, I. Patnaikunu and S. Rahman, "Dynamic Properties of fibre reinforced and plain ultra high performance concrete," Melbourne, 2010.

[6] Y. Lei Voo, B. Nematollahi and A. B. Bin Mohamed Siad, "Application of Ultra High Perfommance Fiber Reinforced Concrete - The Malaysia Perspective," Internation Journal of Sustainable Construction Engineering \& Technology, vol. 3, no. 1, pp. 26-44, 2012.

[7] H. Nowodworski and K. Rosiak, "Ultra-High Perfromacne Concrete with Ductility," in 2nd Material Specialty Conference, Montreal, 2002.

[8] P. Rossi, A. Arca, E, Parant and P. Fakhri, "Bending and Compressive Behavior of a New Cement Composite," Cement and Concrete Research, vol. 35, no. 1, pp. 27-33, 2005. 
[9] K. Habel and P. Gavreau, "Response of ultra-high performance fiber reinforced concrete (UHPFRC) to impact and static loading," Cement and Composite Strucutres, vol. 30, no. 10 pp. 938-946, 2008.

[10] Graybeal, H. G. Russel and B. A, "Ultra-High Performance Concrete: A State-of-the-Art Report for the Bridge Community," Federal Highway Administration FHWA-HRT-13-060, U.S, 2013.

[11] K. Wille. A.E. Naaman. S. El-Tawil, "Optimizing Ultra-High-Performance FiberReinforced Concrete," Concrete International, vol. 33, p. 35-41, 2011.

[12] G.B, "Material Property Characterization of Ultra-High Performance Concrete,," FHWA, U.S. Department of Transportation, Report No. FHWA-HRT-06-103, McLean, Va, 2006.

[13] P. Acker and M. Behloul, "DUCTAL® Technology: A Large Spectrum Of Properties, A Wide Range Of Applications," International Symposium on Ultra High Performacne Concrete, vol. 3, pp. 11-24, 2004.

[14] A. E. Naaman, "High Performance Fiber Reinforced Cement Composites: Classification and Application," in CBM-CI International Workshop, Pakistan, karachi, 2007.

[15] K. Habell, M. Viviani, E. Denarie and E. Bruhwiler, "Development of the Mechanical Properties of an Ultra-High Performance Fiber Reinforced Concrete (UHPFRC)," Cement and Cocnrete Research, vol. 36, pp. 1362-1368, 2006.

[16] E. Fehling and T. Leutbecher, "Design relevant properties of hardened Ultra High Performance Concrete," International Symposium on Ultra High Performance Concrete.,vol. 3, pp. 327 - 338, 2004.

[17] N. C, "Ultra Hiigh Strenght Steel Fibre Reinforced Concrete. Part 1: Basic strength properties of compresit matrix. Part II: Structural application of Compresit.," in University of Denmark, Denmark, 1995. 
[18] B. Graybealm. M. Davis, "Cylinder or Cube: Strength Testing of 80 to $200 \mathrm{MPa}, "$ ACI Materials Journal, vol. 105, no. 6, pp. 603-609, 2008.

[19] B. Graybeal, V. Perry, M. Royce, "Federal Highway Administration," 18 November 2010. [Online]. Available: https://connectdot.connectsolutions.com/n134083201011. [Accessed 8 July 2014].

[20] B. Graybeal, F. Baby, "Development of a Direct Tension Test Method for UHPFRC,"," ACI Materials Journal, vol. 110, no. 2, 2013.

[21] B. Graybeal, "Practical Means for Determination of the Tensile Behavior of Ultra-High Performance Concrete," Journal of ASTM International, vol. 3, no. 8, 2006.

[22] D. L. Grote, S. W. Park, M. Zhou, "Dynamic behavior of concrete at high strain rates and pressures: I. experimental haracterization.," International Journal of Impact Engineeing, vol. 25, no. 9, pp. 869-886, 2001.

[23] Lok.T, Zhao. P, "Impact response of steel fiber reinforced concrete using a split Hopkinson pressure bar," Journal of Materials in Civil Engineering, vol. 16, pp. 54-59, 2004.

[24] R. Malogorzata, "The Influence of Strain Rate on the Strength of Concrete Taking into Account Experimental Techniques," Architecture Civil Engineering Enviriomernt, vol. 3, pp. 77-86, 2011.

[25] L. Crawford, Malvar, Javier, E. John, "Dynamic Increase Factors For Concrete," in TwentyEight DDESB Seminar, Orlando, 1998.

[26] C. E.-I. d. Beton, CEB-FIP Model Code 1990, Wiltshire: Redwood Books, 1993.

[27] P. Bischoff and S. Perry, "Compressive Behaviour of Concrete at High Strain Rates," Materials and Structures, vol. 24, no. 6, pp. 425-450, 1991.

J. G, K. Wille and Parra-Montesinos, "Effect of beam size, casting method, and support J. 
[28] G, K. Wille and Parra-Montesinos, "Effect of beam size, casting method, and support conditions on flexural behavior of ultra-high-performance fiber-reinforced concrete," $A C I$ Materials Journal, vol. 109, pp. 379-388, 2012.

[29] T. Ngo, P. Mendis and T. Krathammer, "Behaviour of Ultra High-Strenght Prestressed Concrete Panels Subjected to Blast Loading," Journal Of Structural Engineering ASCE, vol. 133, no. 11, pp. 1582-1590, 2007.

[30] N. Banthia, S. Midness, A. Bentur and M. Pigeon, "Impact Testing of Concrete Using a Drop-Weight Impact Machine," Experimental Mechanics, vol. 29, no. 1, pp. 63-69, 1989.

[31] B. Riisgaard, T. Ngo, P. Mendis, C. Georgakis and H. Stang, "Dynamic Increase Factors for High Performance Concrete in Compression using Split Hopkinson Pressure Bar," 6th International Conference on Fracture Mechanics of Concrete and Concrete Structures, Catania, Italy, 2005. 


\section{APPENDIX}

\section{Drop Weight Hammer Setup Details}

Figure 1: Detail Drawing of Drop Weight Hammer Setup

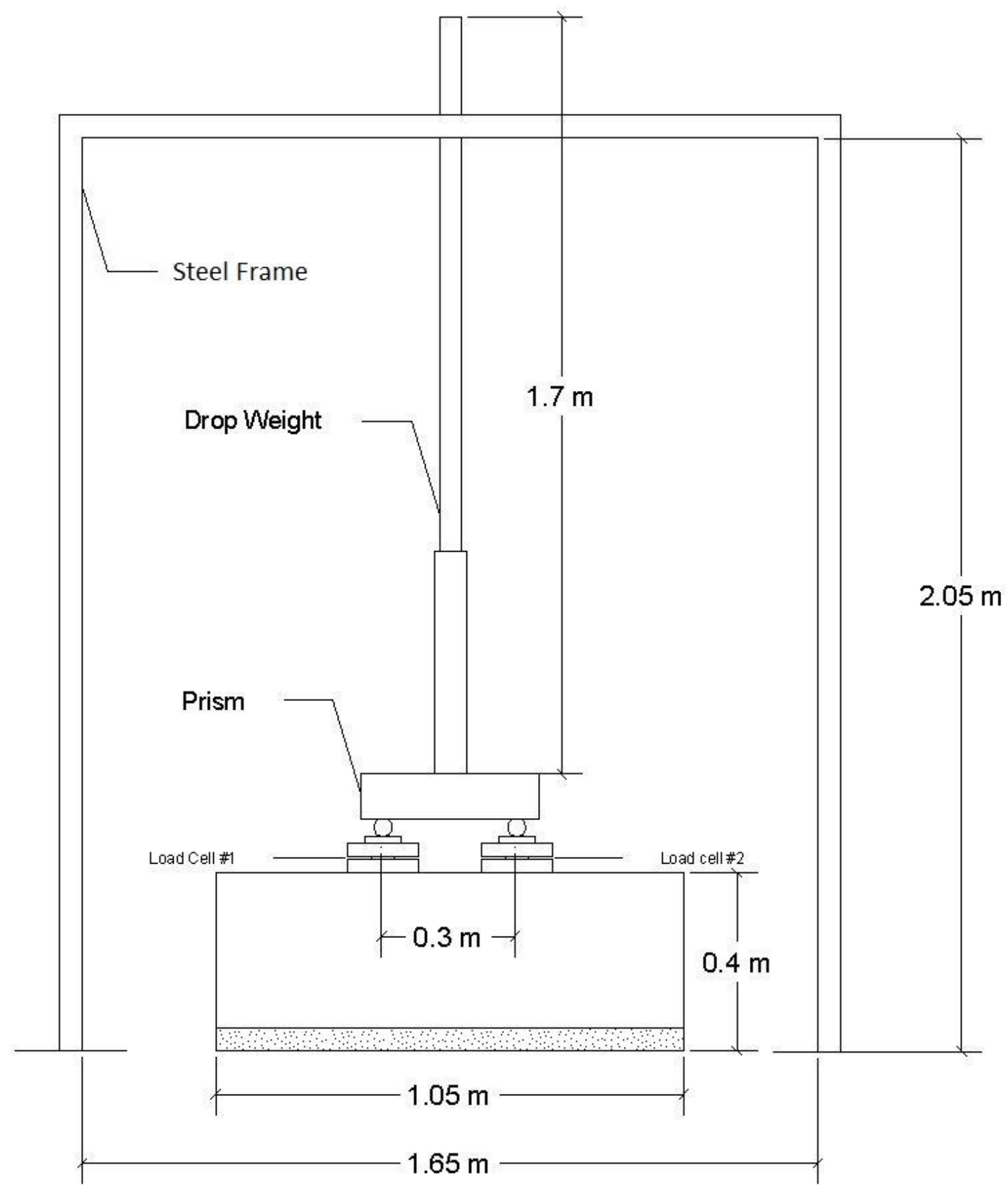


Figure 2: Detail Drawing of Drop Weight Hammer Setup

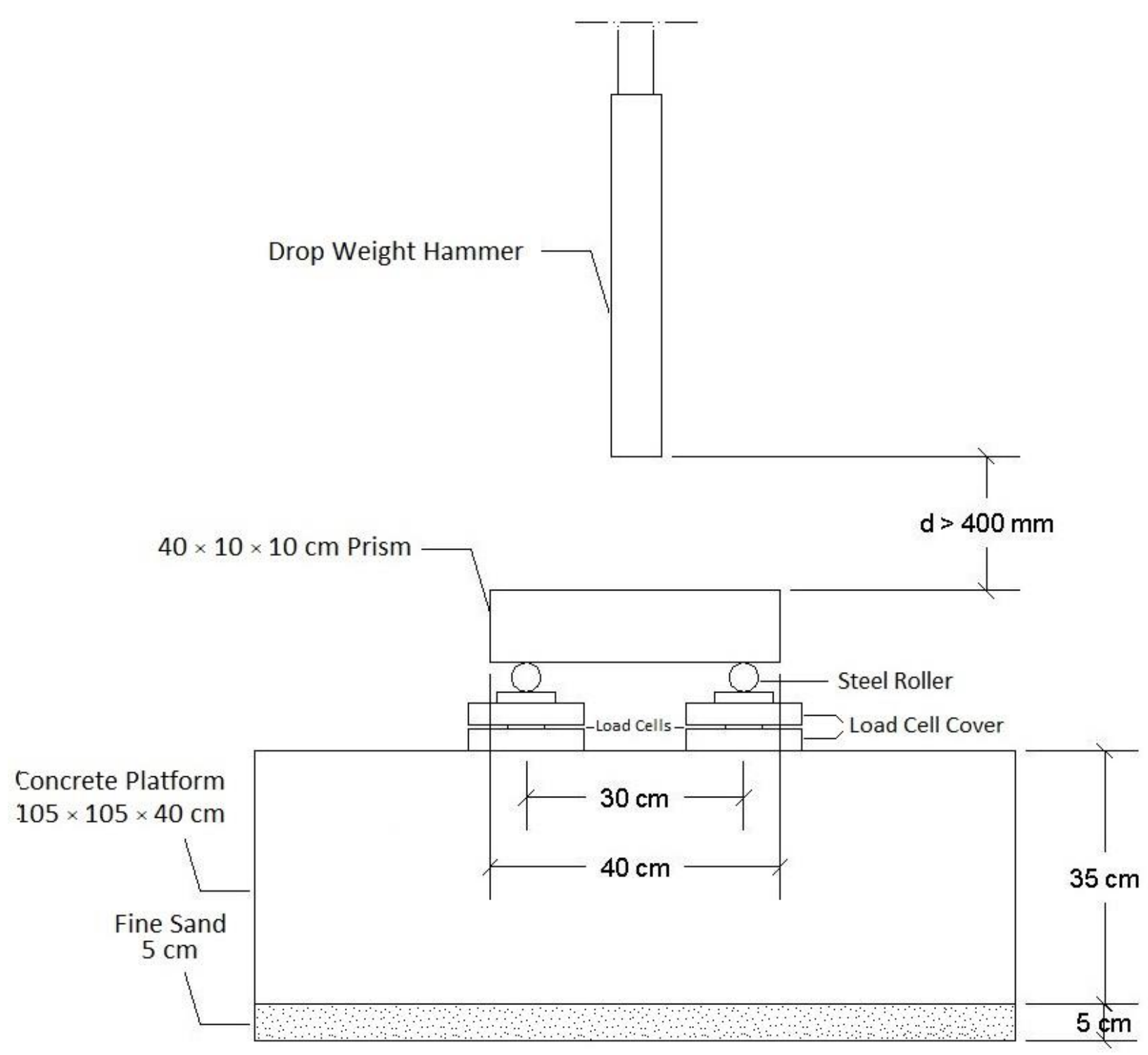

